\title{
DisZIPLINGESCHICHTE HISTORY OF GEOGRAPHY
}

\section{GEOGRAPHEN IM ZWEITEN WELTKRIEG: DIE ,FORSCHUNGSSTAFFEL Z.B.V.6 ${ }^{\text {1) }}$}

\section{Nutzung der Potenziale des Georaumes für militärische Zwecke}

\author{
Hermann HÄUSLER, Wien* \\ Erste Einreichung / Initial submission: 02/18; revidierte Fassung / revised submission: 08/2018; \\ endgültige Annahme / final acceptance: 09/2018 \\ mit 11 Abb. und 4 Tab. im Text
}

INHALT

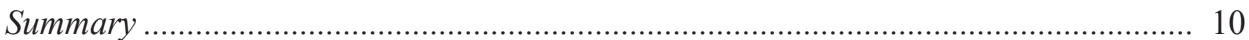

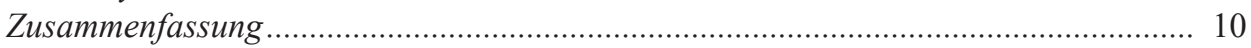

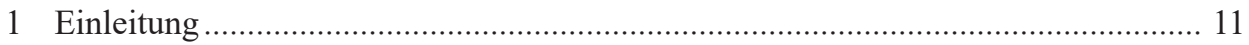

2 Dr. Otto Schulz-Kampfhenkel, „Zoo-Geograph und Forschungsreisender“

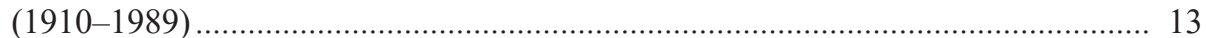

3 Das Sonderkommando Dora 1941-1942 ……................................................... 17

4 Die Forschungsstaffel zur besonderen Verwendung (z.b.V.) 1943-1945................ 19

4.1 Gliederung und Wirkungsbereich der Forschungsstaffel z.b.V...................... 21

4.2 Entwicklung eines “Auswerteschlüssels"................................................ 26

4.3 Beispiele von Karten der Forschungsstaffel z.b.V..................................... 31

1) Die vorliegende Arbeit ist die überarbeitete Kurzfassung einer umfangreicheren Publikation über eine Sondereinheit zur militärgeographischen Beurteilung des Geländes im Zweiten Weltkrieg, die als „Forschungsstaffel zur besonderen Verwendung“ (z.b.V.) bezeichnet wurde (HäUSLER 2007). Diese Arbeit ist in der internen Publikationsreihe des Instituts für Militärisches Geowesen (Bundesministerium für Landesverteidigung Wien, „MILGEO“) erschienen und nicht im Buchhandel erhältlich. Nur einige Belegexemplare der Publikation gelangten damals in deutschsprachige Archive, eine Rezension der Arbeit stammt von KrÜGER (2011). Im Rahmen einer Vortragsreihe der Österreichischen Geographischen Gesellschaft wurde dieses Thema im Sommersemester 2009 bereits kurz vorgestellt.

* Ao. Univ.-Prof. Dr. Hermann HäUSLER, Universität Wien, Department für Umweltgeowissenschaften, Althanstraße 14, A-1090 Wien; E-Mail: hermann.haeusler@univie.ac.at 
5 „MarGeo“ - Die Marine-Geographie.................................................................. 38

6 Wissenschaftliche Mitarbeiter der Forschungsstaffel z.b.V. ................................. 40

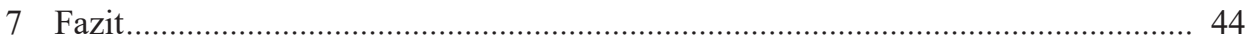

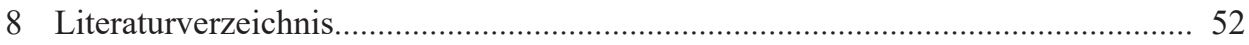

\section{Summary}

GeOgRAPHERS AND THE SECOND WORLd WAR:

The "ForschungsStafFel Z.B.V." - USE OF THE Potentials OF THE Geospace for Military Purposes

On the $31^{\text {st }}$ of July in 1940, geographer Dr. Otto Schulz-Kampfhenkel founded the "Forschungsgruppe Schulz-Kampfhenkel" (Research group Schulz-Kampfhenkel) as a registered association, which used the novel idea of aerial reconnaissance for researching terrain. A second lieutenant in the German Air Force, he became head of a "Sonderkommando Dora" (Special task force Dora) exploration group on September 1 ${ }^{\text {st }}$, 1942. This special command was a mission of the Counter-Intelligence Service of the German Armed Forces High Command ("Oberkommando der Wehrmacht") to update terrain information on the frontier between Libya and Chad. From May to December 1942 he headed the "Forschungsstaffel z.b.V." ("research staff for special terrain evaluation duties") in North Africa to reconnoitre the frontier between Libya and Chad. From 1943 on, this small but exceedingly well-equipped group of the German Counter Intelligence Service was tasked with the development and production of terrain evaluation maps. During the mission in Libya this group consisted of 15 scientific personnel comprising cartographers, geologists, meteorologists and astronomers.

From 1943 on, the civilian-military "Forschungsstaffel z.b.V." increased in number and a total of about 172 scientists; predominantly geographers, plant sociologists, geologists, cartographers and geodesists directly or indirectly served this group. This "Forschungsstaffel z.b.V." developed maps for German Wehrmacht missions in nearly all theatres of war in Europe. Printed as special maps at scales varying from 1:10.000 to 1:50.000 and also 1:300.000, they were distributed to the military commands. After the unconditional surrender of the German Wehrmacht, Allied Secret Services intensively interrogated the former members of the "Forschungsstaffel z.b.V." on their methods and the results of the integrated terrain evaluation.

Keywords: Geographers in World War II, Sonderkommando Dora, Forschungsstaffel z.b.V., Deutsche Wehrmacht, aerial photo interpretation, maps for terrain evaluation, integrated terrain evaluation

\section{Zusammenfassung}

Am 31. Juli 1940 gründete der Geograph Dr. Otto Schulz-Kampfhenkel die „Forschungsgruppe Schulz-Kampfhenkel" als eingetragenen Verein. Wesentliche Neuerung dieser Arbeitsgemeinschaft für wissenschaftliche Expeditionen war die Geländeerkun- 
dung aus der Luft. Am 1. September 1942 wurde Schulz-Kampfhenkel als Fliegerleutnant Kommandant der Gruppe Forschung des ,,Sonderkommandos Dora“ im „,Amt Ausland/ Abwehr" des Oberkommandos der Deutschen Wehrmacht (OKW). Von Mai bis Dezember 1942 leitete er die „Forschungsstaffel zur besonderen Verwendung“ (z.b.V.) in Nordafrika zur Geländeerkundung im Grenzbereich zwischen Libyen und Tschad. In der Folge fungierte diese Forschungsstaffel als eine relativ kleine, aber personell und gerätemäßig äußerst professionell organisierte Sondereinheit des Deutschen Auslandsgeheimdienstes und diente der Entwicklung, Herstellung und Erprobung von Geländebeurteilungskarten.

Bestand die wissenschaftliche Gruppe zur Geländeerkundung in Libyen nur aus 15 Fachleuten für Kartographie, Geologie, Meteorologie und Astronomie, so waren bis Kriegsende rund 172 Wissenschaftler, überwiegend Geographen, Pflanzensoziologen, Geologen, Kartographen und Geodäten direkt oder indirekt an der Entwicklung von Geländebeurteilungskarten beteiligt. Diese Karten der Forschungsstaffel z.b.V. wurden für Einsätze der Wehrmacht in nahezu allen Kriegsschauplätzen in Europa entwickelt und sind je nach Auftrag in Spezialmaßstäben von 1:10.000 über 1:50.000 bis 1:300.000 gedruckt und an die militärischen Bedarfsträger verteilt worden. Nach der bedingungslosen Kapitulation der Deutschen Wehrmacht haben sich die alliierten Geheimdienste bei den ehemaligen Mitarbeitern der Forschungsstaffel eingehend über die Methode zur Ausarbeitung dieser Geländebeurteilungskarten informiert.

Schlagwörter: Geographen im Zweiten Weltkrieg, Sonderkommando Dora, Forschungsstaffel zur besonderen Verwendung, Deutsche Wehrmacht, thematische Luftbildauswertung, Pflanzensoziologie, Geomorphologie, Karten zur Geländebeurteilung, integrierte Geländebeurteilung

\section{Einleitung}

Im Zweiten Weltkrieg arbeiteten viele Geographen - soweit sie nicht an die Front mussten (WARDENGA et al. 2011, S. 69ff) - in öffentlichen Dienststellen oder wurden für militärgeographische Aufgaben eingesetzt, sei es im Kriegskarten- und Vermessungswesen beim Oberkommando des Heeres in Berlin (MülLER und HUBRICH 2009) oder in den Divisionskartenstellen der Truppe (MüLLER 2009). Ihre Tätigkeit bezog sich durchwegs auf ihre Mitwirkung im nationalsozialistischen Regime, auch wenn ihr beruflicher Ermessensspielraum bekanntlich sehr gering war. Über Mitarbeiter von „MilGeo“, der Militärgeographie im Oberkommando des Heeres, oder „MarGeo“, der Marinegeographie im Oberkommando der Marine, sind bisher nur wenige Arbeiten erschienen. Im Gegensatz dazu ist die Verwendung von rund 350 Geowissenschaftlern als so genannte ,Wehrgeologen“ im Krieg (= Kriegsgeologen) eingehend dokumentiert (HäUSLER 1995a,b).

Das bekannteste Beispiel für den gemeinsamen Einsatz von Geowissenschaftlern und Geographen ist das von dem Geographen Dr. Otto Schulz-Kampfhenkel geleitete ,Sonderkommando Dora“, das vom „Amt Ausland/Abwehr“ des Oberkommandos der Wehrmacht in Berlin für Zwecke der Geländeerkundung und Spionageaufgaben 1942 nach Libyen geschickt wurde (PILlewizer 1986; HäUSLER 2007; ROLKE und FLACHOWSKY 2011; KAUFMANN 2015; HëUSLER 2018). 
Das Ziel der vorliegenden Studie ist eine Dokumentation der Mitwirkung von Geographen in der „Forschungsstaffel z.b.V.“, speziell von Geomorphologen und Kartographen, die in Teamarbeit mit anderen Geowissenschaftlern (Geodäten und Photogrammetern, Pflanzensoziologen, Pedologen und Geologen) eine integrative Geländebeurteilung für militärische Zwecke entwickelt haben.

Nach einer kurzen Biographie des Begründers der zivil-militärischen Forschungsstaffel, Dr. Otto Schulz-Kampfhenkel, wird die erfolgreiche Testphase der interdisziplinären Zusammenarbeit für die Geländebeurteilung durch das von ihm geleitete „Sonderkommando Dora“ am Beispiel Libyen geschildert. Im nachfolgenden, über zwei Jahre dauernden Zeitraum wurde ein - aus fachlichen Gründen bemerkenswertes und in dieser Form bis heute unerreichtes - Konzept einer integrierten Geländebeurteilung entwickelt, dessen Methodik neben einer speziellen photogrammetrischen und thematischen Luftbildauswertung stets auch eine ausführliche Geländebeurteilung in Testgebieten beinhaltete.

Für den Autor dieses Beitrags (Jahrgang 1953) war es neben den umfangreichen Archivarbeiten und Recherchen zum Thema auch wichtig, noch in den 1980er-Jahren in persönlichen Gesprächen (“oral history”) mit ehemaligen Mitarbeitern der „Forschungsstaffel z.b.V.“" unter dem fachlichen Aspekt der ,lessons learned“ einen neutralen, distanzierten und nicht ideologiegefärbten Bezug zur damaligen Zeit zu finden.

Wertvolle persönliche Informationen über diese Forschungsstaffel verdankt der Autor (in alphabetischer Reihenfolge, Kontaktjahr in Klammer) Herrn Univ.-Prof. Dr. Hans Bobek (Wien, 1985), Univ.-Prof. Dr. Erwin Boehm (Freiburg/Breisgau, 1990-1991), Dr. Paul Groschopf (Geislingen/Steige, 1986), Univ.-Prof. Dr. Wolfgang Hartke (München, 1984), Univ.-Prof. Dr. Georg Knetsch (Würzburg, 1986), Geologie-Direktor i. R. Dr. Friedrich-Karl Mixius (Burgwedel, 1986), dem ehemaligen Amtschef des Militärgeographischen Amtes in Bad Godesberg, Oberst a.D. Dipl.-Ing. Theo Müller (Bonn, 1985, 2004-2006), Herrn Univ.-Prof. Dr. Herbert Paschinger (Graz, 1984-1985), Univ.-Prof. Dr. Wolfgang Pillewizer (Wien, 1987-1995), Univ.-Prof. Dr. Ernst Preising (Bispingen, 2004-2005), Frau Jutta Schmithüsen (Saarbrücken, 1990), Univ.-Prof. Dr. Sigfrid Schneider (Bonn, 1989, 2004-2005) und Herrn Univ.-Prof. Dr. Ernst Winkler (Wien, 1983).

Archivarbeiten zu diesem Thema erfolgten im Militärhistorischen Museum der Bundeswehr (Dresden; Bestand „Theo Müller“), im Bundesarchiv-Militärarchiv in Freiburg/Breisgau (Dokumente RW5/737-739; RH2/1537 und 3110) und in der „National Archives and Records Administration“" (NARA) in Washington/DC (Dokumente AIU/PIR/63, AIU/IS/25 und AIU/FIR/16). Seit dem 19. September 2000 waren die ehemals amerikanisch verwalteten Bestände des „Berlin Document Centers“ (BDC; speziell die SS Officers Service Records - SSO) vom Bundesarchiv in Koblenz übernommen worden. Gleichzeitig übersiedelten nach der Wiedervereinigung der deutschen Staaten auch Aktenbestände des Koblenzer Archivs in das Bundesarchiv (BA) Berlin-Lichterfelde. ${ }^{2)}$

$\left.{ }^{2}\right)$ Dokumente NS 15 - 135, NS 19 - 3099, NS 21 - 247a, NS 30/9; R 26 III - 172, 180, 204, 205; R 58 - 132, 134, 175; R 4901 - 251; SSO/SS 114-B; F 5124, PK (BDC) L0114; DC (BDC) G 136. 
Eine weitere wichtige Grundlage zum Verständnis der wissenschaftlichen und organisatorischen Tätigkeiten der Forschungsstaffel z.b.V. unter der Leitung von Dr. Otto Schulz-Kampfhenkel vermittelten rund 700 Seiten deutscher und in die englische Sprache übersetzter Befragungsprotokolle von Mitgliedern der Forschungsstaffel und Stellungnahmen der alliierten Geheimdienstoffiziere, die im Archiv des „Public Record Office“ in Kew, Richmond, Surrey bei London (UK) ausgewertet wurden, speziell die Akten der „Operation Dustbin“ von 1946-1947 (British Intelligence Objectives Sub-Committee 1946a,b; BRANDSTÄTTER et al. 1947a,b; Gruppe Dustbin 1947a,b; vgl RöSSLER 1990). Eine sehr detaillierte Zusammenstellung der deutschen militärgeographischen Kriegsaktivitäten findet sich in der Arbeit der beiden U.S.-amerikanischen Militärgeographen Thomas Smith und Lloyd D. Black. Nach Smith und Black (1946) waren in der „Forschungsstaffel zur besonderen Verwendung des Oberkommandos der Wehrmacht" 80 Wissenschaftler und davon eine Gruppe von insgesamt 14 Geographen tätig. Wie gezeigt werden kann, waren es mindestens doppelt so viele.

Nur sehr verstreut finden sich in der Nachkriegsliteratur konkrete Hinweise auf ehemalige Mitglieder der „Forschungsstaffel z.b.V.“ (BоEнм 1987, 1989; BoEHм et al. 1989; Pillewizer 1986, 1995; SANDER 1995; KaUfMANN 2015). Einzelne Originalkarten der Forschungsstaffel z.b.V. befinden sich heute im Privatbesitz. Insgesamt 17 Kartenblätter aus der Fertigung der Forschungsstaffel (1944/45) überließ Prof. Dr. Erwin BoEHM im April 1987 der Stiftung Preußischer Kulturbesitz (Berlin). Zusätzliche Angaben zum „Sonderkommando Dora“, dem Vorläufer der Forschungsstaffel z.b.V., erhielt der Autor von Michael RoLKe (Willstätt), der den Routen des Sonderkommandos in Libyen gefolgt ist und auch die 23 Originalkarten aus dem Jahr 1941 neu aufgelegt hat (RoLKE 2003).

\section{Dr. Otto Schulz-Kampfhenkel, Zoo-Geograph und Forschungsreisender}

Gründer der Forschungsstaffel (z.b.V.) und ihr Leiter bis Kriegsende war der Forschungsreisende, Filmer, Flieger und Geograph Dr. Otto Schulz-Kampfhenkel (1910-1989). Trotz umfangreicher Recherchen ist bisher über dessen Biographie nur relativ wenig bekannt geworden. Um die Hintergründe seiner Interessen, Möglichkeiten und Pläne für die Entwicklung der Karten zur Geländebeurteilung nach der „kombinierten Methode“ besser zu verstehen, wird kurz auf seinen zivilen und militärischen Werdegang eingegangen. ${ }^{3)}$

Am 27. August 1910 als Sohn des Fabrikbesitzers Adolf Schulz und seiner Ehefrau Antonie (geb. Kampfhenkel) in Buckow/Märkisches Höhenland geboren, nahm Otto später den Doppelnamen Schulz-Kampfhenkel wohl deswegen an, da „Schulz“ ein sehr häufiger Familienname war. Nach seinem Abitur begann er 1929 bis 1931 das Studium der Naturwissenschaften mit Hauptfach in Zoologie und Nebenfach in Geologie/Paläontologie in Freiburg/Breisgau. Er unterbrach sein Doktoratsstudium und begann 1930 mit

\footnotetext{
3) Quellen: Bundesarchiv Berlin, SS-Führerpersonalakten, SSO/SS 114-B, NS 15/135, NS 21, R 26 III-204a; Interrogation Report No. 177 (Ref No. ATU/PIR/63 4 Oct 46); Manuskript von Michael RoLkE, Willstätt, 2004; HäUSLER 2007.
} 
naturwissenschaftlichen Studienreisen. Im Sommersemester 1931 an der Universität in Wien inskribiert, verfasste er eine „Denkschrift über Beweggründe, Ziele und Form einer geplanten zoologischen Sammel-, Studien- und Tierexpedition nach Liberia“. Von Dezember 1931 bis Juli 1932 führte er tatsächlich als Student mit Unterstützung des Berliner Zoologischen Gartens eine Tierfang- und Forschungsreise nach Liberia durch.

Kurz nach seiner ersten Afrika-Expedition gründete er im Jahr 1932 die „Forschungsgruppe Schulz-Kampfhenkel“, die sich zum Ziel gesetzt hatte: ,[...] die letzten unerforschten Gebiete dieser Erde“ zu ergründen. Dieser Forschungsgruppe gehörten junge Wissenschaftler, Flieger, Techniker und Publizisten an. Sie kann gewissermaßen als Vorläufer des im Jahr 1940 gegründeten gleichnamigen Vereins bezeichnet werden. Ende 1934 erfolgte seine Ausbildung zum Sportflieger, um bei den nächsten Expeditionen die geplanten Reiserouten in unwegsamen Gebieten aus der Luft vorzuerkunden. Im September 1940 absolvierte er ein Training als Militärpilot und begann dann mit Plänen für eine Expedition nach Nordafrika. Mit seiner Idee, veraltete topographische Karten durch Vermessungsflüge auf den neuesten Stand zu bringen, gewann Schulz-Kampfhenkel dann offensichtlich das Interesse des Amtes Ausland/Abwehr in Berlin.

Nach vorhergehender Ablehnung wegen ,politischer Unzuverlässigkeit“ trat Schulz-Kampfhenkel am 1. Mai 1933 in die NSDAP und am 3. November 1933 in die Schutzstaffel ein. Nach der Beförderung vom SS-Mann zum Unterscharführer am 20. April 1938 wurde er ab 1. Juni 1938, seinem militärischen (Reserve-)Dienstgrad bei der Luftwaffe entsprechend, im Stab des Reichssicherheitshauptamtes als Untersturmführer geführt.

Am 31. Juli 1940 gründete Schulz-Kampfhenkel den gemeinnützigen Verein „Forschungsgruppe Schulz-Kampfhenkel e.V.“ als „Arbeitsgemeinschaft für wissenschaftliche Expeditionen, Naturforschung und Völkerkunde“. Ziel dieses Vereins war die Bildung einer überfachlichen ,auslandskundlichen“ Gesellschaft „,nach Art der Königlich-Geographischen Gesellschaften Großbritanniens und der früheren Niederlande“. Bereits im Herbst 1940 dürfte Schulz-Kampfhenkel mit dem Amt Ausland/Abwehr im Oberkommando der Wehrmacht (OKW) in Kontakt gestanden sein und eine Expedition nach Nordafrika geplant haben. Mit Wirkung vom 1. Juni 1941 wurde er von seiner Dienststellung beim Stab des SS-Personalhauptamtes enthoben und zum Stab des SS-Hauptamtes (= Reichssicherheitshauptamt, RSHA) versetzt. Diese Zuteilung hatte allerdings keine unmittelbare Änderung des Dienstverhältnisses zur Wehrmacht zur Folge.

Nach dem Wechsel seiner Studienrichtung von der Zoologie zur Geographie wurde Schulz-Kampfhenkel am 9. April 1941 am damaligen Institut für Geographie der Universität Würzburg in Geographie bei Prof. Dr. Hans Schrepfer promoviert, angeblich mit summa cum laude zum Dr. rer. nat., wobei weder ein Dissertationsexemplar noch Akten darüber erhalten sind. Schulz-Kampfhenkel nahm (vermutlich bereits im Auftrag des Amtes Ausland/Abwehr) im November/Dezember 1941 als Fliegerleutnant an einem Vorkommando in Italien, Libyen und Griechenland teil, bevor er am 1. September 1942 als Leiter der Gruppe Forschung des „Sonderkommandos Dora“ zum Oberkommando der Wehrmacht (OKW) versetzt wurde.

Schulz-Kampfhenkel wurde dann am 2. Mai 1943 von Reichsmarschall Hermann Göring - in dessen Funktion als Präsident des Reichsforschungsrates - als Beauftragter 
für Sonderaufgaben der erdkundlichen Forschung in den Reichsforschungsrat berufen. ${ }^{4}$ Ferner wurde er zum Leiter der „Forschungsstaffel z.b.V.“ des OKW bestimmt und von Juni bis November 1943 in dieser Eigenschaft in Russland eingesetzt. In diese Zeit fällt die Entwicklung der Karten zur Geländebeurteilung nach der kombinierten Methode. Arbeitsgebiete der Forschungsstaffel z.b.V. waren in der Folge, unter anderen: Griechenland, Dalmatien, Italien, das Dnjepr-Gebiet, die Ukraine und Finnland, wobei er besonders die Bedeutung der Luftbildkartographie für die aktuelle Geländebeurteilung erkannt hatte.

Am 15. Jänner 1944 erfolgte die Eheschließung des (nach eigenen Angaben) „Geographen und Forschungsreisenden" mit Frau Charlotte Caulier-Eimbcke, der Schwester seines Stellvertreters bei der Forschungsstaffel, Günter Caulier-Eimbcke. .) Ihre Flitterwochen verbrachte das Ehepaar im Hotel Panhans am Semmering. Kurz vor der Eheschließung war Schulz-Kampfhenkel im Dezember 1943 noch zum Oberleutnant der Reserve der Luftwaffe befördert worden (HäUSLER 2007, S. 21).

Schulz-Kampfhenkel hatte durch seine hervorragende Rhetorik und zivil-militärisch-politische Postenkumulation folgende Vorteile (HäUSLER 2007, S. 87f):

- Die Aufstellung des Sonderkommandos Dora war ursprünglich nur für wenige Wochen geplant gewesen. Obwohl sich daraus 1943 ein weiteres Kommando, nämlich die Forschungsstaffel entwickelte, blieb das Sonderkommando Dora bis Kriegsende unter wechselnder Führung erhalten. Kontinuität in der Planung, Organisation und Durchführung von Expeditionen, sowie die Verwendung der geeigneten Ausrüstung für Befliegungen und Geländevermessungen und die Entzerrung und Stereoauswertung von Luftbildern waren durch die Forschungsgruppe während der gesamten Kriegszeit sichergestellt.

- Nur in seiner Funktion als Vorsitzender eines gemeinnützigen Vereins konnte Schulz-Kampfhenkel für seine Forschungsgruppe Subventionen des Reichswirtschaftsministeriums, des Propagandaministeriums, der Reichskanzlei sowie der Deutschen Forschungsgemeinschaft (HAMMERSTEIN 1999) in der Höhe von hunderttausenden Reichsmark lukrieren. Die so subventionierte Ausrüstung für zivile Expeditionen kam wiederum direkt dem Sonderkommando Dora bzw. der Forschungsstaffel zugute. Die Forschungsgruppe bildete somit die finanzielle Drehscheibe zwischen vorfinanzierender Stelle (Forschungsgruppe) und durchführender Einheit (Technische Gruppe des Sonderkommandos Dora bzw. danach Forschungsstaffel) sowie Ministerien und Sponsoren der Industrie.

- Schulz-Kampfhenkel konnte somit die militärische Forschungsstaffel durch seine, mithilfe von Spenden und Vereinsgeldern geförderte, Forschungsgruppe substanziell unterstützen, wobei umgekehrt wieder geschultes militärisches Personal der Forschungsstaffel in den Büroräumen des Vereins Arbeiten für die Forschungsgruppe durchführte.

- Er konnte überdies als Staffelführer konsequent jene Projekte des Reichsforschungsrates militärisch verwerten, die er zuerst in seiner Funktion als Sonderbeauftragter

4) Bundesarchiv Berlin, R 26 III-180; Br. B. Nr. Rf. 866/43 vom 2. Mai 1943.

5) Bundesarchiv Berlin, NS 21 247, 247a. 
des Reichsforschungsrates zur Förderung eingereicht hatte. Durch Vergabe von Forschungsaufträgen an Universitäten stieg sein Einfluss in den Forschungsinstitutionen des Dritten Reiches.

- Schulz-Kampfhenkel hatte sich offenbar gegen Veränderungen seines Status als Leiter des zivilen Vereins und der militärischen Staffel bestens abgesichert, sei es in der Wehrmacht selbst (wegen seiner Position im Amt Ausland/Abwehr des Oberkommandos der Wehrmacht), sei es im Reichsforschungsrat (wegen seiner guten Beziehung zu Göring), und sei es selbst im Reichssicherheitshauptamt (wegen seiner Beziehung zum Reichsführer-SS, der dem Reichsforschungsrat angehörte). Somit gelang es ihm - während des Krieges wohl einmalig - ganz nach seinen persönlichen Vorstellungen militärisch begründete, geowissenschaftliche Forschungsarbeiten durchzuführen. Die Karten der Geländebeurteilung wurden in den höchsten Kommandostellen, bis hinauf zum Wehrmachtsführungsstab, sehr geschätzt. Damit stieg der Einfluss von Schulz-Kampfhenkel in der Militärhierarchie, ungeachtet seines niederen militärischen Ranges (zuletzt Oberleutnant). War etwa die Gruppe Militärgeographie (,MilGeo") im Oberkommando des Heeres kurz vor der Auflösung, so bekam er für seine Forschungsstaffel zusätzliche Personalressourcen genehmigt.

Dass das politische Engagement Schulz-Kampfhenkels den Alliierten nach Kriegsende interessanterweise nicht ganz bekannt gewesen sein dürfte, belegt ein Bericht aus dem US-amerikanisch/Britischen „Interrogation Camp“ auf der Burg Kransberg/Usingen (Hessen), in welchem Schmidt (1946) über ihn ausführt:

"Schulz-Kampfhenkel strove for a non-political arrangement; the SS had already shown indications that they were interested in absorbing his organization, a condition that he claims he wanted to avoid at any cost. But as it would have been impossible to continue his project on the scale he had hoped for, without some official backing, he searched about for such backing that would be most likely to allow him to continue his work in a purely scientific vein."

Glaubt man dem abschließenden „Interrogation Report“ des Chief Interrogators Hauptmann Ludwig ScHMIDT im „Interrogation Camp Marcus W. Orr“ (etwas irreführend auch als „Lager Glasenbach“ bezeichnet), so hat Schulz-Kampfhenkel sogleich auch den Alliierten seine Dienste angeboten:

"Schulz-Kampfhenkel is highly desirious of being allowed to continue his work directly for or under the supervision of any of the Allied powers. These hopes are so intense that it is unlikely that he would have given other than accurate information to his interrogators. It is therefore believed that the information given is completely reliable."

Und ferner:

"[...] that Schulz-Kampfhenkel be immediately released in consideration of the above, and because of the fact that his services may be sought by US Army mapping authorities [...]." (SCHMIDT 1946) 
Möglicherweise erleichterten seine Aussagen im Interrogation Camp nach dem Krieg auch den Aufbau eines eigenen Instituts für „Weltkunde in Bildung und Forschung“ (WBF), als deren Institutsleiter und Stiftungsvorstand (für audio-visuelle Lehr- und Forschungsmedien) Schulz-Kampfhenkel in Hamburg von 1962 bis zu seinem Ableben 1989 sehr erfolgreich aufgetreten ist. ${ }^{6}$

\section{Das ,Sonderkommando Dora“6 1941-19427)}

Gegen Ende März 1941 fand im Deutschen Institut und Museum für Länderkunde zu Leipzig eine Besprechung statt, an welcher der Leiter des Instituts, Prof. Dr. R. Reinhard, der Ordinarius für Geographie an der Universität Leipzig, Prof. Dr. H. Schmitthenner, der Ordinarius für Geographie der Universität Münster, Prof. Dr. H. Dörries, der Direktor des Kolonialgeographischen Instituts an der Universität Leipzig, Prof. Dr. Dietzel, Hauptmann der Reserve Lumbeck von der Abwehrstelle VI der Abteilung I des Amtes Ausland/ Abwehr und Dr. Konrad Voppel, Kustos und Stellvertreter des Direktors am Deutschen Institut für Länderkunde, teilnahmen. Prinzipiell wurde Übereinkunft erzielt, dass die vorhandenen französischen Karten 1:1.000.000 von Nordafrika und der Sahara für militärische Zwecke weitgehend ergänzt und berichtigt werden könnten. Dazu wurde auch eine genaue Bearbeitung der deutschen, englischen, französischen und italienischen Literatur empfohlen.

Schulz-Kampfhenkel hatte bereits 1932 während einer Westafrika-Expedition und 1935-1937 während seiner Amazonas-Expedition den Nutzen der Flugzeugerkundung in unerforschten Gebieten erkannt. Für die Organisation weiterer Expeditionen gründete er am 31. Juli 1940 den Verein „Forschungsgruppe Schulz-Kampfhenkel, Arbeitsgemeinschaft für wissenschaftliche Expeditionen, Naturforschung und Völkerkunde e.V.“ Im gleichen Jahr bot er seine Dienste der Deutschen Abwehr im Oberkommando der Wehrmacht an, die im Jänner 1941 einen Einsatz in Nordafrika mit der Code-Bezeichnung „Theo-Dora“ plante (PILlEwizer 1946a).

Die theoretischen Vorbereitungen des Unternehmens erfolgten über die Abwehrstelle in Rheda bzw. deren Außenstelle in Raumkoppel/Schönenberg, Mecklenburg („Gruppe I/Theo“), die Aufstellung des Kommandos lief unter dem Code „Dora I“ und

6) Die Arbeitsweise von Dr. Otto Schulz-Kampfhenkel kann durchaus als genial bezeichnet werden, denn als Oberleutnant der Reserve der Luftwaffe (mit besten Kontakten zum Reichsmarschall und Oberbefehlshaber der Luftwaffe Hermann Göring) und als Leiter der militärischen Forschungsstaffel z.b.V. im Oberkommando der Wehrmacht bzw. als Sonderbeauftragter für die erdkundliche Forschung im Reichsforschungsrat (als Beauftragter des Reichsmarschalls sowie mit Genehmigung des im Reichsforschungsrat vertretenen Reichsführers der SS, Heinrich Himmler, dessen Stab er ja angehörte) konnte er sich über das vereinsrechtliche Konstrukt der zivilen „Forschungsgruppe Schulz-Kampfhenkel e.V.“, deren Vorsitzender er war, nach Absprache mit allen Bedarfsträgern der Wehrmacht ganz legal alle zivilen Nutzungsrechte seiner vielfältigen Unternehmungen in ganz Europa sichern. Da dies während des Krieges kaum Vorteile bringen konnte, dürften sich alle diesbezüglichen Vereinbarungen auf die Zeit nach Beendigung des Krieges und vor allem auf die wirtschaftlich interessanten Planungsziele „im Osten“ konzentriert haben.

7) Dieses Kapitel basiert neben der Auswertung von Archivunterlagen auf den Angaben von Pillewizer (1946a), BrandstätTer et al. (1947a,b), Voppel (1969a,b) und SchneIDER (1989). 
als „Dora II“ wurde in der Folge der Einsatz des „Sonderkommandos Dora“ bezeichnet. Dieses Sonderkommando war ein kampfkräftiges Aufklärungs- und militärwissenschaftliches Erkundungskommando für einen Einsatz in Libyen, südlich von Rommels Afrikakorps. Ursprünglich nur für die Dauer von sechs bis acht Wochen aufgestellt, bestand das Kommando von April 1942 bis zum Jahreswechsel 1942/43. Seine generellen Aufgaben betrafen die Überwachung der Ost- und Südostgrenze Innerlibyens und Feinderkundung gegen das von General Charles de Gaulle und seinen „Freien Französischen Streifkräften“ beherrschte Französisch Äquatorial-Afrika (Tibesti-Gebirge) in der nördlichen Tschad-Kolonie sowie die Schaffung fehlender wehrwissenschaftlicher, insbesondere militär- und luftgeographischer Unterlagen über weite, ungenügend kartierte Gebiete der mittleren und südlichen Libyschen Sahara und des nördlichen Französisch Äquatorial-Afrika.

In dieser Zeit fungierte Leutnant Dr. Otto Schulz-Kampfhenkel als Pilot und Leiter einer Gruppe von 16 Wissenschaftlern, die ebenfalls Soldaten waren. Dieser „Technischen Gruppe" des Sonderkommandos Dora gehörten Fachleute für Kartographie, Geologie, Straßenbau und Astronomie an. Es waren dies nach Pillewizer (1946a) $)^{8)}$ :

- Leutnant-Ingenieur Walter A. Brucklacher (Luftbildfachmann der Firma ZEISS)

- Gefreiter Dr. Drevermann (Meteorologe, Klimatologe und Pilot)

- Feldwebel Dr. Fritsch (Zoologe und Luftbildauswerter)

- Leutnant Dr. Ernst Frowein (Meteorologe und Pilot)

- Dr. Alfons Gabriel (Arzt und Wüstenfachmann)

- Dr. Hiller (Kartograph)

- Dr. Fritz Höhndorf (Meteorologe)

- Hauptmann Prof. Dr. Helmuth Kanter (Mediziner und Geograph)

- Kriegsverwaltungsrat Dr. Georg Knetsch (Geologe)

- Dr. Walter Knörlein (Straßenbaufachmann; vom VW-Werk)

- Unteroffizier Kriegsverwaltungsrat Dr. Friedrich Karl Mixius (Geologe)

- Schütze Diz. Dr. Wolfgang Pillewizer (Topograph und Kartograph)

- Leutnant Doz. Dr. Hans Rothert (Pflanzensoziologe und Ethnologe)

- Dr. Nikolaus Benjamin Richter (Astronom; Routenbestimmung)

- Dr. Max Schlarbaum (Kartograph)

- Gefreiter Dr. A. Teichgräber (Geodät und Astronom)

Dazu kamen drei Photographen für die Luftbildentwicklung und drei Zeichner. Sowohl für die wissenschaftliche als auch für die militärische Gruppe waren noch tätig: ein Filmberichter (Oberleutnant Wild) und ein Bildberichter (Sonderführer Bayer). Die kartographischen Ergebnisse der von März bis Juni 1942 durchgeführten Geländeerkundung wurden mittels astronomischer Routenbestimmung und präziser geodätischer Vermessung ausgewertet. Diese umfassten drei Übersichtskarten 1:1 Million, 20 Expeditionskarten 1:200.000, eine Expeditionskarte 1:50.000 sowie zwei Expeditionskarten 1:25.000. Die Ergebnisse der militärgeologischen Erkundung wurden in zwei Übersichtskarten 1:3 Millionen (Gesteinsformationen, Grundwasser), drei Übersichtskarten 1:1 Million und 14

8) National Archives and Records Administration (NARA), Washington D.C.: FO 1031/110; NARA: ATU/ IS/25. 
Befahrbarkeitskarten 1:200.000 eingetragen (Sonderkommando Dora, Technische Gruppe 1942a,b,c; BoeHM 1989; BrUCKLACHer 1989; HäUSLER 2007, S. $38 f f)$.

Nach der Rückkehr des Sonderkommandos Dora aus Libyen im Jänner 1943 war Schulz-Kampfhenkel mit seiner Gruppe zunächst im Reichsforschungsrat tätig. Dieser war 1937 gegründet worden, um die Naturwissenschaften (Chemie, Physik, Biologie und Landbauwissenschaften) im Rahmen des Vierjahresplanes gezielter einsetzen zu können (RöSSLER 1990, S. 201).

\section{Die „Forschungsstaffel z.b.V.““ 1943-1945 ${ }^{9)}$}

Dass das, ursprünglich nur zeitlich begrenzt geplante, Sonderkommando Dora auch nach dem Libyen-Einsatz weiterhin Bestand hatte, beweist die große fachliche Akzeptanz der Ergebnisse der gemischten Forschungsgruppe und auch den offensichtlichen Bedarf der Wehrmacht an genaueren Unterlagen für die Geländebeurteilung anderer Kriegsschauplätze. Die falsche Beurteilung des Pripjet-Gebietes während des Russlandfeldzugs 1941 (,Sumpfgebiete sind für Panzer nicht befahrbar“), des russischen Winters sowie der spezifischen Eigenheiten der fremden Kampfgebiete durch das Oberkommando der Deutschen Wehrmacht zeigten deutlich, dass auf dem geographisch-kartographischen Sektor maßgebliche Grundlagen für die militärische Planung fehlten. Und genau diese Lücke versuchte der Begründer und Leiter der Forschungsstaffel z.b.V., Otto Schulz-Kampfhenkel, zu schließen, indem er den verstärkten Einsatz der photogrammetrischen Kartenherstellung und der thematischen Luftbildauswertung für die Truppe forcierte (HäUSLER 2007, S. 53f).

Abbildung 1 zeigt die Mitglieder der Forschungsstaffel z.b.V., zivile Forscher und Gäste als Teilnehmer an der Tagung über Luftbild-Interpretation bei Zeiss-Aerotopograph, die vom 20. bis 23. Juni 1944 in Jena abgehalten wurde. Von Universitäten nahmen damals mindestens sechs zivile Wissenschaftler an Projekten der Forschungsstaffel z.b.V. teil, wie z. B. Dr. Ing. R. Burkhardt (Institut für Photogrammetrie der TH Berlin), Prof. Dr. Hans Cloos (Geologisches Institut der Universität Bonn), Prof. Dr. Richard Finsterwalder (Geodätisches Institut der TH Hannover), Prof. Dr. Emil Meynen (Abteilung für Landeskunde Berlin, später Worbis/Thüringen), Doz. Dr. Heinrich Müller-Miny (Abteilung für Landeskunde Berlin), Prof. Dr. Carl Troll (Geographisches Institut der Universität Bonn). Von der Industrie nahmen teil: Oberst-Ingenieur Dr. Claus Aschenbrenner (Fa. Steinheil \& Co, München sowie Luftfahrtministerium bzw. Oberkommando der Luftwaffe, Generalstab, 7. Abteilung), Dipl.-Ing. Gruner (Zeiss-Aerotopograph, Jena), Karl Tietje und E. Messter (beide Zeiss-Aerotopograph, Jena), Prof. Dr. Kurt Schwidefsky (Zeiss-Aerotopgraph, Jena) und Dr. Schilling (Firma Agfa). Auch Vertreter anderer Wehrmachtsteile besuchten die Tagung: Oberst Rueff (Hauptbildabteilung der Luftwaffe/General der Aufklärer/Oberkommando der Luftwaffe), Oberst Ing. Froetschner (Reichsluftfahrtministerium, Bildstelle Farbfilm), Major K. van Oppen (General der Aufklärungsflieger, Gruppe

\footnotetext{
9) Dieses Kapitel basiert auf Archivdokumenten (NARA, Washington D.C.: AIU/IS/25, FO 1031/110) und Angaben von Pillewizer (1946b), SchmithüSEn (1946), BrANDSTÄTter et al. (1947a,b) und Boehm (1987) über die Gliederung und Aufgaben der Forschungsstaffel.
} 


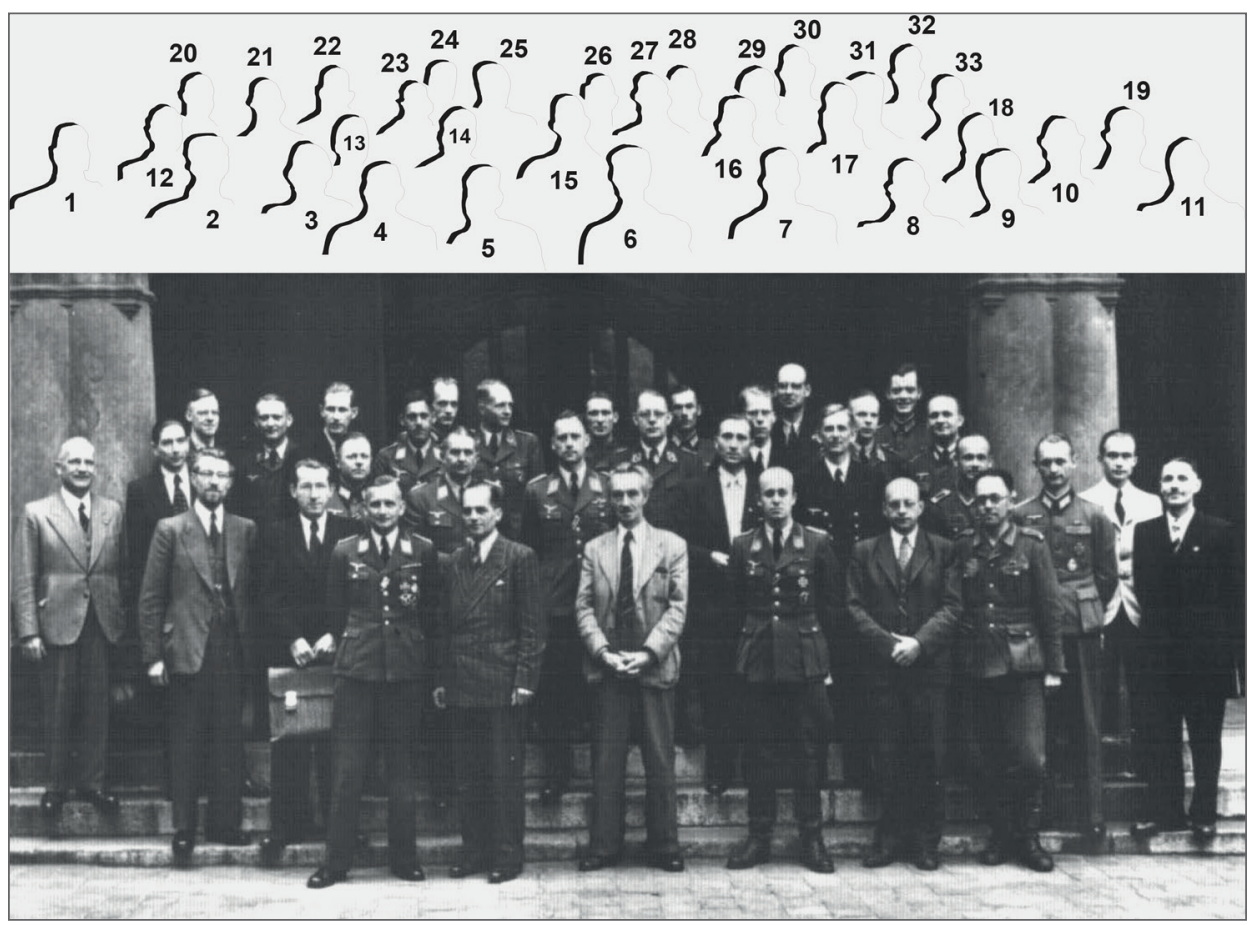

Bei den Teilnehmern dieser Tagung handelte es sich nach Troll (1969) um:

1. Reihe: ${ }^{1}$ E. O. Messter, ${ }^{2}$ Carl Troll, ${ }^{3}$ Kurt Schwidefsky, ${ }^{4}$ Oberst Rueff, ${ }^{5}$ Claus Aschenbrenner, ${ }^{6}$ Hans Cloos, ${ }^{7}$ Otto Schulz-Kampfhenkel, ${ }^{8}$ Richard Finsterwalder, ${ }^{9}$ Hans Bobek, ${ }^{10} \mathrm{König},{ }^{11} \mathrm{H}$. Gruner 2. Reihe: ${ }^{12}$ Schilling, ${ }^{13}$ Erich Otremba, ${ }^{14}$ Oberst Froetschner, ${ }^{15} \mathrm{~K}$. van Oppen, ${ }^{16}$ Heinrich MüllerMiny, ${ }^{17}$ Gottfried Pfeifer, ${ }^{18}$ Wolfgang Hartke, ${ }^{19}$ Karl Tietje

3. Reihe: ${ }^{20}$ G. Foerstner, ${ }^{21}$ R. Burkhardt, ${ }^{22} \mathrm{~K}$. H. Paffen, ${ }^{23}$ Walter Brucklacher, ${ }^{24}$ Günter Caulier-Eimbcke, ${ }^{25}$ Heinz Ellenberg, ${ }^{26}$ Ernst Preising, ${ }^{27}$ Wilhelm von Laer, ${ }^{28}$ Nietsch, ${ }^{29} \mathrm{~K}$. Rinner, ${ }^{30}$ Emil Meynen, ${ }^{31}$ Künold, ${ }^{32}$ F. Jung, ${ }^{33}$ Josef Schmithüsen.

Quelle: verändert nach Troll 1969, Bild 1; vgl. auch HäUSLER 2007, Abb. 21

Abb. 1: Mitglieder der Forschungsstaffel z.b.V., zivile Forscher und Gäste als Teilnehmer an der Tagung über Luftbild-Interpretation bei Zeiss-Aerotopograph vom 20. bis 23. Juni 1944 in Jena

Luftbild), Oberleutnant F. Jung (Artillerie Lehr-Regiment 4), Prof. Dr. Gottfried Pfeifer (MarGeo - Marinegeographie) und Dr. K. Rinner (Amtsgruppe Nautik).

Zur Interpretation der Luftbilder von Einsatzgebieten der Forschungsstaffel wurden Experten mit wissenschaftlichen Erfahrungen und Kenntnissen auf bodenkundlichen, pflanzensoziologischen, ökologischen und geographischen Fachgebieten herangezogen. Für die Auswertung von Luftbildern der Pripjetsümpfe waren z. B. die örtlichen Kenntnisse eines russischen Moorforschers von großem Nutzen; in einem Moor südlich von Riga wurden neben Pflanzensoziologen auch zahlreiche Forstleute, aber auch Hydrologen und Geologen mit Luftbildauswertungen beauftragt. 
Von der Forschungsstaffel wurden 1943 bis 1944 insgesamt 17 Gebiete bearbeitet, in denen Erfahrungen in der Auswertung von Luftbildern gewonnen werden konnten. Dabei handelte es sich um Großlandschaften wie die Taiga und Tundrenzone Lapplands, die Niederungen Osteuropas (Narwa-Gebiet nördlich des Peipus-Sees, Moorgebiet bei Riga, Memel-Niederung in Ost-Preußen, Weichsel-Niederung und Warthe-Niederung in Polen, Pripjet-Sümpfe in Polen und Russland, der Raum südlich Kowel in Polen und die Dnepr-Niederung von seiner Mündung bis Saporoshe), Tieflands- und Moorgebiete West-Deutschlands (Emden - Bentheim, die Blätter 1:200.000: Wesel, Düsseldorf, Münster und Osnabrück, Truppenübungsplatz Grafenwoehr/Oberpfalz, Südwestungarisches Hügelland und Norditalienische Tiefebene vom Isonzo bis zum Po) sowie um Gebirgslandschaften Südost-Europas (Karstgebiete von Istrien und Dalmatien; Albanien und Nord-Griechenland) (HäUSLER 2007, S. 54).

Die Karten wurden von der Forschungsstaffel bewusst nicht „Geländebeurteilungskarten“, sondern „Karten zur Geländebeurteilung“ genannt. Dadurch sollte zum Ausdruck gebracht werden, dass sie den Benützern zwar Unterlagen für die Beurteilung des Geländes bieten sollten, diese Beurteilung jedoch für einen bestimmten Zweck (das heißt also, für einen bestimmten militärischen Auftrag) Sache der Benutzer selbst war (Pillewizer 1989). Nach dem inhaltlichen Aufbau und der Darstellungsweise unterschied SchmithüSEN (1946) drei Typen der Karten zur Geländebeurteilung und zwar den synthetischen Typ, den analytischen Typ und den gemischten Typ. Im ,synthetischer Typ“ wurden von den Bearbeitern im Kartenbild klar gegeneinander abgegrenzte Raumeinheiten ausgeschieden, während im ,,analytischen Kartentyp“ die verschiedenen Geländeeigenschaften wie Oberflächenform, Gesteins- und Bodenart, Bodenfeuchte, Überschwemmung oder Vegetation durch Signaturen einzeln dargestellt wurden. Aus Zweckmäßigkeitsgründen wurde in einem späteren Stadium der Kartenentwicklung meistens ein gemischter Typ verwendet, der weder rein analytisch noch synthetisch war (SCHNEIDER 1989).

In Hinblick auf die Kartenanwendung für verschiedene Zwecke bzw. durch unterschiedliche Benützerkreise erfolgte eine Unterscheidung in drei Maßstabsklassen: kleinmaßstäbliche Karten für strategische Zwecke (für höhere Stäbe), Karten in mittleren Maßstäben für taktische Zwecke (für Kommandanten der Feldtruppeneinheiten) und großmaßstäbliche Karten für Spezialzwecke wie z. B. für Pionierstäbe oder Baueinheiten. Dementsprechend wurden Karten im Maßstab 1:300.000 und kleiner als „Übersichtskarte zur Geländebeurteilung“, im Maßstab 1:50.000 bis 1:250.000 als „Truppenkarte zur Geländebeurteilung“ und im Maßstab größer als 1:50.000 als „Spezialkarten und Pläne“ bezeichnet.

\subsection{Gliederung und Wirkungsbereich der „Forschungsstaffel z.b.V.“}

Nach Beendigung des Libyeneinsatzes im Dezember 1942 wurde Schulz-Kampfhenkel am 2. Mai 1943 zum Leiter der „Forschungsstaffel z.b.V. des Oberkommandos der Wehrmacht" ernannt. Diese blieb bis Kriegsende eine sehr selbstständig agierende Einheit, wobei es zu einer engen organisatorischen Verflechtung mit der zivilen „Forschungsgruppe 
Schulz-Kampfhenkel e.V.“ kam (HäUSLER 2007, S. 89). Die umfangreichste Organisation bestand 1944-1945 (Abb. 2). Sie ist für die Einsatzgruppen in Europa in Abbildung 3 schematisch dargestellt.

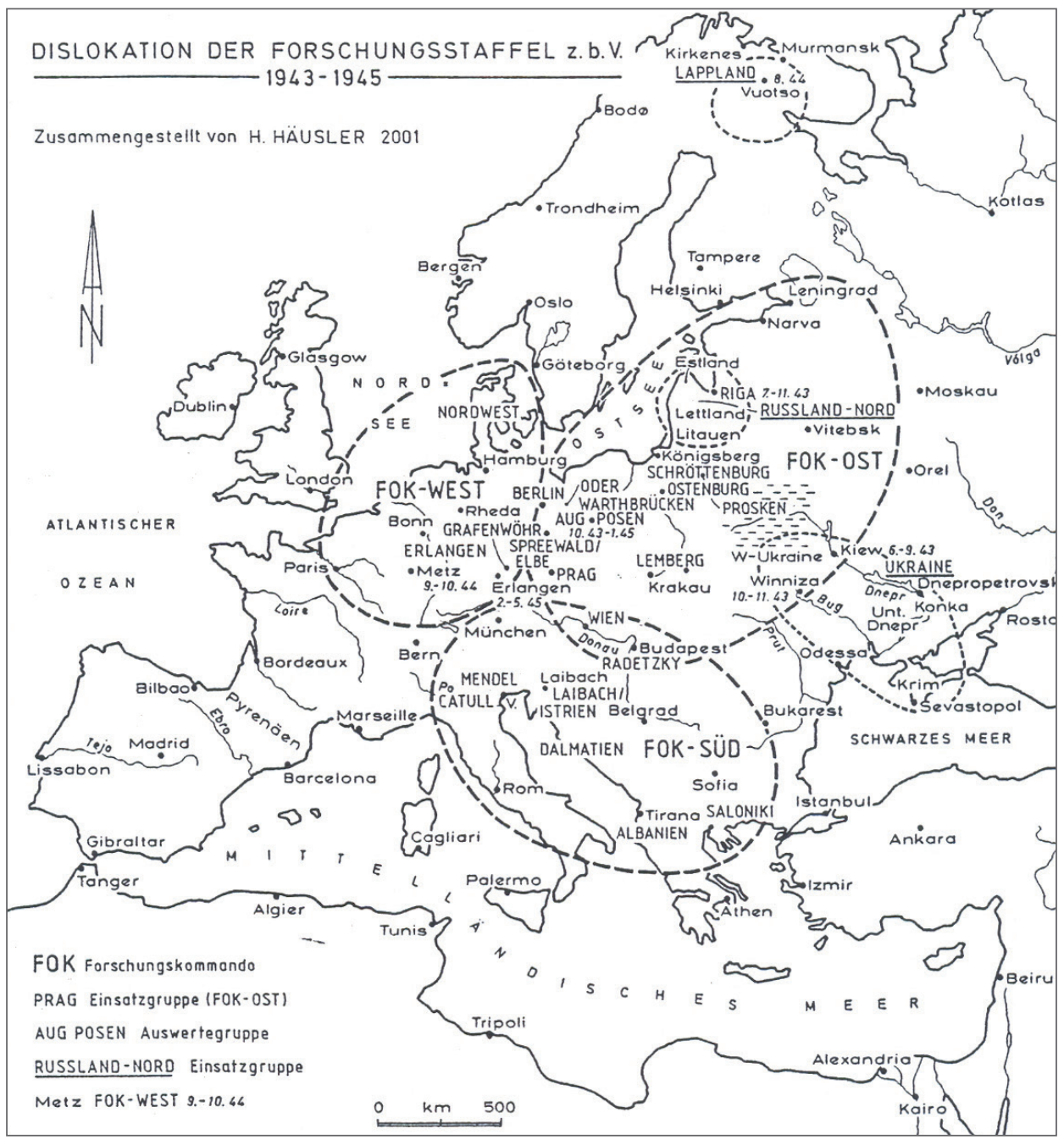

Quelle: HäUSLER 2007, Abb. 25

Abb. 2: Dislozierung der Forschungskommandos und Einsatzgruppen der Forschungsstaffel z.b.V. in Europa 1943-1945

Die Staffel wurde von Schulz-Kampfhenkel und seinen beiden Stellvertretern Brockob und Grotelüschen geführt, Schmithüsen war wissenschaftlicher Verbindungsoffizier, Caulier-Eimbcke Nachschuboffizier, Bobek und Pillewizer fungierten als Kartenoffiziere. 


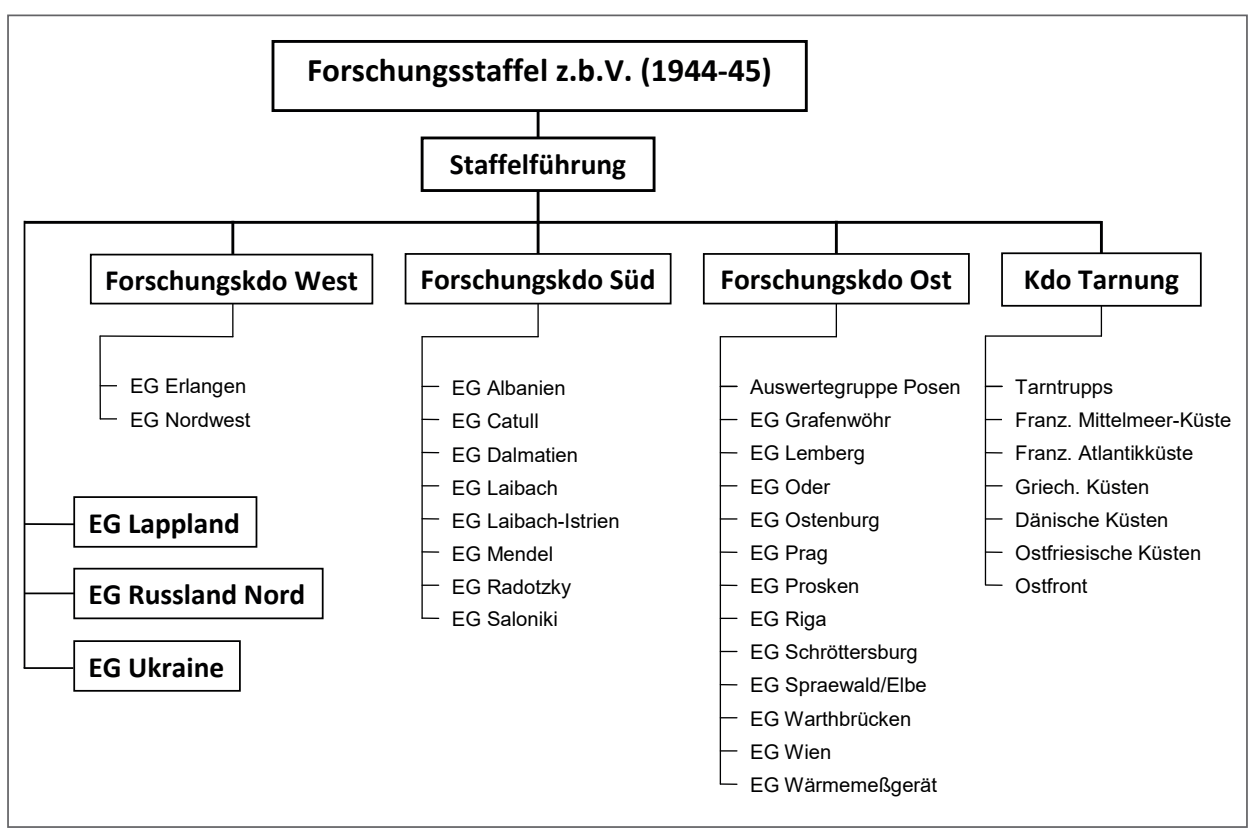

Quelle: verändert nach HäUSLER 2007, Abb. 24

Abb. 3: Gliederung der Forschungsstaffel z.b.V. (1944-1945). Abkürzungen: Kdo = Kommando; EG = Einsatzgruppe

Dazu kamen ein Panzerverbindungsoffizier, ein Forstlicher Verbindungsoffizier, ein weiterer Mitarbeiter des Staffelführers (Huttenlocher) und ein Verwalter des Kartenarchivs (Künold). Der Staffelführer Schulz-Kampfhenkel hatte von April 1943 bis Kriegsende sowohl die militärische als auch die wissenschaftliche Gesamtführung der Forschungsstaffel inne. Sein Stellvertreter in militärischen Belangen leitete die Organisation in Personalangelegenheiten, in Bezug auf die militärische Ausrüstung, die Kraftfahrzeuge und die organisatorische Vorbereitung der Einsätze etc. Der Wissenschaftliche Verbindungsoffizier stellte die Verbindung zwischen der Staffelführung und den Forschungskommandos der Staffel in wissenschaftlichen Angelegenheiten sicher, ferner die Verbindung zwischen Forschungsstaffel und der zivilen Wissenschaft. Durch ihn erfolgte die Beratung des Staffelführers betreffend den Einsatz der wissenschaftlichen Mitarbeiter sowie die Einführung neuer Mitarbeiter in die Aufgaben der Forschungsstaffel. Die Aufgaben betrafen Beschaffung, Verteilung und Versendung der wissenschaftlichen Geräte und Verbrauchsmaterialien an die Kommandos, Beschaffung, Archivierung und Versendung der Luftbilder.

Der Sitz der Staffelführung war von April bis August 1943 in Berlin, im September 1943 bei der Einsatzgruppe Ukraine, von Oktober 1943 bis Jänner 1945 in Neudorf am Grödnitzberg, von Februar bis März 1945 in Tauberbischofsheim, zirka vom 27. März bis 12. April 1945 in Harburg und zirka vom 13. bis 25. April 1945 in Unterauerbach. Danach hatte die Staffelführung bis Kriegsende keinen festen Sitz mehr. 
Im Folgenden wird über die „Einsatzgruppe Lappland“ (a), über Neuentwicklungen der „Einsatzgruppe Tarnung“ (b) und über die Experimente der „Einsatzgruppe Wärmemeßgerät“" (c) näher berichtet (PILLEWIZER 1946b).

a) Die „Einsatzgruppe Lappland“ (Leutnant Dr. Pillewizer, Geologe Dr. Nietsch) war der Staffelführung direkt unterstellt. Nach Pillewizer (1968) bzw. Pillewizer und JuNG (1954) wurden für die Aufnahme des Gebietes Vuotso in Nord-Finnland im August 1944 rund 250 Stereo-Luftbilder im mittleren Bildmaßstab 1:30.000 geflogen. Die Entzerrung erfolgte nach Routenpunkten der Radialtriangulation mittels Kleinentzerrungsgeräten. Die höhenähnlichen Formlinien im 20-Meter-Abstand wurden mit einem Aeroprojektor Multiplex im Maßstab 1:20.000 ausgemessen.

Die Geländeaufnahmen dienten der geodätischen Passpunktbestimmung sowie der Geländeerkundung zum Zweck der Beurteilung der Durchgängigkeit von ausgewählten Testgebieten. Dazu standen bereits die Luftbildpaare zur virtuellen räumlichen Auswertung mittels Spiegelstereoskop zur Verfügung. In Lappland wurden bei den Aufnahmeflügen erstmalig Aufnahmen mit der „Pleonkammer“ gemacht. Dies war eine von der Firma ZEISS entwickelte Kammer mit einem Aufnahmeobjektiv von ganz großer Öffnungsweite, bis ca. $120^{\circ}$. Die gegen die Ränder stark verzerrten Bilder wurden mit einem - ebenfalls von ZEISS entwickelten - „Pleonentzerrungsgerät" entzerrt. Die so gewonnenen Bilder zeigten einen kreisrunden Geländeausschnitt von großem Flächeninhalt mit einem mittleren Maßstab von 1:50.000. Die Befliegung erfolgte in $6.000 \mathrm{~m}$ Höhe bei $330 \mathrm{~km} / \mathrm{h}$.

Die Feldaufnahmen für das $4.000 \mathrm{~km}^{2}$ große Gebiet nahmen nur etwa einen Monat in Anspruch und in einem weiteren Monat erfolgten die Bildtriangulation, die Luftbildentzerrung und der Kartendruck im Maßstab 1:50.000. An den Arbeiten der Forschungsstaffel in Lappland waren insgesamt vier Geodäten/Photogrammeter, zwei Geographen, in der mobilen Druckerei 15 Soldaten und zusätzlich 33 Hilfskräfte beteiligt (PILlewizer 1986, 1989).

b) Einen weiteren Wirkungsbereich der Forschungsstaffel z.b.V. bildete von April 1944 bis Kriegsende das „Kommando Tarnung“ (HäUSLER 2007, S. 99). Die Tätigkeit dieses Kommandos betraf in der Zentrale die Bearbeitung und Herausgabe von Tarnanleitungen sowie Lehrgänge über landschaftsgerechte Tarnung. Die Tarntrupps führten Tarnungsberatung bei Stellungsbauten durch, wobei die Tarnung durch Einpassung in die Landschaft und durch Begrünung mit standortgemäßer Vegetation betont wurde. Tarntrupps der Forschungsstaffel waren eingesetzt im Bereich

- Französische Mittelmeer-Küste (April 1944 bis Ende Mai 1944)

- Französische Atlantik-Küste bzw. Hinterland (April 1944 bis August 1944)

- Griechische Küsten (April 1944 bis September 1944)

- Dänische Küsten (? April 1944 bis Kriegsende)

- Ostfriesische Küste (? Oktober 1944 bis Kriegsende)

- Ostfront (zahlreiche kleine Tarntrupps ab September/Oktober 1944 bis März/April 1945) (vgl. Abb. 4)

Im Kommando Tarnung arbeiteten zahlreiche Botaniker, Diplomgärtner, Pflanzensoziologen und Pedologen als Experten für Tarnungsberatung. Es bestand eine enge 
Zusammenarbeit des Tarnkommandos der Forschungsstaffel mit dem Festungspionierstab der Marine bzw. dem Inspekteur im Oberkommando der Marine.

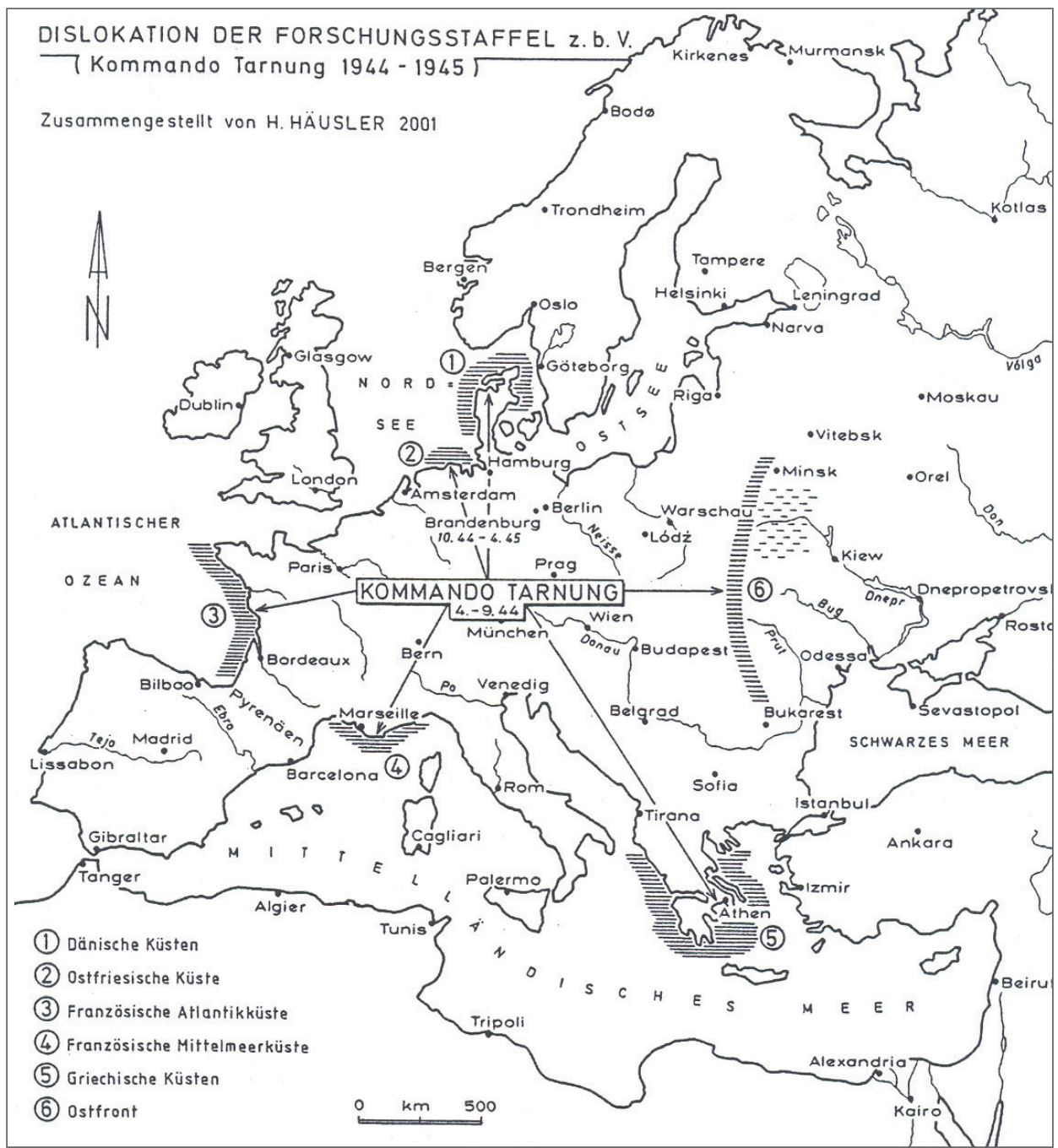

Quelle: HäUsLER 2007, Abb. 26

Abb. 4: Dislozierung des Kommandos „Tarnung“ der Forschungsstaffel z.b.V. (19441945)

c) Besonders erwähnenswert ist noch eine Einsatzgruppe zur Erprobung eines Wärmemessgeräts, die vom Pflanzensoziologen Dr. Ellenberg geleitet wurde. Diese führte im April 1944 Befliegungen eines Moors bei Riga mit gleichzeitigen Bodenuntersuchun- 
gen und Temperaturmessungen am Boden durch. Die Erprobung erfolgte in Hinblick auf eine Verwendung des am Flugzeug montierten Wärmemessgerätes zur Herstellung spezieller Geländebeurteilungskarten. Das Wärmemessgerät wurde von Oberregierungsrat Dr. Albrecht am Meteorologischen Observatorium in Potsdam entwickelt (RössLER 1990, S. 217).

Nach Angaben von Sigfrid SchneIDER $(1957,1974)$ handelte es sich bei dem Wärmemessgerät um eine Röhre mit einem Hohlspiegel an einem Ende, der die Wärmeausstrahlungen der Erdoberfläche auffing und sammelte. Im Brennpunkt befand sich ein elektrischer Wärmemesser, ein sogenanntes Thermoelement, das die jeweilige Temperatur anzeigte. Die Temperaturen wurden auf einem Papierstreifen registriert. Das Gerät ist von der Forschungsstaffel für Temperaturmessungen über Mooren angewendet worden. Von Interesse war die Temperaturverteilung der Moore während der Tauperiode im Hinblick auf die Beurteilung der Befahrbarkeit noch gefrorener Moor-Abschnitte, was durch gleichzeitige Bodenmessungen kontrolliert wurde.

\subsection{Entwicklung eines „Auswerteschlüssels ${ }^{6(10)}$}

Im Wesentlichen wurde die Entwicklung einer Luftbildauswertung für verschiedene Sachgebiete vom Reichsforschungsrat an Universitätsinstitute vergeben In den Jahren 1942/43 erfolgten ferner durch das Reichsforstamt in den besetzten Ostgebieten (Polen, Russland) Forsttaxierungen auf Grund von Luftbildauswertungen. Bei allen Auswertungsarbeiten wurden hauptsächlich Senkrechtaufnahmen der Maßstäbe 1:8.000 bis 1:30.000 im Format $18 \times 18 \mathrm{~cm}$ oder 30x30 cm benützt, selten auch Bilder kleinerer Maßstäbe, z. B. 1:50.000. In geringem Umfang fanden auch Schrägluftbilder Verwendung. Neben Aufnahmen auf panchromatischem Film wurden auch Infrarotbilder benützt (z. B. vom Reichsforstamt und von der Forschungsstaffel), aber nur in wenigen Fällen Farbbilder (z. B. bei der Forschungsstaffel). Publikationen über die Anwendung von Luftbildauswertungen und Vorarbeiten für die rein wissenschaftliche Entwicklung eines „Auswerteschlüssels" erfolgten durch Vertreter der Fachgebiete Geographie, Geomorphologie, Geologie, Eisforschung, Gletscherkunde, Gewässerkunde, Vegetationskunde, Forstwissenschaft, Bodenkunde, Archäologie und Moorforschung.

Für die Entwicklung der Kartengestaltung galt der Grundsatz: Klare Gesamtrichtung, aber im einzelnen „beweglicher Plan“. Es wurde zwar als Ziel Einheitlichkeit der Karten angestrebt, aber doch im Interesse der Weiterentwicklung den einzelnen Kommandos ein möglichst großer Spielraum zur Entfaltung eigener Initiative gelassen. Es gab kein starr festgelegtes Schema, sondern nur einige allgemeine Grundlinien, in deren Rahmen die Entwicklung von den Kommandos weitergetrieben werden sollte. Weiters galt: „Alles auf einem Stück Papier“, das heißt, Texte, Nebenkärtchen, Bilder, Diagramme oder sonstige

10) Das im Archiv des Militärhistorischen Museums der Bundeswehr in Dresden vorhandene Manuskript über „Bemerkungen zu den von der Forschungsstaffel hergestellten Karten zur Geländebeurteilung“ (ScHмIтнÜSEN 1946) behandelt Inhalt und Darstellungsweise des Kartenbildes in verschiedenen Maßstäben, enthält aber keine Angaben über Geländeerkundung und Luftbildauswertung. Auszüge von ScHмITHÜSENS Manuskript mit entsprechenden Karten- und Legendenbeispielen finden sich auch in HäUSLER (2007, S. 124ff). 
Zugaben zu der Karte mussten, soweit sie erforderlich waren, auf dem Kartenblatt selbst untergebracht werden. Deckblätter, Erläuterungshefte oder dergleichen waren nicht zugelassen.

Der Benützer sollte alles Notwendige auf kleinstem Raum beisammen haben. Dadurch sollte verhindert werden, dass das Material, so wie es z. B. mit den meisten Beschreibungen von Mil.Geo. geschah, unbenützt in den Panzerschränken der Stäbe verschwand. Aus dem gleichen Grund wurden auch die Karten der Forschungsstaffel jeweils mit dem niedrigst möglichen Geheimhaltungsgrad herausgegeben. Die Geheimhaltungsstufe wurde deshalb für jedes einzelne Kartenblatt gesondert festgesetzt (SCHMIтHÜSEN 1946).

Im Rahmen der allgemeinen Richtlinien war jedoch den Kommandos für die Gestaltung der von ihnen bearbeiteten Karten weitgehend freie Hand gelassen. Damit wurde zwar zunächst keine völlige äußere Einheitlichkeit der Karten erreicht, aber der Erprobung neuer kartographischen Ideen Spielraum gegeben, was für die gesamte Entwicklung sehr förderlich war. Nach der Fertigstellung jeder neuen Karte, wenn möglich vor deren Druck, wurden in den „Legendenbesprechungen“ die Vor- und Nachteile der von den Bearbeitern vorgeschlagenen Darstellungsweise erörtert. In manchen Fällen wurden auch Probedrucke in verschiedenen Darstellungsmöglichkeiten hergestellt, bevor neue Signaturen in Auflagendrucken erschienen.

Erst nachdem auch die Kritik der Benützer bekannt war, wurden die zunächst nur probeweise angewandten Veränderungen entweder wieder verworfen oder als Verbesserungen anerkannt und in dieser Form dann für die Kommandos verbindlich gemacht. Auf diese Weise wurde in einem natürlichen Ausgleich von zielbewusster Lenkung und freiem Experimentieren die Gesamtentwicklung der Kartendarstellung Schritt für Schritt gefördert. Die Kommandos hatten dabei die Aufgabe, für die aus der Eigenart ihres Arbeitsgebietes (z. B. Gebirgsland oder Flachland) sich ergebenden kartographischen Probleme Lösungen zu suchen (SCHMITHÜSEN 1946).

Aufgabe der Staffelführung war es, dafür zu sorgen, dass die von den regionalen Notwendigkeiten her entwickelten Vorschläge der verschiedenen Kommandos miteinander in Einklang gebracht werden. So konnte trotz der weiten räumlichen Trennung und der Selbstständigkeit der einzelnen Kommandos in relativ kurzer Zeit doch bereits eine gewisse Einheitlichkeit des neuentwickelten Kartentyps erreicht werden.

Folgende Personen wurden nach Angaben der Gruppe Dustbin (1947a, S. 2-3) zur Mitarbeit an der Studie über die Verwendung von Luftbildern während des Krieges verpflichtet:

- Günter Caulier-Eimbcke (Geschäftsführer der Forschungsgruppe ab 1942; Nachschuboffizier und Luftbildbeschaffer der Forschungsstaffel z.b.V. 1943-1945; Stellvertreter für Verwaltungsfragen des Beauftragten für Sonderaufgaben der erdkundlichen Forschung im Reichsforschungsrat)

- Dipl.-Ing. Werner Göpner (Photogrammeter; Forschungsstaffel 1943-1945)

- Dr. Ingrid Mathiesen (Geographin; Abteilung für Landeskunde, wissenschaftliche Sachbearbeiterin ab 01.09.1941)

- Prof. Dr. Emil Meynen (Geograph, wissenschaftlicher Leiter der Abteilung für Landeskunde seit 01.01.1941)

- Dr. Erich Otremba (Geograph; Forschungsstaffel z.b.V., Okt. 1944 bis April 1945; wissenschaftlicher Kommandoführer) 
- Prof. Dr. Gottfried Pfeifer (Geograph; MarGeo - Marinegeographie; wissenschaftlicher Mitarbeiter 1943 - April 1945)

- Dr. Wolfgang Pillewizer (Geograph, Topograph; Forschungsstaffel 1943-1945, wissenschaftlicher Kommandoführer und Kartenoffizier)

- Dr. Angelika Sievers (Geographin; Abteilung für Landeskunde, wissenschaftliche Sachbearbeiterin seit 01.08.1943; nach Kriegsende im Interrogation Camp: Übersetzung der deutschsprachigen Berichte der Gruppe Dustbin)

- Dr. Josef Schmithüsen (Geograph; Abteilung für Landeskunde, wissenschaftlicher Sachbearbeiter 01.04.1941 - 03.11.1942; Forschungsstaffel 01.11.1943 - 1945; wissenschaftlicher Verbindungsoffizier in der Staffelführung von 01.02.1944 - 1945; Mitarbeiter und seit November 1944 wissenschaftlicher Vertreter des Beauftragten für Sonderaufgaben der erdkundlichen Forschung im Reichsforschungsrat)

- Dr. Sigfrid Schneider (Geograph; Forschungsstaffel Nov. 1944 - 1945; wissenschaftlicher Mitarbeiter).

Tabelle 1 gibt einen Überblick über die Vergabe von ,dringlichen kriegs- und staatswichtigen“" Forschungsaufträgen an Mitglieder der Forschungsstaffel z.b.V. sowie universitäre Mitarbeiter im Jahr 1944.

\begin{tabular}{|l|l|l|}
\hline Bearbeiter & \multicolumn{1}{|c|}{ Institution } & \multicolumn{1}{|c|}{ Thema } \\
\hline Beckmann & $\begin{array}{l}\text { Amt für Wellenausbreitung } \\
\text { der Forschungsanstalt der } \\
\text { Deutschen Reichspost }\end{array}$ & $\begin{array}{l}\text { Methoden zur Ergänzung der Truppenkarten der } \\
\text { Geländebeurteilung in Hinblick auf die militä- } \\
\text { risch-funktechnische Brauchbarkeit eines Opera- } \\
\text { tionsgeländes (Feldstärkemessungen). }\end{array}$ \\
\hline Behrmann & $\begin{array}{l}\text { Direktor Geographisches } \\
\text { Institut in Frankfurt/Main }\end{array}$ & $\begin{array}{l}\text { Entwicklung kartographischer Methoden zur } \\
\text { Unterstützung kleiner Landungs- und Kommando- } \\
\text { unternehmen }\end{array}$ \\
\hline Blüthgen & $\begin{array}{l}\text { Geographisches Institut der } \\
\text { Universität Greifswald }\end{array}$ & $\begin{array}{l}\text { Übersichtskarte zur wehrgeographischen Gelände- } \\
\text { beurteilung von Europa 1:1 Million, Blatt Nord } \\
\text { (Skandinavien) }\end{array}$ \\
\hline Cloos & $\begin{array}{l}\text { Geologisches Institut der } \\
\text { Universität Bonn }\end{array}$ & $\begin{array}{l}\text { Geologische Luftbildauswertung für militärische } \\
\text { Geländebeurteilungskarten }\end{array}$ \\
\hline Credner & $\begin{array}{l}\text { Geographisches Institut } \\
\text { der Techn. Hochschule } \\
\text { München }\end{array}$ & $\begin{array}{l}\text { Landwirtschaftsgeographische Luftbildauswer- } \\
\text { tung für militärische Geländebeurteilungskarten; } \\
\text { Marinegeographische Kartierung der Festlandküs- } \\
\text { ten Schwedens }\end{array}$ \\
\hline Dörries & $\begin{array}{l}\text { Geographisches Institut } \\
\text { der Universität Münster in } \\
\text { Westfalen }\end{array}$ & $\begin{array}{l}\text { Übersichtskarte zur wehrgeographischen Gelände- } \\
\text { beurteilung von Europa 1:1 Million, Blatt West } \\
\text { (Britische Inseln) }\end{array}$ \\
\hline Ellenberg & $\begin{array}{l}\text { Forschungsstaffel z.b.V, } \\
\text { Forschungskommando Ost }\end{array}$ & $\begin{array}{l}\text { Übersichtskarte zur wehrgeographischen Gelände- } \\
\text { beurteilung von Europa 1:1 Million, Blatt Ost; } \\
\text { Bearbeitung verschiedener OT-Aufgaben im Ge- } \\
\text { biet Narwa; Bearbeitung verschiedener Gelände- } \\
\text { abschnitte der Ostfront, Darstellung von Gelände- } \\
\text { beurteilungskarten; Wissenschaftliche Auswertung } \\
\text { von Befliegung einzelner Gebiete des Baltikums }\end{array}$ \\
\hline
\end{tabular}




\begin{tabular}{|c|c|c|}
\hline Bearbeiter & Institution & Thema \\
\hline $\begin{array}{l}\text { Finster- } \\
\text { walder }\end{array}$ & $\begin{array}{l}\text { Technische Hochschule } \\
\text { München }\end{array}$ & $\begin{array}{l}\text { Topographische Auswertung von Luft- und Erd- } \\
\text { bild für militärische Geländebeurteilungskarten; } \\
\text { Erprobung des Theodolit TA L }\end{array}$ \\
\hline Frebold & $\begin{array}{l}\text { Arktische Abteilung des } \\
\text { Deutschen Wissenschaftli- } \\
\text { chen Instituts in Kopenhagen }\end{array}$ & $\begin{array}{l}\text { Küstenmorphologische Untersuchungen an den } \\
\text { dänischen Küsten (außer Jütland) }\end{array}$ \\
\hline Groschopf & MarGeo Würzburg & $\begin{array}{l}\text { Untersuchung der Riffbildungen vor den europäi- } \\
\text { schen Küsten }\end{array}$ \\
\hline Jessen & $\begin{array}{l}\text { Geographisches Institut der } \\
\text { Universität Rostock }\end{array}$ & $\begin{array}{l}\text { Marinegeographische Kartierung der deutschen } \\
\text { Ostseeküste }\end{array}$ \\
\hline Kanter & $\begin{array}{l}\text { Geographisches Institut der } \\
\text { Universität Marburg }\end{array}$ & $\begin{array}{l}\text { Übersichtskarte zur wehrgeographischen Gelände- } \\
\text { beurteilung von Europa 1:1 Million, Blatt Italien }\end{array}$ \\
\hline Kolb & MarGeo Würzburg & $\begin{array}{l}\text { Auswertung von Luftbildern für die Morphologie } \\
\text { der verschiedenen Küstentypen und Entwicklung } \\
\text { nautisch-geographischer Kartierungsmethoden }\end{array}$ \\
\hline Kraus & $\begin{array}{l}\text { Geographisches Institut der } \\
\text { Universität Köln }\end{array}$ & $\begin{array}{l}\text { Küstenmorphologische Forschungen und marine- } \\
\text { geographische Kartierung der belgisch-niederlän- } \\
\text { dischen Küste }\end{array}$ \\
\hline Lehmann & $\begin{array}{l}\text { Kartograph. Anstalt des } \\
\text { Bibliographischen Instituts, } \\
\text { Meinersdorf/Erzgebirge) }\end{array}$ & $\begin{array}{l}\text { Kartographische Methoden zur Herstellung von } \\
\text { „Karten zur militärischen Geländebeurteilung“ }\end{array}$ \\
\hline Lendl & $\begin{array}{l}\text { Geographisches Institut der } \\
\text { Universität Wien }\end{array}$ & Landeskundliche Bearbeitung der Narentafurche \\
\hline Louis & $\begin{array}{l}\text { Geographisches Institut der } \\
\text { Universität Köln/Rhein }\end{array}$ & $\begin{array}{l}\text { Küstenmorphologische Untersuchungen über } \\
\text { die türkische Küste einschließlich Bosporus und } \\
\text { Dardanellen und die Küsten Ost-Griechenlands; } \\
\text { Übersichtskarte zur wehrgeographischen Gelände- } \\
\text { beurteilung von Europa 1:1 Million, Blatt Südost } \\
\text { (Spezialgebiete) }\end{array}$ \\
\hline Maull & $\begin{array}{l}\text { Geographisches Institut der } \\
\text { Universität Graz }\end{array}$ & $\begin{array}{l}\text { Übersichtskarte zur wehrgeographischen Gelände- } \\
\text { beurteilung von Europa 1:1 Million, Blatt Südost } \\
\text { (Balkan) }\end{array}$ \\
\hline $\begin{array}{l}\text { Meyer } \\
\text { (?-Hetling) }\end{array}$ & $\begin{array}{l}\text { (? Stabshauptamt Planung } \\
\text { und Boden) }\end{array}$ & $\begin{array}{l}\text { Kartographisch-technische Entwicklung des Dru- } \\
\text { ckes von Geländebeurteilungskarten in verschie- } \\
\text { denen Maßstäben }\end{array}$ \\
\hline Metz & $\begin{array}{l}\text { Geographisches Institut der } \\
\text { Universität Freiburg/Br. }\end{array}$ & $\begin{array}{l}\text { Übersichtskarte zur wehrgeographischen Gelände- } \\
\text { beurteilung von Europa 1:1 Million, Blatt West } \\
\text { (Südteil) }\end{array}$ \\
\hline Meynen & $\begin{array}{l}\text { Reichsamt für Landesauf- } \\
\text { nahme, Berlin }\end{array}$ & $\begin{array}{l}\text { Bearbeitung geographischer Grundlagen für einen } \\
\text { Luftbildleseschlüssel zur Herstellung von Gelän- } \\
\text { debeurteilungskarten }\end{array}$ \\
\hline Morawetz & $\begin{array}{l}\text { Geographisches Institut der } \\
\text { Universität Graz }\end{array}$ & $\begin{array}{l}\text { Länderkundliche Bearbeitung eines Dalmatini- } \\
\text { schen Küstenabschnittes unter Berücksichtigung } \\
\text { der militärischen Geländebeurteilung }\end{array}$ \\
\hline
\end{tabular}




\begin{tabular}{|c|c|c|}
\hline Bearbeiter & Institution & Thema \\
\hline Mortensen & $\begin{array}{l}\text { Geographisches Institut der } \\
\text { Universität Göttingen }\end{array}$ & $\begin{array}{l}\text { Übersichtskarte zur wehrgeographischen Gelände- } \\
\text { beurteilung von Europa 1:1 Million, Blatt West } \\
\text { (Südteil) }\end{array}$ \\
\hline $\begin{array}{l}\text { Müller- } \\
\text { Miny }\end{array}$ & $\begin{array}{l}\text { Reichsamt für Landesauf- } \\
\text { nahme, Berlin }\end{array}$ & $\begin{array}{l}\text { Bearbeitung geographischer Grundlagen für einen } \\
\text { Luftbildleseschlüssel zur Herstellung von Gelän- } \\
\text { debeurteilungskarten }\end{array}$ \\
\hline $\begin{array}{l}\text { Müller- } \\
\text { Wille }\end{array}$ & $\begin{array}{l}\text { Geographisches Institut der } \\
\text { Universität Göttingen }\end{array}$ & $\begin{array}{l}\text { Übersichtskarte zur wehrgeographischen Gelände- } \\
\text { beurteilung von Europa 1:1 Million, Blatt West } \\
\text { (Südteil) }\end{array}$ \\
\hline Pillewizer & $\begin{array}{l}\text { Kartenoffizier der For- } \\
\text { schungsstaffel z.b.V. }\end{array}$ & $\begin{array}{l}\text { Erarbeitung von Unterlagen für die Führung im } \\
\text { Bereich O.B. Südost, Quellenauswertung, Feld- } \\
\text { einsätze, Kartographische Darstellung, Berichte, } \\
\text { Befliegungen, Luftbildauswertung }\end{array}$ \\
\hline Preising & $\begin{array}{l}\text { Zeitweise Angehöriger der } \\
\text { Forschungsstaffel }\end{array}$ & $\begin{array}{l}\text { Bearbeitung dringender Tarnungsaufgaben am } \\
\text { Atlantikwall, kartographische Darstellung und } \\
\text { Quellenauswertung }\end{array}$ \\
\hline Schrepfer & $\begin{array}{l}\text { Geographisches Institut der } \\
\text { Universität Würzburg }\end{array}$ & $\begin{array}{l}\text { Landschaftliche Kartierung der Inseln Bornholm, } \\
\text { Gotland und Öland mit besonderer Berücksichti- } \\
\text { gung der küstenmorphologischen Verhältnisse }\end{array}$ \\
\hline Sölch & $\begin{array}{l}\text { Geographisches Institut der } \\
\text { Universität Wien }\end{array}$ & $\begin{array}{l}\text { Küstenmorphologie Südenglands und Kartierung } \\
\text { der Ergebnisse im Stile der MarGeo-Karten }\end{array}$ \\
\hline Spreitzer & $\begin{array}{l}\text { Geographisches Institut der } \\
\text { Universität Prag }\end{array}$ & $\begin{array}{l}\text { Untersuchung der morphologischen Verhältnisse } \\
\text { an den Schwarzmeerküsten Rumäniens und Bul- } \\
\text { gariens; Übersichtskarte zur wehrgeographischen } \\
\text { Geländebeurteilung von Europa 1:1 Million, Blatt } \\
\text { Südost (Balkan) }\end{array}$ \\
\hline Stickel & $\begin{array}{l}\text { Geographisches Institut der } \\
\text { Universität Bonn }\end{array}$ & $\begin{array}{l}\text { Küstenmorphologische Untersuchungen und Mar- } \\
\text { Geo-Kartierung der iberischen Halbinsel }\end{array}$ \\
\hline Storm & $\begin{array}{l}\text { Geographisches Institut der } \\
\text { Universität Freiburg/Br. }\end{array}$ & $\begin{array}{l}\text { Übersichtskarte zur wehrgeographischen Gelände- } \\
\text { beurteilung von Europa 1:1 Million, Blatt West } \\
\text { (Südteil) }\end{array}$ \\
\hline Thomson & $\begin{array}{l}\text { Forschungsstaffel z.b.V, } \\
\text { Forschungskommando Ost }\end{array}$ & $\begin{array}{l}\text { Übersichtskarte zur wehrgeographischen Gelände- } \\
\text { beurteilung von Europa 1:1 Million, Blatt Ost }\end{array}$ \\
\hline Troll & $\begin{array}{l}\text { Geographisches Institut der } \\
\text { Universität Bonn }\end{array}$ & $\begin{array}{l}\text { Geographische Luftbildauswertung und Nutzbar- } \\
\text { machung russischer Literatur }\end{array}$ \\
\hline Tüxen & $\begin{array}{l}\text { Zentralstelle für Vegeta- } \\
\text { tionskartierung }\end{array}$ & $\begin{array}{l}\text { Erarbeitung pflanzensoziologischer Unterlagen } \\
\text { für militärische Geländebeurteilungskarten und } \\
\text { Entwicklung der Methode pflanzensoziologischer } \\
\text { Luftbildauswertung, Erarbeitung von Methoden } \\
\text { zur Auswertung von Luftbildern für Gelände- } \\
\text { beurteilungskarten in Zusammenarbeit mit der } \\
\text { Luftwaffe. }\end{array}$ \\
\hline
\end{tabular}




\begin{tabular}{|l|l|l|}
\hline Bearbeiter & \multicolumn{1}{|c|}{ Institution } & \multicolumn{1}{c|}{ Thema } \\
\hline Vilbig & $\begin{array}{l}\text { Amt für Wellenausbreitung } \\
\text { der Forschungsanstalt der } \\
\text { Deutschen Reichspost }\end{array}$ & $\begin{array}{l}\text { Methoden zur Ergänzung der Truppenkarten der } \\
\text { Geländebeurteilung in Hinblick auf die militä- } \\
\text { risch-funktechnische Brauchbarkeit eines Opera- } \\
\text { tionsgeländes (Feldstärkemessungen). }\end{array}$ \\
\hline Walther & $\begin{array}{l}\text { Forschungsstaffel z.b.V, } \\
\text { Forschungskommando Ost }\end{array}$ & $\begin{array}{l}\text { Übersichtskarte zur wehrgeographischen Gelände- } \\
\text { beurteilung von Europa 1:1 Million, Blatt Ost }\end{array}$ \\
\hline Zaar & $\begin{array}{l}\text { Geodätisches Institut der } \\
\text { Technischen Hochschule } \\
\text { Graz }\end{array}$ & $\begin{array}{l}\text { Untersuchung der Möglichkeiten, aus sich über- } \\
\text { deckenden Senkrecht- und Schrägaufnahmen von } \\
\text { Wasserflächen, monokular und stereoskopisch } \\
\text { Tiefen zu messen. }\end{array}$ \\
\hline
\end{tabular}

Quelle: Bundesarchiv Berlin, R 26 III-180; HäUSLER 2007, Tab. 3 und 4, ergänzt

Tab. 1: Vergabe von „dringlichen kriegs- und staatswichtigen“ Forschungsaufträgen durch den Beauftragten für Sonderaufgaben der erdkundlichen Forschung, Schulz-Kampfhenkel, im Jahr 1944 ${ }^{11)}$

Dem Monatsbericht des Beauftragten für Sonderaufgaben der erdkundlichen Forschung (Schulz-Kampfhenkel) für Juli 1944 ist zu entnehmen, ${ }^{12)}$ dass der Forschungsstaffel z.b.V. vom Führungsstab des Oberkommandos der Wehrmacht (OKW) eine Rahmenstärke von 250 Personen zugewiesen wurde, um die von ihr entwickelten neuen Methoden der wehrgeographischen Luftbildauswertung und ihre „Karten der Geländebeurteilung“ und „Sonderkarten für Panzertruppen“ schnell und auf breiter Grundlage für Führung und Truppe auszunutzen.

Wesentliche Neuerungen für die Geländebeurteilung bot die durch die Forschungsstaffel z.b.V. entwickelte Methode der integrativen Luftbildauswertung. Die Zeitschrift für „Landeskundliche Luftbildauswertung im Mitteleuropäischen Raum“ wurde nach dem Krieg von ehemaligen Mitarbeitern der Forschungsstaffel z.b.V., und zwar von H. Bobek, Th. Kraus, W. von Laer, E. Otremba und C. Troll gemeinsam mit E. Meynen, H. Müller-Miny und S. Schneider herausgegeben, nachdem auf dem Internationalen Geographentag in Washington 1952 der landeskundlichen Luftbildinterpretation eine besondere Kommissionssitzung gewidmet worden war.

\subsection{Beispiele von Kartenwerken der „Forschungsstaffel z.b.V.“}

Je nach Lageentwicklung auf den europäischen Kriegsschauplätzen wurden von der Staffelführung vorausschauend und rechtzeitig Aufträge zur Ausarbeitung von Geländebeurteilungskarten an die Forschungskommandos und Einsatzgruppen vergeben (Tab. 2).

\footnotetext{
11) Die Beträge für die Forschungsaufträge in der Höhe von jeweils 300 bis 1000 Reichsmark setzten sich aus Material, Dienstreisen, Geräten (z.B. Stereoskope) und gelegentlich Kosten für Hilfskräfte zusammen und wurden von Caulier-Eimbcke, dem Stellvertreter des Beauftragten für Sonderaufgaben der erdkundlichen Forschung, verwaltet und von der Deutschen Forschungsgemeinschaft angewiesen.

12) Bundesarchiv Berlin, R 26 III-180, Anlage 1 zu Br.B.Nr. 726/44 1116/44 geh. vom 31.07.1944.
} 


\begin{tabular}{|c|c|}
\hline Bearbeitung durch: & Themenkarten \\
\hline $\begin{array}{l}\text { Einsatzgruppe Lap- } \\
\text { pland (Nordeuropa) }\end{array}$ & Truppenkarten Vuotso 1:50.000 und Lätäseno 1:100.000 \\
\hline $\begin{array}{l}\text { Forschungskommando } \\
\text { Ost (Osteuropa) }\end{array}$ & $\begin{array}{l}\text { Geländebeurteilung von Leningrad 1:300.000 } \\
\text { Geländebeurteilung Blatt Narwa 1:300.000 } \\
\text { Landschaftsgliederung als Nebenkarte im Maßstab 1:1.200.000 mit } \\
\text { Bildplan des Narwa-Gebietes 1:25.000 } \\
\text { Konka-Niederung südlich Saporoshje 1:50.000 (in Zusammenarbeit mit } \\
\text { dem höheren Offizier des Kriegskarten- und Vermessungswesens sowie } \\
\text { den Wehrgeologenstellen } 6 \text { und 16) } \\
\text { Durchgängigkeit des Pripjet-Gebietes 1:300.000 mit Rückseitenaufdruck } \\
\text { (Beurteilung der Durchgängigkeit des Pripjet-Gebietes 1:1.000.000) }\end{array}$ \\
\hline $\begin{array}{l}\text { Forschungskommando } \\
\text { West (Einsatzgruppe } \\
\text { Nordwest: Deutsch- } \\
\text { land) }\end{array}$ & Befahrbarkeitskarten 1:100.000 für motorisierte Truppen \\
\hline $\begin{array}{l}\text { Forschungskommando } \\
\text { Süd (Südosteuropa) }\end{array}$ & $\begin{array}{l}\text { Übersichtskarte zur Geländebeurteilung von Nord-Griechenland und } \\
\text { Thrazien im Maßstab 1:500.000, Raum Larissa-Prewesa-Ohrid-Ditimo- } \\
\text { tichon-Alexandrupolis; Gesteinskarte Nord-Griechenland 1:1.500.000; } \\
\text { Karte der Malariaverbreitung 1:1 750.000; Truppenkarte zur Gelände- } \\
\text { beurteilung 1:200.000, Blatt 33/44: Zara/Zadar und 34/44: Split/Spalato } \\
\text { mit Nebenkarte der Gesteins- und Bodenarten Südosteuropa 1:200.000; } \\
\text { Sonderausgabe Panzerkarte 1: 200.000, Raum Zara-Knin-Sibenik; } \\
\text { Wasserkarte Adriatischer Karst 1: 500.000; Truppenkarte zur Gelän- } \\
\text { debeurteilung Italien 1:100.000, Blätter 50: Padua, 51:Venezia, 63: } \\
\text { Legnano, 64: Rovigo und 65: Adria; Sonderausgabe Panzerkarte Italien } \\
\text { 1:100.000; Übersichtskarte Wien-Budapest 1:500.000; Übersichts- } \\
\text { karte zur Geländebeurteilung der Südalpen 1:500.000 mit Nebenkarte } \\
\text { 1:1.000.000 über die Dauer der Schneelage in den südlichen Ostalpen; } \\
\text { Truppenkarte zur Geländebeurteilung Südosteuropas 1:200.000, Blatt } \\
\text { Laibach-Cilli-Pota-Senj; Geländebeurteilung Laibach-Cilly 1:200.000: } \\
\text { Wien-Pressburg 1:200.000, Fürstenfeld-Varaždin 1:200.000. }\end{array}$ \\
\hline
\end{tabular}

Quelle: nach SchмiтнüSEN 1946

Tab. 2: Beispiele von thematischen Kartenwerken, die von den Forschungskommandos Ost, West und Süd sowie von der Einsatzgruppe Lappland ausgearbeitet und gedruckt wurden

Wie bereits erwähnt, variierten diese Themenkarten in den Maßstäben von 1:25.000 über 1:100.000, 1:200.000, 1:300.000 bis 1:500.000 und enthielten gelegentlich Nebenkarten in kleineren Maßstäben (Tab. 3).

\begin{tabular}{|l|l|}
\hline Maßstab & \multicolumn{1}{c|}{ Thema } \\
\hline $1: 25.000$ & $\begin{array}{l}\text { Geländebeurteilung Griechenland, Estland } \\
\text { Grenava, Griechenland; Narwa-Gebiet, Estland }\end{array}$ \\
\hline $1: 50.000$ & $\begin{array}{l}\text { Geländebeurteilung Ukraine, Lappland, Ostland } \\
\text { Konka-Niederung, Ukraine; Vuotso, Lappland (Finnland); Ostland }\end{array}$ \\
\hline
\end{tabular}




\begin{tabular}{|l|l|}
\hline \multicolumn{1}{|c|}{ Maßstab } & \multicolumn{1}{c|}{ Thema } \\
\hline $1: 100.000$ & $\begin{array}{l}\text { Geländebeurteilung Norwegen, Italien, Deutschland } \\
\text { Lätäseno, Norwegen/Finnland; Italien; Luftlandemöglichkeiten }\end{array}$ \\
\hline $1: 200.000$ & $\begin{array}{l}\text { Geländebeurteilung Südosteuropa } \\
\text { Geländebeurteilung Mitteldalmatien; Geländebeurteilung Zadar; Gesteins- und } \\
\text { Bodenarten Südosteuropa; Gesteins- und Bodenkarte Krim }\end{array}$ \\
\hline $1: 300.000$ & $\begin{array}{l}\text { Geländebeurteilung Osteuropa } \\
\text { Geländebeurteilung Narwa-Narwa; Geländebeurteilung Leningrad; Landschafts- } \\
\text { gliederung Narwa Narwa; Durchgängigkeit Pripjet-Gebiet }\end{array}$ \\
\hline $1: 500.000$ & $\begin{array}{l}\text { Geländebeurteilung Griechenland, Adria, Südalpen } \\
\text { Geländebeurteilung Nord-Griechenland; Gesteinsarten Nordgriechenland; Ge- } \\
\text { wässerkarte Adriatischer Karst; Geländebeurteilung Südalpen }\end{array}$ \\
\hline $1: 1.000 .000$ & $\begin{array}{l}\text { Nebenkarten: Durchgängigkeit Pripjet-Gebiet; Schneelage in den südlichen Ost- } \\
\text { alpen }\end{array}$ \\
\hline $1: 1.500 .000$ & Nebenkarte: Gesteinskarte Nordgriechenland \\
\hline $1: 1.750 .000$ & Nebenkarte: Malariaverbreitung Nord-Griechenland (West- und Ostteil) \\
\hline
\end{tabular}

Quelle: nach SCHмIтHÜSEN 1946

Tab. 3: Beispiele der von der Forschungsstaffel z.b.V. in verschiedenen Maßstäben ausgearbeiteten und gedruckten Themenkarten

Nachfolgend werden aus der Arbeit von HäUSLER (2007) Kartenbeispiele von Karten der Geländebeurteilung in den Maßstäben 1:300.000 („Durchgängigkeit des Pripjet-Gebietes“, Abb. 5), 1:100.000 („Panzerkarte“ als Sonderausgabe der Truppenkarte zur Geländebeurteilung 1:100.000 von Italien, Abb. 6) sowie 1:50.000 (Konka-Niederung südlich Saporoshje, Abb. 7 und 8) vorgestellt.

Gemäß dem Monatsbericht des Beauftragten für Sonderaufgaben der erdkundlichen Forschung, Dr. Schulz-Kampfhenkel, wurde im November 1943 (Bf. Nr. 207/43/761/43) auf Ersuchen des Oberkommando des Heeres die „,beschleunigte“ wissenschaftliche Gestaltung der vom Chef des Generalstabes des Heeres (auf Ersuchen des Generals der Pioniere in Minsk, Heeresgruppe Mitte) kurzfristig geforderten „Militärgeographischen Karte zur Geländebeurteilung des Pripjetgebiets 1:300.000“ in Angriff genommen.

Neben einer generellen Beurteilung der Durchgängigkeit des Pripjet-Gebiets 1:1.000.000 (als Rückseitenaufdruck zu detaillierteren Karten) wurden ab November 1943 detailliertere Karten der Durchgängigkeit des Pripjet-Gebietes 1:300.000 (zweite Ausgabe mit Stand vom 1. März 1944) auf Grundlage der Deutschen Heereskarte 1:300.000 gedruckt. In dieser Karte sind die nach dem Gesamtkomplex der wichtigsten Geländeeigenschaften gleichartigen Gebiete abgegrenzt und durch einheitliche Flächenfarben oder Flächensignaturen zusammengefasst, wobei nur die militärisch am meisten interessierenden nassen und feuchten Gebiete nach Geländetypen ausgegliedert sind. Da das trockene Gelände militärisch keine besonderen Probleme aufwies, blieb es ungegliedert und erscheint in der Karte ohne Farbenaufdruck in der Darstellungsweise der zugrunde gelegten topographischen Karte. 


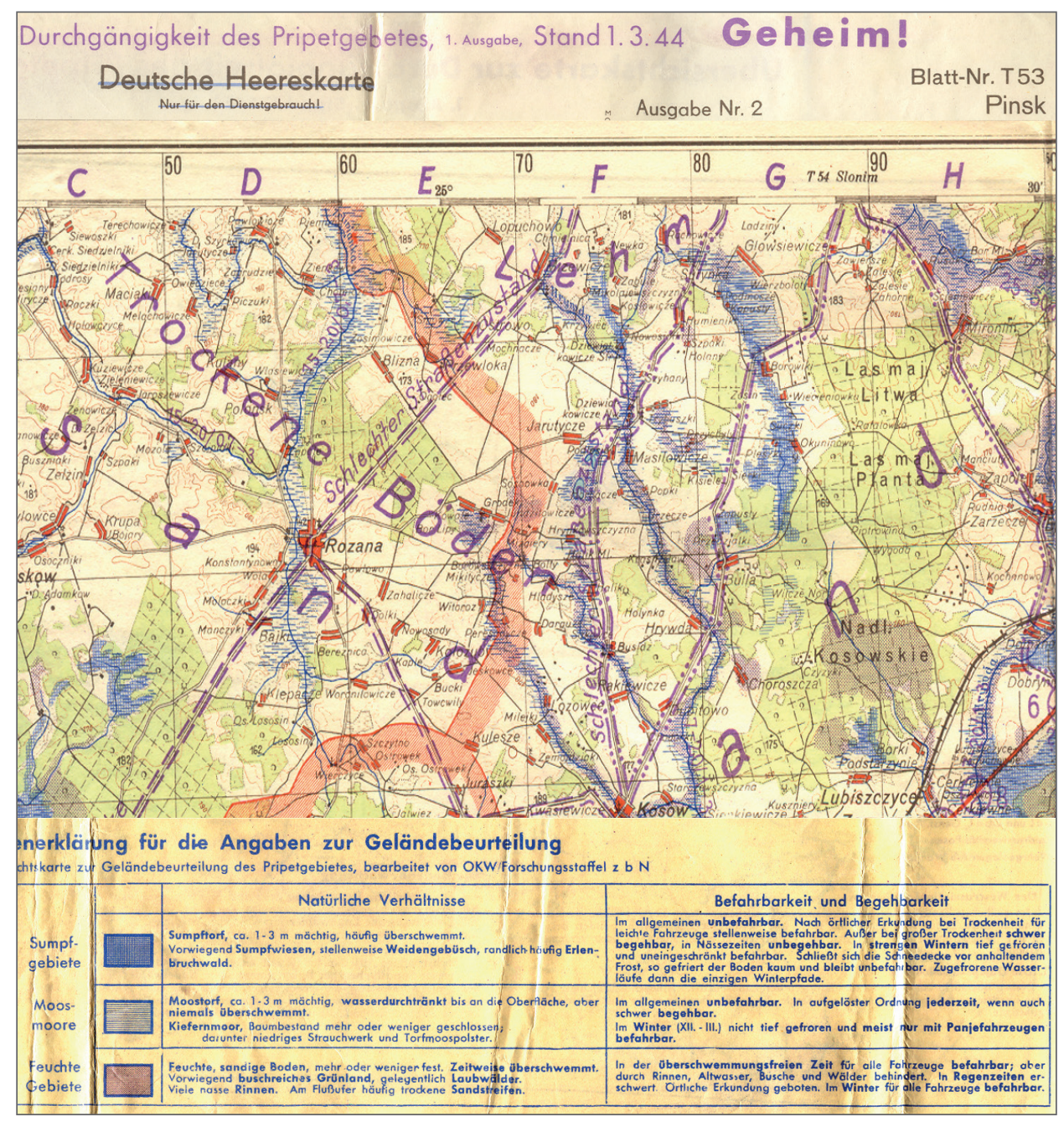

Quelle: Reproduktion mit freundlicher Genehmigung der Stiftung Preußischer Kulturbesitz, Berlin; verändert nach HäUSLER 2007, Abb. 43

Abb. 5: Ausschnitt der Karte 1:300.000 „Durchgängigkeit des Pripjet-Gebietes“, BlattNr. T 53, Pinsk mit Stand vom 01.03.1944

Innerhalb des feuchten bis nassen Bereichs sind drei Geländetypen, nämlich „Sumpfgebiete“, „Moosmoore“ und „feuchte Gebiete“ ausgeschieden. Diese sind in Flächenfarben mit drei verschiedenen Blau- und Violetttönen auf der Karte herausgehoben. „Sumpfgebiete" bestanden beispielsweise aus häufig überschwemmtem ein bis drei Meter mächtigem Sumpftorf mit oberflächennahem Grundwasser, auf dem vorwiegend Sauergraswiesen, stellenweise Weidengebüsch und am Rand der Sumpfflächen häufig Erlenbruchwälder 


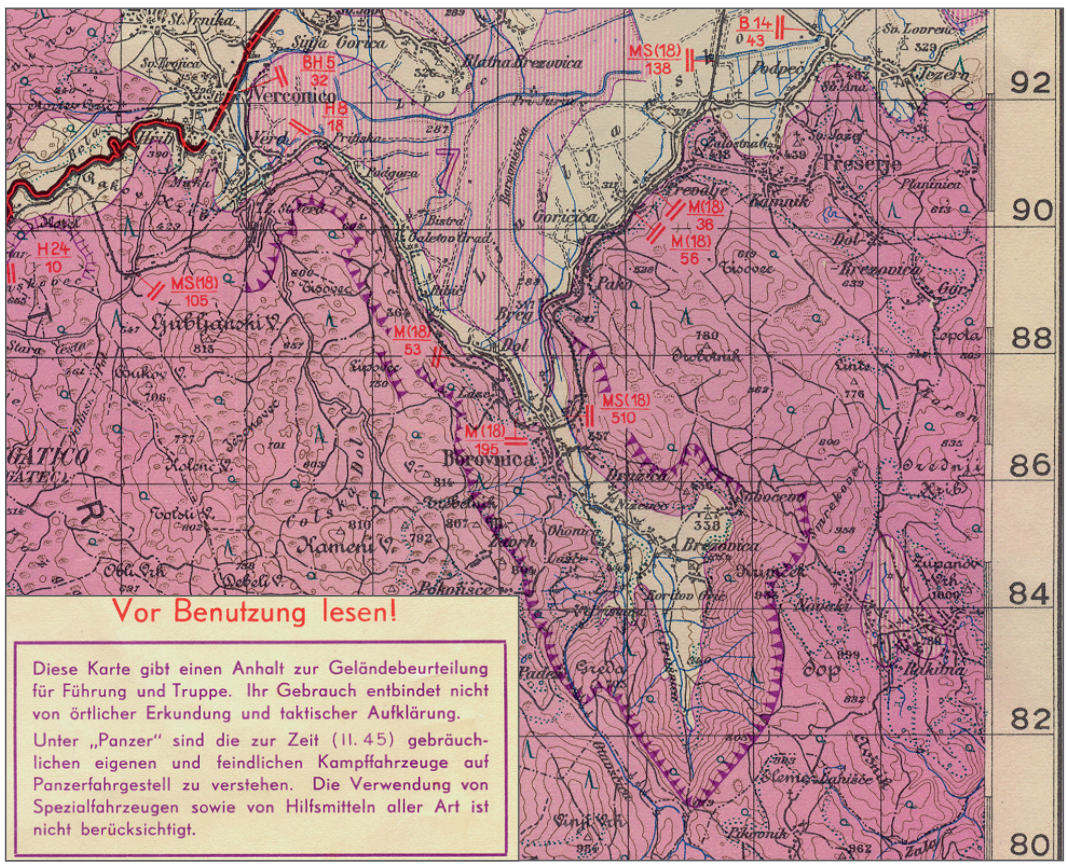

\begin{tabular}{|c|c|c|}
\hline \multicolumn{3}{|c|}{$\begin{array}{l}\text { Zeichenerklärung } \\
\text { Befanrbarkelt des Bodens für gepanzerte Kettenfahrzeuge }\end{array}$} \\
\hline & Befahrbar. & 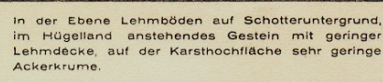 \\
\hline [In & $\begin{array}{l}\text { Bedingt oder zweifelhaft } \\
\text { befahrbar. }\end{array}$ & 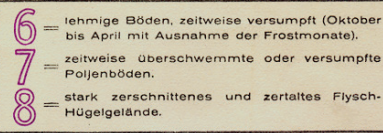 \\
\hline & Unbefahrbar. & Stark verkarstotos Berg- und Hugolgolsnde. \\
\hline \multicolumn{3}{|c|}{ Geländestufen } \\
\hline TाTाTाTाt & Schräghänge. & $\begin{array}{l}\text { Hango mit unter } 30 \text { Grad Neigung. In Rogenzoitten boi } \\
\text { Lehmboden Rutschgetanr. }\end{array}$ \\
\hline morm & Steilhänge. & Henge mit uber 30 Grad Neigung. \\
\hline mampm & Felswänce. & \\
\hline \multicolumn{3}{|r|}{ Wald } \\
\hline$\frac{1}{1-1}$ & $\left.\begin{array}{l}\text { Nadelwald. } \\
\text { Laubwald. }\end{array}\right\}$ Hochwald. & \\
\hline $\begin{array}{r}11 \\
611 \\
60\end{array}$ & $\left.\begin{array}{l}\text { Nadelwald. } \\
\text { Laubwald. }\end{array}\right\}$ Niederwald. & \\
\hline
\end{tabular}

Quelle: Reproduktion mit freundlicher Genehmigung der Stiftung Preußischer Kulturbesitz, Berlin; verändert nach HäUSLER 2007, Abb. 36

Abb. 6: Ausschnitt der „Panzerkarte“ als Sonderausgabe der Truppenkarte zur Geländebeurteilung 1:100.000 von Italien, Blatt Nr. 40B Postumia, Stand Februar 1945 
wuchsen (SCHMITHÜSEN 1946). Abbildung 5 zeigt einen Karten- und Legendenausschnitt dieser Geländebeurteilungskarte mit einer farblichen Klassifizierung der natürlichen Verhältnisse (Sumpfart, Moostorf und feuchte sandige Böden) mit erfahrungsgemäßen Angaben der Begehbarkeit und Befahrbarkeit (durch Truppenverbände). ${ }^{13)}$ Mit Hilfe dieser Karte konnte z. B. das Oberkommando der 2. Panzerarmee (der Heeresgruppe Mitte) sehr detailliert die Durchgängigkeit des Pripjet-Gebietes beurteilen (HäUSLER 2007, S. 151f).

Gegen Ende des Krieges sind für den italienischen Kriegsschauplatz noch im Februar 1945 vier Kartenblätter der Panzerkarte 1:100.000 (Blatt Nr. 40: Palmanova, 40A: Goriza, 40B: Postumia und 53B: Fiume) als Sonderkarten der Truppenkarte zur Geländebeurteilung 1:100.000 im Druck erschienen. Abbildung 6 zeigt einen Karten- und Legendenausschnitt der „Panzerkarte“ des Blattes Nr. 40B Postumia (nordöstlich von Venedig).

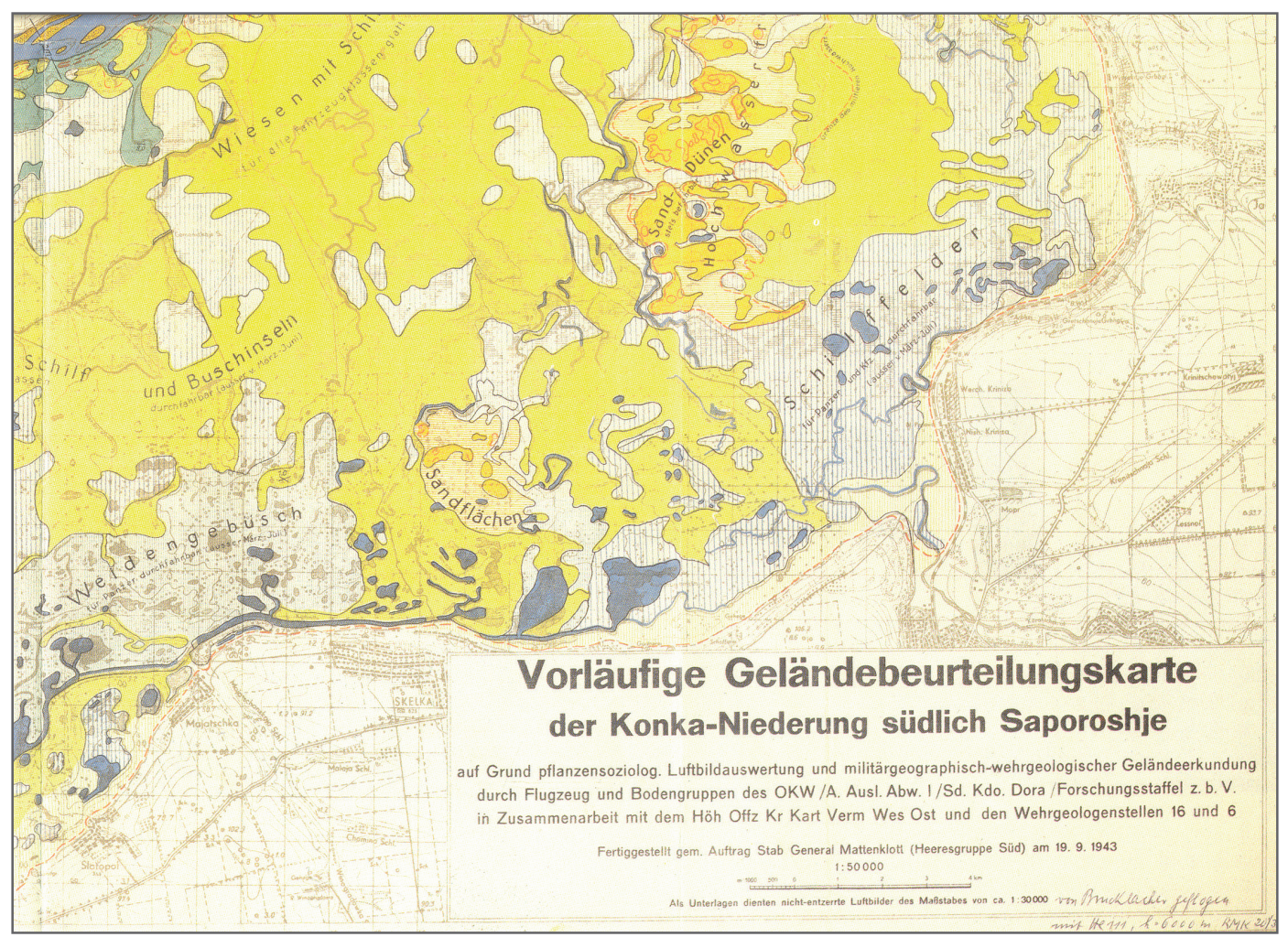

Quelle: Pillewizer 1989, Beilage 1; Häusler 2007, Abb. 27; Reproduktion mit freundlicher Genehmigung der Österreichischen Akademie der Wissenschaften, Wien

Abb. 7: Vorläufige Geländebeurteilungskarte der Konka-Niederung südlich Saporoshje 1:50.000 für die Heeresgruppe Süd im September 1943

\footnotetext{
13) Vgl. Bundesarchiv Berlin: R 26 III-180; Monatsbericht des Beauftragten für Sonderaufgaben der erdkundlichen Forschung, Anlage 1 z. Bf. Nr. 207/43/761/43 vom 30.11.1943.
} 


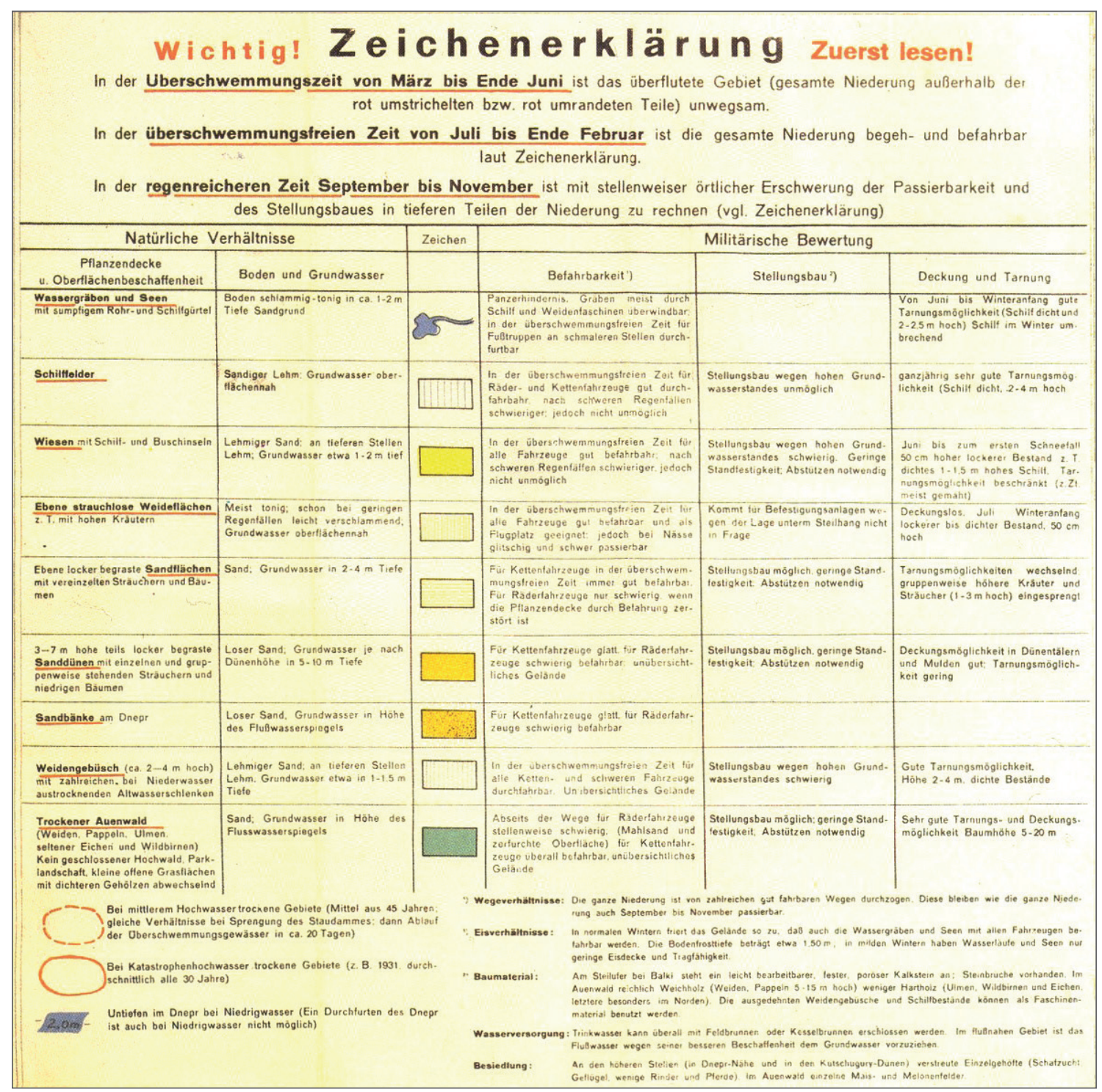

Quelle: Pillewizer 1989, Beilage 1; Häusler 2007, Abb. 28; Reproduktion mit freundlicher Genehmigung der Österreichischen Akademie der Wissenschaften, Wien

Abb. 8: Legende der Konka-Karte 1:50 000 mit militärischer Bewertung der natürlichen Verhältnisse

Zur Beurteilung der Befahrbarkeit des Geländes wurden die Böden, Geländestufen und der Wald klassifiziert. In Bezug auf die Befahrbarkeit des Bodens abseits des Straßenund Wegenetzes erfolgte die Angabe von witterungsmäßig oder vom Grundwasser beein- 
flussten Varianten (,6-8“), so dass sich der Kartenbenützer selbst eine Meinung über die lokale Situation bilden konnte. Für diese „,bedingt bis zweifelhaft befahrbaren“ Geländeabschnitte wurde auf die Zweckmäßigkeit einer lokalen Geländeerkundung hingewiesen (Ausschnitt Abb. 6: „Vor Benutzung lesen!“). Allein die Tatsache, dass diese "Panzerkarten" noch mit Stand Februar 1945 und weitere Truppenkarten 1:100.000 von Italien mit Stand März 1945 im Druck erschienen sind, weist auf die Akzeptanz derartiger Geländebeurteilungskarten der Forschungsstaffel z.b.V. für die damalige militärische Führung hin.

Die Konka-Karte 1:50.000 in Abbildung 7 ist ein Beispiel einer Karte des so genannten „synthetischen Typus“ (SchmithüsEn 1946, S. 13). In ihr sind die nach dem Gesamtkomplex der wichtigsten Geländeeigenschaften gleichartigen Gebiete abgegrenzt und durch einheitliche Flächenfarben oder Flächensignaturen zusammengefasst, zum Beispiel: Ebene, sandig, lehmige, von Schilf bestandene Flächen mit oberflächennahem Grundwasser in blauer senkrechter Schraffur; Ebene Wiese mit Schilf- und Buschinseln auf lehmigem Sand mit Grundwasser in 1 bis $2 \mathrm{~m}$ Tiefe mit hellgrüner Flächenfarbe (PILlewizer 1989).

Neun, in dieser Weise als „Gesamtkomplexe“ von Geländeeigenschaften (Vegetationsdecke, Bodenbeschaffenheit, Oberflächenform, Grundwasser- und Feuchtigkeitsverhältnisse) definierte Geländetypen sind mit ebenso vielen verschiedenen Flächenzeichen auf der Karte ausgeschieden. Als Zusatzsignaturen erscheinen lediglich die Linien der Hochwassergrenzen für mittleres und extremes Hochwasser (Abb. 8). Das Kartenbild ist sehr übersichtlich, da keine Überdeckungen von Signaturen vorkommen, erfordert aber eine verhältnismäßig ausführliche Charakteristik jedes der ausgeschiedenen Geländetypen in der Legende. Die dargestellten Einheiten sind „Ökotope“, das heißt, naturräumliche Einheiten mit einer bestimmten Bedeckung.

\section{5 „MarGeo“ - Die Marine-Geographie}

Neben der Militärgeographie im Oberkommando des Heeres (OKH/MilGeo) bearbeitete die nautisch-wissenschaftliche Abteilung im Oberkommando der Marine bzw. Kriegsmarine („MarGeo“) - vermutlich seit 1942 - Küstenkarten mit Angaben über Anlandemöglichkeiten und Verteidigungsstellungen. Leiter der Amtsgruppe Nautik (OKM/ MarGeo) war der Berliner Ozeanograph Prof. Dr. Georg Wüst. Dessen Dienststelle bestand aus einem technischen Stab von mehreren Geographen und einem Geologen, zwei bis drei Schreibkräften und ebenso vielen Zeichnerinnen (HäUSLER 1995a, S. 11; HÄUSLER und WiLLIG 2000, p. 153f).

Um die Zahl der geographischen Küstenbearbeitungen zu erhöhen, wurde auf Intention von Schulz-Kampfhenkel am 20. Juli 1944 durch Reichsmarschall Hermann Göring, in dessen Funktion als Präsident des Reichsforschungsrates, eine „Marinegeographische Arbeitsgemeinschaft“" unter der Leitung von SS-Oberführer Prof. Dr. Georg Wüst eingerichtet (Abb. 9).

Bereits Anfang August 1944 erteilte der Leiter des Geschäftsführenden Beirats des Reichsforschungsrats, Ministerialdirektor Prof. Dr. Mentzel, Forschungsaufträge an die Leiter Geographischer Institute in Deutschland einschließlich des eingegliederten Österreich (Alpen- und Donau-Reichsgaue). Die hohe Priorität marinegeographischer For- 


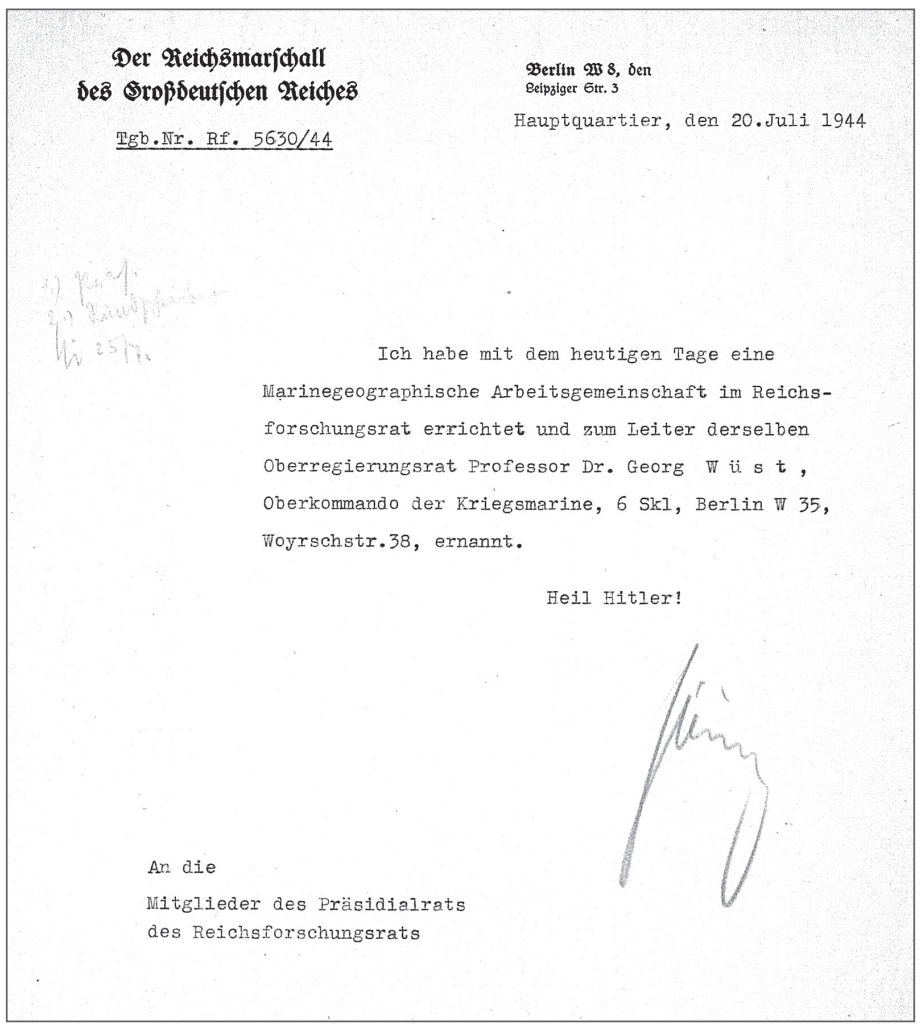

Quelle: Reproduktion mit freundlicher Genehmigung des Bundesarchivs Berlin-Lichterfelde, Bestand R 26 III-172

Abb. 9: Beauftragung des Ozeanographen Prof. Dr. Georg Wüst mit der Leitung der neu gegründeten „Marinegeographischen Arbeitsgemeinschaft“ durch den Präsidenten des Reichsforschungsrates, Reichsmarschall Hermann Göring

schungsarbeiten belegt ein Schreiben des Leiters der Marinegeographischen Arbeitsgemeinschaft vom 24. Oktober 1944, ${ }^{14)}$ in dem nachfolgende Universitätsprofessoren zu vordringlicher Mitarbeit an marinegeographischen Forschungsprojekten aufgefordert wurden: Die Geographen Dr. Walter Behrmann, Dr. W. Credner, Dr. Dörries, Dr. O. Jessen, Dr. Th. Kraus, Dr. H. Louis, Dr. E. Scheu und Dr. H. Schrepfer (vgl. Tab. 1).

Die von der Amtsgruppe Nautik (MarGeo) gedruckten Küstenkarten der Deutschen Bucht 1:100.000 (Blatt Emden und Blatt Bremerhaven - Wesermünde - Bremervörde) enthielten als zusätzliche Signaturen zur topographischen Grundkarte Angaben zu: Meeresböden, Tiefenlinien und Stromangaben; Küstenformen; Landgewinnungs- und Küstenschutzbauten; Geländedarstellung; Rohstoffvorkommen; Häfen und Anlageplätze sowie Verkehrsanlagen und zusätzlich Text- und Tabellenangeben über Gezeitenströme (Abb. 10).

14) Bundesarchiv Berlin, Bestand R 26 III-172 (Buchnr. 86/44 W/H). 


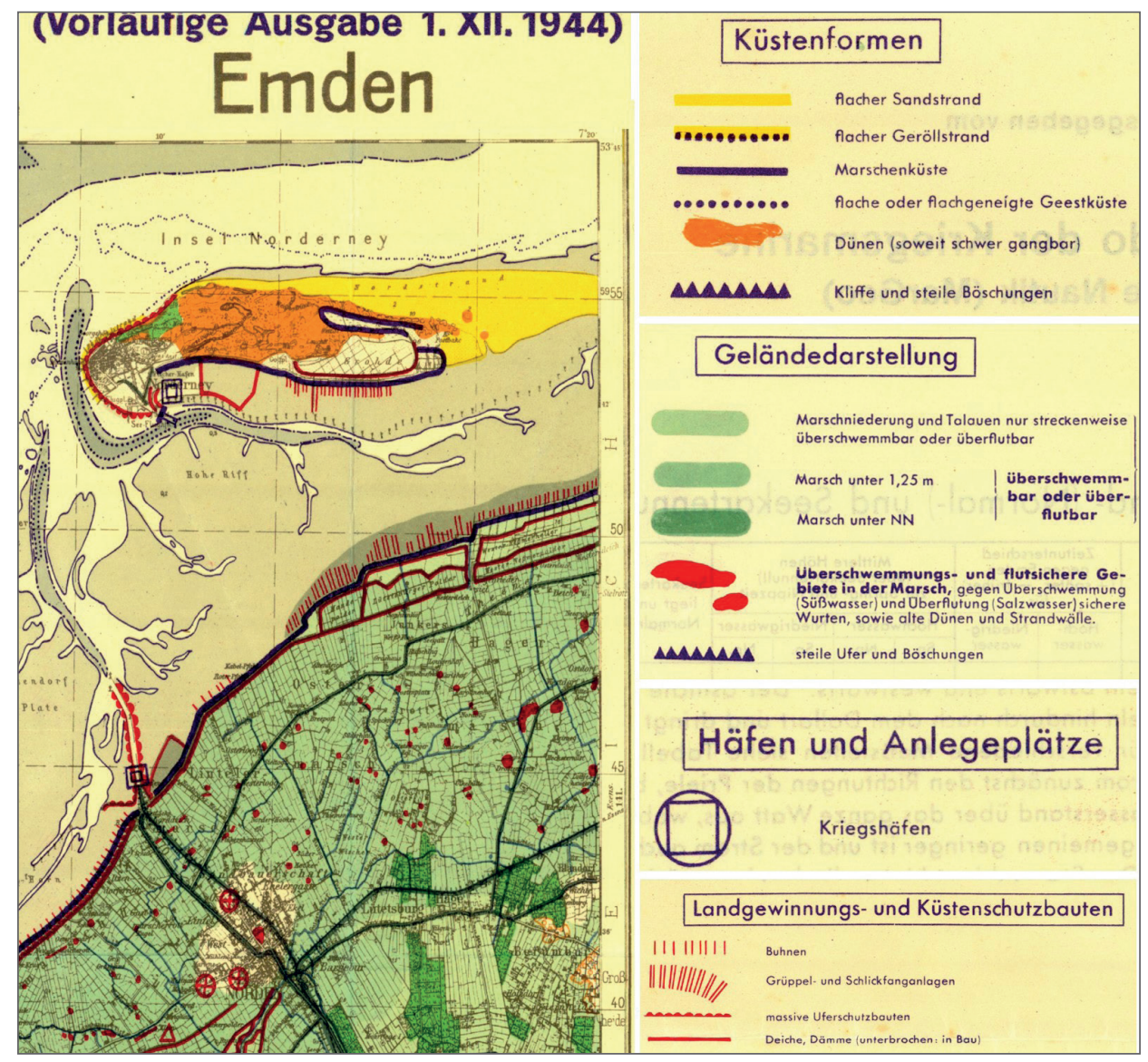

Quelle: Archiv Hermann HäUSLER

Abb. 10: Karten- und Legendenausschnitt der MarGeo-Küstenkarte Deutsche Bucht, Blatt Emden 1:100.000 herausgegeben vom Oberkommando der Kriegsmarine, Amtsgruppe Nautik (MarGeo) mit Stand vom 1. Dezember 1944

\section{Wissenschaftliche Mitarbeiter der Forschungsstaffel z.b.V.}

Den Kampftruppen der D-Day Invasion vom Juni 1944 folgten einige zehntausend Geheimdienstoffiziere der Allierten, die als (technical) „T-Force“ bezeichnet wurden, um vor allem deutsche Wissenschaftler und Forschungsunterlagen in Besitz zu nehmen. Das Internierungslager wurde als „Dustbin“ (= Abfallkiste) bezeichnet (BowER 1987). Je nachdem, in welcher militärischen Zone Angehörige der Forschungsstaffel aufgegriffen wurden, erfolgte dort auch das anfängliche Verhör. Somit entstanden 1946-1947 sog. „Interrogation Camps“ in der Amerikanischen und Britischen Zone, und gemäß alliierter 
Vereinbarung wurden die Camps unter gemeinsamer amerikanischer und britischer Bewachung geführt (HäUSLER 2007, S. $161 \mathrm{ff}$ ).

Mechtild RössLer (1990, S. 203) führt in ihrer Studie an, dass über die okkupierten Ostgebiete an nahezu alle Geographieordinarien auf reichsdeutschen Hochschulen kriegswichtige Forschungsaufträge für die Forschungsstaffel z.b.V. (aber auch für MarGeo Marinegeographie) vergeben wurden. Die enge Verknüpfung von Ideologie und Praxis kommt auch in den beiden Fallstudien über universitäre Geographie und Nationalsozialismus von RösSLER (1989) und FAHLBUSCH (1989) zum Ausdruck.

In vielen Fällen haben Wissenschaftler mit finanzieller Unterstützung des Reichsforschungsrats an Geländebeurteilungskarten der Forschungsstaffel mitgearbeitet, ohne aber selbst Angehörige dieser Staffel gewesen zu sein. Allein für die Luftbildauswertung und die damit verbundenen Geländeerkundungen in den Ostgebieten wurden insgesamt 35 Wissenschaftler eingesetzt, und zwar neun Geographen, zwölf Pflanzensoziologen, vier Forstfachleute, vier Bodenkundler und Moorfachleute, zwei Geologen, zwei Hydrologen und zwei Photogrammeter (zur Durchführung von Stereometermessungen an Reliefformen und Baumhöhen).

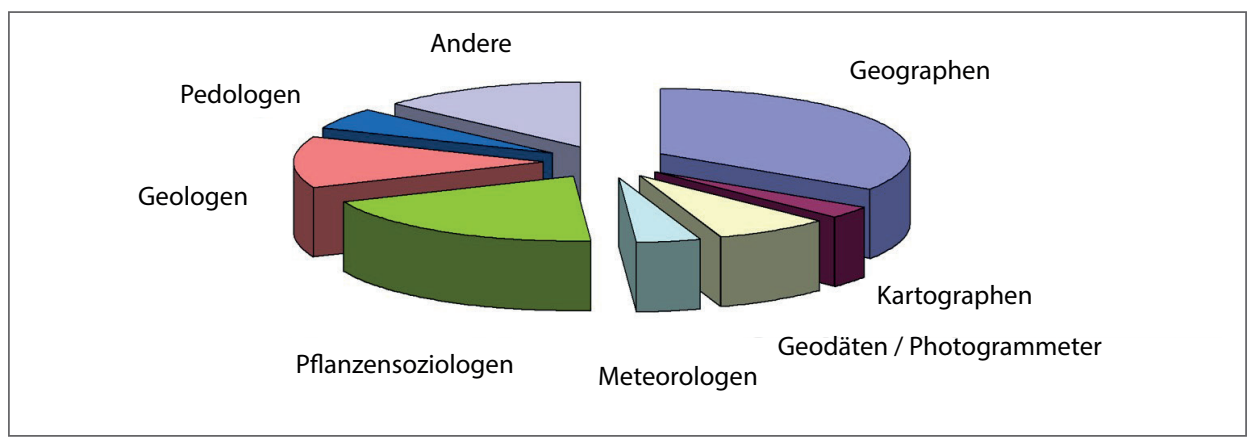

Abb. 11: Berufliche Zuordnung der Mitarbeiter der Forschungsstaffel z.b.V. (Auswertung von insgesamt 172 Personen): Geographen: 34\%, Kartographen: 3\%, Geodäten/ Photogrammeter: 8\%, Meteorologen: 4\%, Pflanzensoziologen: 20\%, Geologen: 13\%, Pedologen: 5\%). Bei Personen mit Angabe mehrerer Fachbereiche wurde jeweils das Hauptfach gezählt.

Die stärkste Gruppe der überwiegend akademischen Mitarbeiter der Forschungsstaffel (Abb. 11) setzte sich zu 45\% aus Geographen, Geodäten, Photogrammetern und Kartographen zusammen, gefolgt von 20\% Pflanzensoziologen (inklusive Forstleuten und Botanikern), 18\% Geologen und Pedologen sowie 5\% Meteorologen (bzw. Astronomen). Diese Aufteilung spiegelt einerseits die Arbeitsschwerpunkte der Forschungsstaffel im Gelände (z. B. Geländeaufnahmen von Geodäten, Geologen, Pedologen, Pflanzensoziologen und Astronomen - zur Routenbestimmung in unbewohnten Gebieten) und andererseits die umfangreiche Luftbildauswertung und Kartenherstellung durch Photogrammeter und Kartographen wider. In der relativ großen Personengruppe namentlich nicht angeführter 
oder anderer Spezialberufe (,Andere“: 13\%) finden sich z.B. Straßenbaufachleute, Hydrologen, Mediziner (Ärzte), Zoologen und Ethnologen.

Waren die älteren Jahrgänge der deutschen Geographen z. B. entweder schon vom Kriegsdienst freigestellt oder zunächst zu MilGeo (der Militär-Geographie) bzw. MarGeo (der Marine-Geographie) eingezogen, so gelangten viele der mittleren und vor allem jüngeren Jahrgänge der Geographen aus der Truppe oder aus anderer Verwendung aufgrund ihrer benötigten fachspezifischen Kenntnisse zur Forschungsstaffel.

Die folgenden 172 Wissenschaftler und Mitarbeiter waren direkt oder indirekt an der Entwicklung von Geländebeurteilungskarten für das Sonderkommando Dora bzw. für die Forschungsstaffel z.b.V. beteiligt (vgl. dazu Gruppe Dustbin 1947a; SCHRÖDTER 2002; HÄUSLER 2007, S. 167ff). ${ }^{15)}$ Die Namen sind in alphabetischer Reihenfolge angegeben; ferner der Beruf und der akademische Titel zu Kriegsende (Geographen in Fettschreibung); einige Vornamen konnten trotz umfangreicher Recherchen nicht eruiert werden (militärische Abkürzungen: Gefr. - Gefreiter, Uffz. - Unteroffizier, Fw. - Feldwebel):

Pflanzensoziologe Uffz. Apel, russischer Botaniker Univ.-Prof. Dr. Anufriew, Oberst-Ingenieur Dr. Claus (Claudius) Aschenbrenner (1894-?), Gefr. F. W. Assmann;

Geodät und Bauingenieur (Staßenbauexperte) Dipl.-Ing. Ofw. Rudolf Josef Bardodej, Geograph Uffz. Dr. Fritz Bartz (1908-1970), Dr. B. Beckmann, Geograph Univ.-Prof. Dr. Walter Behrmann (1882-1955), Geograph Univ.-Prof. Dr. Joachim Blüthgen (19121973), Geograph Uffz. Univ.-Prof. Dr. Hans Bobek (1903-1990), Geograph Hauptmann Univ.-Prof. Dr. Erwin Boehm (1913-2002), Kartograph und Photogrammeter Uffz. Dipl.Ing. Dr. Leonhard Brandstätter (1906-2012), Botaniker und Medizinalexperte Oberapotheker Dr. Branko, Leutnant Dipl.-Ingenieur Walter A. Brucklacher (1910-1995);

Nachschuboffizier Günther Caulier-Eimbcke (1919-1986), Geologe Univ.-Prof. Dr. Hans Cloos (1885-1951), Geograph Univ.-Prof. Dr. Wilhelm Credner (1892-1948), Photogrammeter und Landesplaner Dr. Czikos;

Geograph Univ.-Prof. Dr. Hans Dörries (1897-1945), Meteorologe und Botaniker Leutnant Dr. Willy Domke, Architekt, Meteorologe und Flieger Gefreiter Dr. Drevermann;

Pflanzensoziologe Oberleutnant Univ.-Prof. Dr. Heinz Ellenberg (1913-1997), Forstassessor Oberleutnant Ewald;

Photogrammeter, Geodät und Kartograph Dr. Dipl.-Ing. Richard Finsterwalder (1899-1963), Gefr. Dr. Fischer, Dr. G. Foerstner, Geologe Univ.-Prof. Dr. Hans Frebold (1899-1983), Landschaftsarchitekt Leutnant Dipl.-Gärtner Fresenius, Zoologe und Luftbildauswerter Feldwebel Dr. Fritsch, Meteorologe und Pilot Dr. Ernst Frowein, Pflanzensoziologe Uffz. Dr. Fröde, Gefr. Dr. W. Fröhlich, Geograph Dr. Ernst R. Fugmann (1905-1998);

Arzt und Wüstenfachmann Dr. Alfons Gabriel (1894-1976), Geodät und Photogrammeter Uffz. Dipl.-Ing. Heinrich Gänger (1912-1993), Moorforscher Univ.-Prof. Dr. Helmut Gams (1893-1976), Geograph Hauptmann Dr. Hans Günter Gewehr, Photogrammeter Gefr. Dipl.-Ing. Werner Göpner (1911-?), Geograph und Geologe Dr. Hans Graul

15) National Archives and Records Administration (NARA), Washington D.C.: AIU/IS/25, Zusammenfassender Bericht des Chief Interrogators Ludwig F. Schmidt vom 26. April 1946 (SchmidT 1946). 
(1909-1997), Gefr. Dr. Grewe (1911-2000), Geologe Dr. Paul Groschopf (1909-2000), Geograph Hauptmann Univ.-Prof. Dr. Wilhelm Grotelüschen (1904-1977), Photogrammeter Dr. Grünler;

Landschaftsarchitekt Uffz. Dipl.-Gärtner Dr. Hansen (1912-2001), Geograph Uffz. Univ.-Prof. Dr. Wolfgang Hartke (1908-1997), Geograph Dr. Hugo Hassinger (18771952), Geodät Fw. Dipl.-Ing. Heller, Kartograph Uffz. Hiller, Pflanzensoziologe Uffz. Dr. Hinz, Pflanzensoziologe Leutnant Richard Hölscher, Meteorologe Dr. Fritz Höhndorf, Kartograph Dr. Fritz Hölzel (1899-1977), Geologe Dr. Wilhelm Hollstein (1898-1973), Pflanzensoziologe Univ.-Prof. Dr. Horvatic, Geograph Hauptmann Doz. Dr. Friedrich Huttenlocher (1893-1973);

Geograph Inspektor Dr. Karl Ilg (1913-2000), ungarischer Pedologe Univ.-Prof. von Imrédy;

Pflanzensoziologe Uffz. Jahns, Geograph Univ.-Prof. Dr. Otto Jessen (1891-1951), Hydrologe, Morphologe und Höhlenforscher Fw. Dr. Rudolf Jordan (1911-?), Geologe und Geomorphologe Fw. Dr. Jörg;

Geograph Univ.-Prof. Dr. Helmuth Kanter (1891-1976), Geologe Schütze Keil, Geograph Univ.-Prof. Dr. Hans Kinzl (1898-1979), Geologe Univ.-Prof. Dr. Georg Knetsch (1904-1997), Geograph Univ.-Prof. Dr. Albert Kolb (1906-1990), Geologe Gefr. Dr. Körnke, Geograph Dr. Hans-Peter Kosack (1912-1976), Pflanzensoziologe Dipl.-Gärtner Oberleutnant Gert Kragh (1911-1986), Geograph Univ.-Prof. Dr. Theodor Kraus (18941973), Pflanzensoziologe Uffz. Dr. Werner Krause, Gefr. Dr. W. Krämer, Geograph Uffz. Studienrat Dr. Gustav Kreuzer, Studienrat Kuhlmann, Pedologe Univ.-Prof. Dr. E. Kuron;

Oberforstmeister Dr. Wolfgang (? Wilhelm) van Laer, Pedologe Dr. Willi Laatsch (1905-1997), Geograph und Kartograph Dr. Edgar Theodor Lehmann (1905-1990), Geograph Uffz. Dr. Lembcke, Geograph Dr. Egon Lendl (1906-1989), Pflanzensoziologe Uffz. Dr. Wilhelm Lohmeyer, Geologe Leutnant Lohr, Geograph Univ.-Prof. Dr. Herbert Louis (1900-1985), Geograph Uffz. Dr. Löw, Geologe und Moorbotaniker Regierungsrat Dr. Lutz;

russischer Pedologe Univ.-Prof. Machow, Pflanzensoziologe Fw. Univ.-Prof. Dr. Friedrich Markgraf (1897-1987), Geographin Dr. Ingrid Mathiesen (1909-?), Geograph Univ.-Prof. Dr. Otto Maull (1887-1957), Geograph Leutnant Dr. A. Menzel, Geograph Dr. Konrad Meyer(-Hetling) (1901-1969), Geograph Univ.- Prof. Dr. Friedrich Metz (18901969), Geograph Univ.-Prof. Dr. Emil Meynen (1902-1994), Geologe Dr. Friedrich Mixius (1911-1989), Geograph Univ.-Prof. Dr. Sieghard Morawetz (1903-1993), Geologe Kriegsverwaltungsrat Univ.-Prof. Dr. Carl Mordziol (1886-1958), Geograph Univ.-Prof. Dr. Hans Mortensen (1894-1964), Geograph Doz. Dr. Heinrich Müller-Miny (1900-1981), Geograph Univ.-Prof. Dr. Wilhelm Müller-Wille (1906-1983), Gefr. Dr. H. Münnich;

Gefr. Dipl.-Gärtner Neef, Photogrammeter und Geodät Dipl.-Ing. Karl Neumaier (1898-1999), Geologe und Paläontologe Oberleutnant Dr. Helmuth Nietsch (1890-?), Geologe Hauptmann Dr. Ernst Nowack (= Nowak; 1891-1946);

Pflanzensoziologe Fw. Dr. Erich Oberdorfer (1905-2002), Geograph und Kartograph Oberleutnant Doz. Dr. Ruthard Oehme (1901-1987), Student der Geologie Uffz. Oertel, Pedologe Dr. Ostendorf, Geograph Leutnant Univ.-Prof. Dr. Erich Otremba (1910-1984);

Geograph und Pflanzensoziologe Dr. Karlheinz Paffen (1914-1983), Geograph Regierungsrat Univ.-Prof. Dr. Herbert Paschinger (1911-1992), Hygieniker und Ornitho- 
loge Dr. Panser, Geograph Univ.-Prof. Dr. Wolfgang Panzer (1896-1983), Geograph Dr. Gottfried Pfeifer (1901-1985), Photogrammeter, Geograph, Kartograph und Glaziologe Leutnant Univ.-Prof. Dr. Wolfgang Pillewizer (1911-1999), Geodät und Photogrammeter Fw. Dipl.-Ing. Dr. techn. Walter Polland (1914-?), Pflanzensoziologe Univ.- Prof. Dr. Ernst Preising (1911-2007), Pedologe Fw. Dipl.-Ing. Dr. Arnold Proissl, Pflanzensoziologe Schütze Prügel;

Pflanzensoziologe Dr. Rabe, Geograph Fw. Dr. Heinz-Hermann Reichenbach-Klinke (1914-1995), Meteorologe und Geograph Uffz. Assessor Reinhard, Geologe Fw. Dr. Rest (1884-1961), Meteorologe und Astronom Dr. Nikolaus Benjamin Richter (1910-1980), Ethnologe Leutnant Dr. Hans Rothert, Kartograph Rosenstock, Geologe und Geophysiker Gefr. Dr. Per Rössle (1906-?);

Pflanzensoziologe Oberleutnant Dr. Scheerer, Geologe Gefr. Dr. Schenk, Geograph Univ.-Prof. Dr. Erwin Scheu (1886-1981), Geograph Schütze Dr. Heinrich Schiffers-Davringhausen (1901-1982), Kartograph Inspektor Max Schlarbaum, Hydrologe Fw. Dipl.Ing. Josef Schmidt, Pedologe Uffz. Dr. R. Max Schmidt, Geograph Dozent Dr. Josef Schmithüsen (1909-1984), Geograph und Geologe Dr. Heinrich Schmitthenner (1887-1957), Geograph Leutnant Univ.-Prof. Dr. Sigfrid Schneider (1915-2006), Pedologe Dr. Ernst Schönhals (1909-1993), Geograph Univ.-Prof. Dr. Hans Schrepfer (1897-1945), Geograph Oberleutnant Dr. Otto Schulz-Kampfhenkel (1910-1989), Photogrammeter Dr. Kurt Schwidefsky (1905-1986), russischer Geologe und Pedologe Univ.-Prof. Dr. Semljakow, Pedologe Dr. Siegl, Geographin Dr. Angelika Sievers (1912-2007), Geograph Univ.-Prof. Dr. Johann Sölch (1883-1951), russischer Pflanzensoziologe Dr. Soest, Botaniker Dr. Soos, Karsthydrologe Inspektor Ing. Richard Gottfried Spöcker (1897-1975), Geograph und Geomorphologe Univ.-Prof. Dr. Hans Spreitzer (1897-1974), Forstmeister Oberleutnant Steigerwald, Geologe Oberleutnant Doz. Dr. Hans Steinlein (1911-1945), Geograph Univ.- Prof. Dr. Rudolf Stickel, Geograph Leutnant Stitz, Geograph Dr. Storm, Forstassessor Gefr. Strytz;

Geodät und Astronom Obergefreiter Dr. Arthur Teichgräber (?-1946), Geologe Hauptmann Univ.-Prof. Dr. Thomson, Pflanzensoziologe Hauptmann Studienrat Johann Tobken, Meteorologe und Botaniker Dr. Ernst Günter Triloff, Geograph Univ.-Prof. Dr. Carl Troll (1899-1975), Pflanzensoziologe Univ.-Prof. Dr. Reinhold Tüxen (1899-1980);

Hydraulikingenieur Dr. Uhl, Botaniker Schütze Dr. Herbert Ulbricht;

Dr. F. Vilbig, Geograph Dr. Konrad Voppel (1892-1973);

Pflanzensoziologe Uffz. Dr. Wagner, Pflanzensoziologe Dr. Heinrich Walter, Pflanzensoziologe Uffz. Dr. Kurt Walther (1910-2003), Geologe Univ.-Prof. Dr. Artur Winkler-Hermaden (1890-1963), Studienrat Wünderich;

Geodät Univ.-Prof. Dr.-Ing. Karl Zaar (1880-1949), Pflanzensoziologe Fw. Dr. Hans Zeidler (1915-2003).

\section{Fazit}

Wie nahezu alle Naturwissenschaftler im „Dritten Reich“ waren auch die Mitglieder und Auftragnehmer der Forschungsstaffel z.b.V. in das Gesamtsystem der damals so genannten „Wehrwissenschaften“, seien es Wehrgeographie, Wehrgeologie oder Wehrgeo- 
politik etc., der nationalsozialistischen Parteidiktatur und Militärpolitik eingebunden (vgl. BöHm 1995; Brogiato 2004; ReICHHERZER 2012; SvateK 2015). Kein einziger Name der wissenschaftlichen Mitarbeiter der Forschungsstaffel z.b.V. findet sich jedoch beispielsweise in dem Band „Forschen für den Führer“ (CORNwell 2004), im „Personenlexikon zum Dritten Reich“ (KLeE 2013) oder - mit Ausnahme von Hans Dörries und Helmuth Kanter - im Bekenntnis der deutschen Professoren zu Adolf Hitler und dem nationalsozialistischen Staat vom 11. November 1933. ${ }^{16}$

Die Organisation der Forschungsstaffel z.b.V. „[...] war das Ergebnis individueller Fähigkeiten einer ,Managerpersönlichkeit', die die Methoden und Verfahren der Schaffung einer unabhängigen Dienststelle im Netzwerk eines offenbar doch nicht so totalitären Staates - dem Dritten Reich - erlernte und schließlich beherrschte. Es war die Mehrfachverankerung der Forschungsstaffel z.b.V. in diesem Netzwerk, die paradoxerweise erst die weitgehende Unabhängigkeit dieser Dienststelle schuf!“ (MANG 2007). Soweit bekannt, haben nahezu alle ehemaligen Mitarbeiter des Teams um Dr. Otto Schulz-Kampfhenkel den Krieg überlebt.

Die nachfolgende Liste (Tab. 4) gibt Auskunft über die Qualifikation von 24 Akademikern, die als Angehörige, aber auch als Auftragnehmer der Forschungsstaffel z.b.V. nach dem Krieg facheinschlägige Publikationen und Lehrbücher verfasst haben oder wieder auf akademischem Boden Fuß fassen konnten. Es handelt sich dabei um einen Geologen, drei Pflanzensoziologen und 20 Geographen. ${ }^{17)}$

Die durch die Mitarbeiter der Forschungsstaffel z.b.V. während des Krieges entwickelte Methode der integrativen Luftbildauswertung ging zu Kriegsende nicht verloren, da viele Wissenschaftler bald nach dem Krieg wieder auf akademischem Boden wirken konnten und in Deutschland und Österreich maßgeblich die Forschung und Lehre in Geographie, Kartographie und Photogrammetrie geprägt haben. Es waren dies nach HäUSLER (2007):

Dr. Fritz BARTZ (1908-1970) war von 1946 bis 1949 als Dozent an der Universität Kiel tätig, 1949 wurde er auf den Lehrstuhl für Wirtschaftsgeographie nach Bonn berufen und trat 1960 die Nachfolge von Prof. Metz am Lehrstuhl für Geographie (II) an der Universität Freiberg an.

Dr. Hans BoвEK (1903-1990) war im Jahr 1941 Referent beim deutschen Militärattacheé in Ankara, seit 1942 Dozent an der Universität Berlin und von 1940-1943 Kriegsverwaltungsrat im Oberkommando des Heeres. Nach der Stellenbesetzung der Dienststelle „Chef des Kriegskarten- und Vermessungswesens“ vom März 1943 war Bobek Leiter des Referates IVc 3 der Gruppe IV Mil.Geo. Er leitete die Redaktion und Teilbearbeitung zahlreicher militärgeographischer Länderbeschreibungen (so z. B. über England, Irland, Vorderer Orient, Europäisch Türkei, Syrien, Palästina und Transjordanien, Irak, Iran, Afghanistan und Baluchistan, Malta und Sizilien. Obwohl nur im Unteroffiziersrang war er seit 1944 im Kommando der Forschungsstaffel z.b.V. eingesetzt. BoBEK verfasste unter anderem eine

\footnotetext{
16) Vgl. u. a. https://de.wikipedia.org/wiki/Bekenntnis_der_deutschen_Professoren_zu_Adolf_Hitler (letzter Zugriff: 10.01.2018).

17) Weitere Angaben zu Funktionen und Aufgaben von Geographen im Zweiten Weltkrieg finden sich in RösSLER (1990) und WARDENGA et al. (2011).
} 
Arbeit über die Bedeutung des Luftbildes für die Geomorphologie (Bobek 1941) sowie über den Einsatz der geographischen Wissenschaft im modernen Krieg und die Aufgaben der Militärgeographie (Bовек 1942). Gemeinsam mit SCHмітнÜSEN verfasste er bald nach Kriegsende die fundamentale Arbeit über „Die Landschaft im logischen System der Geographie“" (Bobek und Schmithüsen 1949). Nach dem Krieg war BobeK von 1946 bis 1948 als Professor an der Universität Freiburg/Breisgau und von 1949 bis 1951 an der Wirtschaftsuniversität Wien tätig und wurde schließlich als Nachfolger von Hugo HaSsINGER als Ordinarius an das Geographische Institut der Universität Wien berufen (1951-1971). 1962/63 war er Dekan der Philosophischen Fakultät der Universität Wien, 1962 bis 1965 Präsident der Österreichischen Geographischen Gesellschaft (vormals „Geographische Gesellschaft in Wien").

Dipl.-Ing. Dr. Leonhard BrandsTäTTER (1906-2012) war Kartograph und Photogrammeter und verfasste während des Krieges in der Hauptvermessungsabteilung XIV in Wien Arbeiten über die Geländedarstellung von Hochgebirgskarten. Er war 1944/45 als Kartograph und Topograph in der Forschungsstaffel z.b.V. eingesetzt. BRANDSTäTTER prägte nach dem Krieg 1969-1979 die Alpenvereinskartographie auf aero-photogrammetrischer Grundlage.

Dr. Heinz Ellenberg (1913-1997) verfasste 1939 eine richtungweisende, synökologische Arbeit auf der Grundlage klar abgrenzbarer Vegetationstypen. Er gehörte zur Schule von Reinhard TüXEN (1899-1980), dem Begründer der Angewandten Pflanzensoziologie, und Josias Braun-Blanquet. EllendBerg erhielt 1931 eine Arbeitsstelle für Theoretische und Angewandte Pflanzensoziologie an der Tierärztlichen Hochschule Hannover, der ersten pflanzensoziologischen Institution in Deutschland, die 1939 in Zentralstelle für Vegetationskartierung des Reiches (ZfV) umbenannt wurde. ElLENBERG war Präsident der im Jahr 1939 gegründeten Internationalen pflanzensoziologischen Gesellschaft. Als Oberleutnant war er 1943-1945 fachlich als Pflanzensoziologe und Leiter des Forschungskommandos Ost der Forschungsstaffel z.b.V. tätig. Im Jahr 1953 übernahm ElLENBERG eine Professur in Hamburg, ab 1958 war er Direktor am Geobotanischen Institut in Zürich. 1966 wechselte er an das Geobotanische Institut der Universität Göttingen. Er war als Biologe, Botaniker und Landschaftsökologe Wegbereiter einer ganzheitlichen Sicht der Ökosystemforschung in Deutschland.

Dr. Richard FinsterwaLder (1899-1963) habilitierte sich bereits 1930 mit einer Arbeit über die Grenzen und Möglichkeiten der terrestrischen Photogrammetrie, besonders auf Forschungsreisen. Anschließend an seine Teilnahme an der Luftbildtagung in Jena (20.-23. Juni 1944) übernahm er einen Forschungsauftrag des Reichsforschungsrats über die geodätisch-topographische Auswertung von Luft- und Erdbildern hinsichtlich ihrer topographischen Grundlagen für Karten der Geländebeurteilung. FinsterwaLDER ist Autor eines Lehrbuchs über Photogrammetrie und bekannt für seine speziellen hochgebirgskartographischen Arbeiten (z. B. FinsterwaldeR und SCHNEIDER 1958). Nach dem Krieg war FinsTERWALDER erster Vorsitzender der Deutschen Gesellschaft für Photogrammetrie.

Dr. Wolfgang HARTKE (1908-1997) war als wissenschaftliche Hilfskraft am Berliner Geographischen Institut bzw. an der Abteilung für Übersee und Kolonialgeographie, zeitweise als Vertreter von Carl Troll, tätig und erhielt 1937 eine Stelle als planmäßiger Assistent in Frankfurt am Main, wo er sich 1938 habilitierte. Eine Dozentur wurde in Frankfurt zunächst wegen ,politischer Unzuverlässigkeit“" verweigert. 1944/45 war er als Geograph im Unteroffiziersrang Mitglied der Forschungsstaffel z.b.V. HARTKE wurde 1952 an das Geographische Institut der Technischen Hochschule München berufen und forschte im Bereich der Sozialgeographie. HARTKEs besonderes Anliegen war es, dem Fach Geographie auch in der Öffentlichkeit die notwendige Anerkennung zu verschaffen. Eine Denkschrift zur Lage 
der Geographie 1960 und die Einrichtung eines Diplomstudiums zeigten frühzeitig sein Engagement für die Angewandte Geographie.

Dr. Fritz HöLzEL (1899-1977) studierte von 1919 bis 1924 Geographie an der Universität in Leipzig, wurde dort 1923 promoviert und legte ferner das Examen für das Höhere Lehramt ab. Im Reiseführerverlag von Baedeker bearbeitete er danach von 1923-1940 die Reisehandbücher von Deutschland, Österreich, Schweiz und Ungarn. Im Jahr 1940 erneut zum Wehrdienst eingezogen, war HöLzel als wissenschaftlicher Geograph und Kartograph bei der Abwehrstelle Münster in Rheda von 1941-1944 tätig und anschließend ein Jahr für militärgeographische Arbeiten beim Kommando der K-Verbände der Marine in Schönberg in Mecklenburg. Mit seiner Rückkehr nach Rheda 1945 begann seine freiberufliche Tätigkeit für rund 30 Verlage und Institute.

Dr. Helmuth KANTER (1891-1976), der bereits als Jäger und Feldunterarzt im Ersten Weltkrieg eingesetzt war, hatte von 1938 bis 1945 den Lehrstuhl für Geographie der Phillips-Universität Marburg inne, wurde zu Beginn des Zweiten Weltkrieges eingezogen, dann aber kurzfristig beurlaubt, um seine Vorlesungen an der Universität Marburg wieder aufzunehmen. 1942 war er Mitglied des Sonderkommandos „Dora“ und bearbeitete das Kartenwerk 1:100.000 des tripolitanischen Gebietes südlich des 29. Breitengrades. Im Sommer 1943 versuchte er seine Vorlesungen wieder aufzunehmen, wurde aber nach Melitopol versetzt, von dort für kurze Zeit an die Heeresgasschutzschule in Celle und kam erst im November frei, wo er dann versuchte, in Marburg den Institutsbetrieb notdürftig aufrechtzuerhalten (KANTER 1967).

Dr. Georg KNETSCH (1904-1997) wurde nach dem Frankreichfeldzug Leutnant. Danach war er als Geologe verschiedenen Wehrgeologenstellen zugeteilt. Darüber hinaus war er Leiter der Fachgruppe „Geologie und Bodenforschung“ der Kolonialwissenschaftlichen Abteilung des Reichsforschungsrats im Reichsministerium für Wissenschaft, Erziehung und Volksbildung. Nach dem Krieg wirkte KNETSCH 1949 an der Universität in Bonn, dann am Geologischen Institut in Köln. 1951-1953 leitete er das Geologische Institut der Universität Kairo in Gizeh. 1953-1955 nahm er seine Lehrtätigkeit am Geologischen Institut in Köln wieder auf und folgte 1955 dem Ruf als Ordinarius an die Universität Würzburg, wurde zweimal Dekan und 1960-1963 Rektor.

Dr. Herbert Louis (1900-1985) nahm 1935 eine Berufung auf den Geographischen Lehrstuhl der neu gegründeten Philosophischen Fakultät in Ankara an. Im Sommer 1943 kehrte er nach Deutschland zurück und wirkte als Ordinarius für Geographie an der Universität Köln. Von dort aus hat er gegen Kriegsende Geländestudien für den Reichsforschungsrat ausgearbeitet. 1952 übernahm LouIs den Lehrstuhl für Geographie an der Münchner Universität, den er bis zu seiner Emeritierung im Jahre 1967 innehatte.

Dr. Otto Maull (1887-1957) bearbeitete in Graz Aufträge des Reichsforschungsrats zur Entwicklung von Karten der Geländebeurteilung. Nach dem Krieg lehrte MaULL an der Universität Graz und vertrat vor allem die vergleichende und systematische Länderkunde.

Dr. Emil Meynen (1902-1994) kehrte nach einjährigem Militärdienst im August 1941 nach Berlin zurück und wurde im April 1941 Leiter der „Abteilung für Landeskunde im Reichsamt für Landesaufnahme“. In diesem Amt hat er eine große Karten- und Luftbildsammlung aufgebaut. Seit dem Wintersemester 1942/43 oblag ihm als einzig verbliebenem Lehrenden die Führung des Geographischen Instituts der Berliner Universität. MEYNEN unterstützte die Forschungsstaffel z.b.V., war selbst aber nicht direkt für sie tätig, sondern bekam in Berlin Aufträge des Reichsforschungsrats zur Entwicklung von Karten der Geländebeurteilung. Er gelangte Ende des Zweiten Weltkriegs in Gefangenschaft und verfasste im Interrogation 
Camp „Dustbin“ ein umfangreiches Manuskript über geographische Forschungsaktivitäten des „Dritten Reiches“. Der Wissenschaftshistoriker und Geograph Michael FAHLBUSCH hebt in seinem Artikel „Die verlorene Ehre der deutschen Geographie“ die Mitwirkung von Emil MeYNEn bei der Erstellung von landeskundlichen und siedlungsgeographischen Studien für die Umsetzung der NS-Volksgruppenpolitik im Osten, speziell durch die von ihm gegründete „Publikationsstelle Ost“ hervor (http://hsokult.geschichte.hu-berlin.de/beitrag/ essays/ fami0500.htm). 1955 wurde MEYNEN an der Universität Köln Honorarprofessor mit Lehrauftrag für Landeskunde und thematische Kartographie. Er war z. B. Mitbegründer und Leiter des Arbeitskreises für „Namengebung und Namenschreibung“, aus dem der „Ständige Ausschuss für Geographische Namen“ (StAGN) hervorging, sowie des Arbeitskreises „Dokumentation und Kartographische Begriffe“, der 1975 in „Kartographische Terminologie" umbenannt wurde. Er ist vor allem durch sein mehrsprachiges Wörterbuch Kartographischer Begriffe in 14 Sprachen (MEYNEN 1973) und durch sein mehrsprachiges Internationales Geographisches Glossarium bekannt geworden (MEYNEN 1985).

Dr. Sieghard Morawetz (1903-1993) habilitierte sich 1932 für das Gesamtgebiet der Geographie mit morphologischen Themen und wurde 1939 zum außerplanmäßigen Professor ernannt. Er arbeitete in Graz an Aufträgen des Reichsforschungsrats zur Entwicklung von Karten der Geländebeurteilung. MoRAwETZ wurde 1951 zum außerordentlichen Titularprofessor und 1963 zum ordentlichen Titularprofessor ernannt und erhielt neben dem Ordinariat von Univ.-Prof. Dr. Herbert PAsChINGER den 1967 neu bewilligten zweiten Lehrstuhl für Geographie in Graz.

Dr. Erich OтREMBA (1910-1984) war 1941 bei der Bau-Organisation Todt (OT), habilitierte sich 1942 an der Universität Erlangen und war 1943 als Leutnant Kommandoführer der Forschungsstaffel z.b.V. Von ihm ist nach dem Krieg eine Arbeit über die Verwendung von Luftbildern für die Geographie erschienen (OtRemba 1950). 1947 wurde er Lehrstuhlvertreter für Geographie und schließlich 1950 außerplanmäßiger Professor in Erlangen. 1951 bis 1963 war er ordentlicher Professor für Wirtschaftsgeographie an der Universität Hamburg, wo er 1957/58 und 1960/61 auch Dekan war, ab 1963 Professor für Wirtschafts- und Sozialgeographie an der Universität zu Köln. OtRemba war in der Nachkriegszeit einer der bekanntesten und angesehensten Wirtschaftsgeographen.

Dr. Herbert Paschinger (1911-1992) wurde im Jahr 1941 zur Wehrmacht eingezogen, im März 1942 aus dem Soldatendienst entlassen und danach zum Wetterdienstinspektor (im Oberleutnantsrang) ernannt. Vom 4.3. bis 31.3.1943 arbeitete PASCHINGER als Wetterdienstinspektor auf Kriegsdauer in der Wetterwarte am Fliegerhorst in Eindhoven. Von April bis Mai 1943 erfolgte eine Infanterieausbildung in Gütersloh und danach bis August ein Einsatz als Jäger vor Leningrad - damals eine Vorbedingung zum Aufstieg eines Meteorologen der Luftwaffe. Im April 1944 wurde PASCHINGER zum Meteorologen als Regierungsrat auf Kriegsdauer (im Majorsrang) ernannt. Erst von Mai 1944 bis 12. Mai 1945 leitete er als Regierungsrat eine Arbeitsgruppe der Forschungsstaffel z.b.V. 1948 wirkte PASCHINGER als Dozent in Innsbruck und 1958 bis 1981 als Universitätsprofessor in Graz. Seine Arbeiten umfassten Geomorphologie, Glazialmorphologie, Gletscherkunde sowie Siedlungs- und Wirtschaftsgeographie.

Dr. Wolfgang Pillewizer (1911-1999) wurde 1934 an der Universität Graz mit einer geomorphologischen Dissertation promoviert. 1937 nahm er unter der Leitung von Prof. FINSTERWALDER an der photogrammetrischen Vermessung eines norwegischen Gletschers teil. Im selben Jahr erhielt PiLLEwIZER als Angestellter des Deutschen und Österreichischen Alpenvereins eine Kartenauswertestelle an der damaligen Technischen Hochschule in Hannover und nahm 1938 an der Deutschen Spitzbergen-Exkursion teil. Von Dezember 1939 bis Februar 1942 war er Referatsleiter in der II. Kartographischen Abteilung des Reichsamtes 
für Landesaufnahme in Berlin. Er habilitierte sich im März 1942, musste allerdings im Folgemonat nach Spandau bei Berlin einrücken. Im Mai 1942 flog der „Schütze“ PILlEwizer im Stab des Sonderkommandos Dora nach Tripolis. Im Juni 1943 wurde er als Mitglied der neu aufgestellten Forschungsstaffel z.b.V. in die Ukraine entsandt, wo er mit Unterbrechungen bis Juli 1944 blieb. Im Juli 1944 wurde er zum Leutnant befördert. Von August 1944 bis November 1944 war Pillewizer mit der „Einsatzgruppe Lappland“ der Forschungsstaffel z.b.V. in Nord-Finnland und anschließend bis Kriegsende als Hauptkartograph der Forschungsstaffel z.b.V. in Deutschland. Als „Kartenoffizier“ der Forschungsstaffel z.b.V. war Leutnant Dr. Pillewizer für die Entwicklung, Gestaltung und Fertigung der Karten zur militärischen Geländebeurteilung zuständig. Im Jahre 1958 erging an PILLEwIZER der Ruf an den neu gegründeten Lehrstuhl für Kartographie der Technischen Hochschule in Dresden. 1971 übersiedelte PILLEwizer in sein Heimatland und übernahm das Ordinariat und das neu eingerichtete Institut für Kartographie und Reproduktionstechnik an der damaligen Technischen Hochschule in Wien.

Dr. Ernst Preising (1911-2007) studierte Pflanzensoziologie und Standortkunde bei Prof. Reinhold TüXEN, der die damalige ,Arbeitsstelle für theoretische und angewandte Pflanzensoziologie“ (ab 1938: „Reichsstelle für Vegetationskartierung“) in Hannover leitete. Im Jahre 1939 legte PreISING sein Diplom ab und wurde 1940 zum „Dr. agr.“ der Landbauwissenschaften promoviert. Eine einjährige Tätigkeit als wissenschaftlicher Assistent führte ihn 1939/40 an die Versuchsanstalt für Waldwirtschaft nach Eberswalde. Im Krieg war Preising als Sonderführer zeitweise Mitglied der Forschungsstaffel z.b.V. und führte eine Kartierung des Weichselgebietes durch. Er leitete von 1943 bis 1945 die Einsatzgruppe „Russland-Nord“ (des Forschungskommandos Ost der Forschungsstaffel z.b.V.), die ihm besondere Möglichkeiten des Studiums der Vegetation - vor allem der Moore - im nordöstlichen Europa eröffnete. Von 1950 bis 1954 war Preising Lehrbeauftragter für Pflanzensoziologie an der damaligen Technischen Universität Hannover. Gleichzeitig mit der Leitung der damaligen Niedersächsischen Landesstelle für Naturschutz und Landschaftspflege in Benthe bei Hannover betraut, wurde er ab April 1954 auch Lehrbeauftragter für Naturschutz an der Universität Hannover, wo er dann 1961 zum Honorarprofessor bestellt wurde.

Dr. Josef SCHMITHÜSEN (1909-1984) studierte ab 1927 an der Technischen Hochschule in Aachen Chemie, Geologie, Mineralogie und Botanik. 1929 wechselte er zur Universität Bonn, wo er dann - trotz seiner ursprünglichen Absicht, Botaniker (und Pflanzensoziologe) zu werden - zur Geographie wechselte und 1934 promoviert wurde. Seine Habilitationsschrift über „Das Luxemburger Land, Landesnatur, Volkstum und bäuerliche Wirtschaft“ erschien 1940. Bis 1941 setzte SCHMITHÜSEN seine Lehrtätigkeit als Dozent für Geographie an der Universität Bonn fort und wurde ab 1. April 1941 wissenschaftlicher Mitarbeiter bei der Abteilung Landeskunde des Reichsamtes für Landesaufnahme in Berlin. Dort begründete er im Jahre 1942 die „,naturräumliche Gliederung 1:200.000“ im Rahmen einer systematisch-geographischen Landesaufnahme. Am 3. November 1942 erfolgte seine Einberufung zur Wehrmacht, im Winter 1942/43 seine Ausbildung als Infanterist und ab März 1943 war er als MG-Schütze in Russland eingesetzt. Erst am 1. November 1943 erfolgte seine Versetzung zur Forschungsstaffel z.b.V., von November bis Dezember 1943 zum Forschungskommando Ost in Posen. Anfang Jänner 1944 wurde SCHMITHÜSEN anlässlich einer Arbeitsbesprechung der Forschungsstaffel z.b.V. in Graz mit der Aufgabe eines wissenschaftlichen Verbindungsoffiziers beauftragt. Dieser Auftrag beinhaltete die Zusammenarbeit zwischen der Forschungsstaffel z.b.V. (und auch für den Beauftragten für Sonderaufgaben der erdkundlichen Forschung des Reichsforschungsrates, Dr. Otto SchUlz-KAMPFHENKEL) mit den einschlägigen Universitätsinstituten und zentralen wissenschaftlichen Einrichtungen sowie die Koordination der Wissenschaftler innerhalb der Forschungsstaffel z.b.V. Darüber 
hinaus war SchmiтHÜSEN noch für die theoretische Systematisierung der Gesamtansätze der Forschungsarbeiten der Forschungsstaffel verantwortlich. Im Juni 1944 nahm ScHмITHÜSEN an der Arbeitstagung über Luftbildauswertung in Jena teil. Ende August 1944 wurde er Leiter einer Einsatzgruppe in Frankreich. Ende Februar 1945 bearbeitete er eine Übersichtskarte zur Geländebeurteilung des Gebietes zwischen Oder und Elbe. Gemeinsam mit Hans BobeK verfasste Josef SсHмiтнüsEn nach dem Krieg die fundamentale Arbeit über das logische System der Geographie (BoBEK und SchmithüsEN 1949), ein theoretisches Konzept, das somit auf den einschlägigen Erfahrungen einer langjährigen Praxis beruhte. Als Ordinarius für Geographie an der Universität Saarbrücken veröffentlichte er das in drei Auflagen erschienene Lehrbuch über „Vegetationsgeographie“ und 1976 das Lehrbuch über „Allgemeine Geosynergetik“, in welchem er die zentrale Bedeutung der Geo-Wirkungszusammenhänge betonte (SCHMITHÜSEN 1976).

Dr. Heinrich Schmitthenner (1887-1957) studierte Geologie und Geographie und war als Kriegsgeologe im Westfeldzug eingesetzt. Aus dem Kolonialgeographischen Institut der Universität Leipzig, welches SCHMITTHENNER während des Zweiten Weltkriegs leitete, sind zahlreiche Geographen und Afrikaexperten hervorgegangen, die in der Abwehrstelle Rheda als Referenten für den afrikanischen Kriegsschauplatz aufgenommen wurden. Bald nach Kriegsende erhielt SCHMitTHENNER einen Ruf als Ordinarius für Geographie an der Universität Leipzig.

Dr. Sigfrid SCHNEIDER (1915-2006) studierte ab 1934/35 Geschichte, Geographie und Geologie in Berlin und begann 1939 mit einer Dissertation bei Prof. Dr. Julius BüDEL am Geographischen Institut in Berlin, wo er Anfang 1940 promoviert wurde. Nach Mitarbeit bei der Gruppe „Mil.Geo.“ in der Abteilung für Kriegskarten- und Vermessungswesen wurde SchNeIDER am 1. Oktober 1941 zum Heer eingezogen. Nach seinem Einsatz bei der Ostfront 1942 erfolgte seine Beförderung zum Gefreiten und Unteroffizier, im März 1944 zum Leutnant der Reserve der Artillerie. Nach einer Abkommandierung nach Frankreich gelangte SCHNEIDER erst im November 1944 zur Forschungsstaffel z.b.V. Er war zunächst beim Forschungskommando Ost in Posen tätig und später in Warthbrücken [poln.: Koło]. Ab Mitte Jänner 1945 übernahm er das Kommando in Posen, danach erfolgte die Rückführung des Kommandos Ost nach Hamburg. Nach dem Krieg wirkte ScHNEIDER als Professor der Geographie an der Universität des Saarlandes und war gleichzeitig wissenschaftlicher Direktor in der Bundesforschungsanstalt für Landeskunde und Raumordnung in Bonn Bad Godesberg. Er verfasste mehrere Arbeiten über Luftbildauswertung (SCHNEIDER 1957, 1989) sowie ein umfangreiches Lehrbuch über Luftbildinterpretation (SCHNEIDER 1974). Gemeinsam mit H. BobeK, Th. Kraus, W. v. Laer, E. Otremba, C. Troll, E. Meynen und H. MüLLER-MinY war er an der Bundesanstalt für Landeskunde und Raumforschung in Bonn - Bad Godesberg Herausgeber der Reihe „Landeskundliche Luftbildauswertung im mitteleuropäischen Raum“.

Dr. Kurt SCHWIDEFSKY (1905-1986) war Photogrammeter bei der Firma Zeiss-Aerotopograph in Jena und Verfasser einer „Einführung in die Luft- und Erdbildmessung“, die 1942 bereits in dritter Auflage erschienen ist (SCHWIDEFSKY 1942). Von ihm stammt außerdem ein handliches Kompendium über einen „Grundriss der Photogrammetrie“, das erstmals 1936 gedruckt wurde. Es erschien 1939 in deutscher (2. Auflage) und gleichzeitig in japanischer Ausgabe (Tokyo), 1942 in 3. deutscher und 1943 in erster spanischer Ausgabe (Barcelona), in 4. Auflage 1950 und 5. Auflage 1954 wieder in deutscher Sprache, in erster englischer Ausgabe 1959 in London und erster türkischer Ausgabe 1961 in Istanbul. SchWIDEFSKY war nach dem Krieg Ordinarius an der Technischen Hochschule in Karlsruhe. Wohl in Reminiszenz an die Arbeiten der Forschungsstaffel z.b.V. merkte SCHWIDEFSKy (1963, S. 328) an: „Die Photogeologie ist in den letzten Jahren methodisch zu einem eigenen Arbeitsge- 
biet entwickelt worden. Sie hat über das Luftbild zu einer fruchtbaren Arbeitsgemeinschaft zwischen Geographie, Geologie, Bodenkunde und Pflanzengeographie geführt.“

Dr. Hans SPREITZER (1897-1974) ist im Ersten Weltkrieg als Zugsführer in russische Gefangenschaft geraten. Von 1939 bis 1945 wirkte er als o. Professor und Direktor des Geographischen Instituts der Deutschen Karls-Universität in Prag, wo er für den Reichsforschungsrat an Projekten für die Geländebeurteilung mitgearbeitet hat. SPREITZER wurde nach dem Krieg 1947 zum Ordinarius am Geographischen Institut der Universität Graz ernannt und wechselte 1952 auf den Lehrstuhl für Physische Geographie nach Wien. 1955 bis 1962 und 1965/66 war er Präsident der Österreichischen Geographischen Gesellschaft (vormals „Geographische Gesellschaft in Wien“).

Dr. Carl Troll (1899 - 1975) war ab 1936 Abteilungsleiter des Institutes und Museums für Meereskunde und führte 1934 und 1937 Expeditionen zum Nanga Parbat durch. 19361938 war er ordentlicher Professor der Abteilung Wirtschaftsgeographie am Berliner Institut für Meereskunde und danach ordentlicher Professor und Direktor am Geographischen Institut in Bonn. In dieser Funktion war er auch vom Reichsforschungsrat mit einem Projekt über die geographische Luftbildauswertung und die Nutzbarmachung russischer Literatur für die Forschungsstaffel z.b.V. beauftragt worden. TroLl war jedoch selbst kein Mitarbeiter der Forschungsstaffel z.b.V. Bereits vor dem Krieg verfasste Carl Troll neben Arbeiten zur Anthropogeographie (Troll 1939a) eine umfangreiche Arbeit über den „Luftbildplan und ökologische Bodenforschung“ (Troll 1939b). 1941 erschien von ihm eine Einführung zu dem von Hans BoBEK verfassten Band über Luftbild und Geomorphologie, die als Band 20 der Reihe Luftbild und Luftbildmessung von der Hansa Luftbild G.m.b.H. herausgegeben worden ist (Troll 1941). Unter dem Vorsitz von Dr. Carl Troll und Oberst-Ingenieur Dr. Claus AschenBRENNER vom Reichsluftfahrtministerium fand am 20/21. Februar 1942 eine Arbeitstagung „Das Luftbild als Hilfsmittel für koloniale Raumforschung" statt, die gemeinsam mit der Gesellschaft für Erdkunde zu Berlin und der Lilienthal-Gesellschaft für Luftfahrtforschung organisiert wurde. Noch im gleichen Jahr wurde durch die (am 7. Juli 1941) neu konstituierte Deutsche Geographische Gesellschaft bei der Gesellschaft für Erdkunde zu Berlin eine wissenschaftliche Luftbildstelle gegründet. TROLL veröffentlichte knapp nach dem Krieg eine kritische Stellungnahme zur geographischen Wissenschaft in Deutschland in den Jahren 1933 bis 1945 (Troll 1947), in welcher er die Forschungsstaffel z.b.V. ,[...] als wehrwissenschaftliche Arbeitsgruppe von Geographen, Geologen, Biologen, Kartographen, Photogrammetern [...]“ beschrieb, die landschaftsökologische Forschung auf der Grundlage der Luftbildauswertung betrieben hat. Troll leitete von 1938 bis 1966 das Geographische Institut in Bonn. Im Jahr 1947 gründete Troll die Zeitschrift „Erdkunde“, war mit Unterbrechungen von 1956 und 1968 Vizepräsident der „International Geographical Union“ (IGU) und von 1960 bis 1964 deren Präsident. 1961/62 leitete er als Rektor die Universität Bonn. Auf Troll geht der Begriff der Landschaftsökologie zurück.

Dr. Kurt WALTHER (1910-2003) war als Unteroffizier in den Jahren 1943 bis 1945 als Moosexperte und Pflanzensoziologe in der Forschungsstaffel z.b.V. tätig. Er führte zusammen mit Dr. Heinz Ellenberg in Estland, Nordgriechenland und Mazedonien pflanzensoziologische Kartierungen für Übersichtskarten der Geländebeurteilung durch. 1948 bis 1961 war WALTHER Mitarbeiter an der Bundesanstalt für Vegetationskartierung in Stolzenau an der Weser, 1969 erfolgte seine Ernennung zum Dozenten und 1971 zum Professor an der Universität Hamburg.

Tab. 4: Karrieren von Angehörigen oder Auftragnehmern der Forschungsstaffel z.b.V. nach dem Zweiten Weltkrieg 


\section{Literaturverzeichnis}

Bовек H. (1941): Luftbild und Geomorphologie. In: Luftbild und Luftbildmessung, 20, S. 8-161, zahlr. Abb.

Вовек H. (1942a): Der Einsatz der geographischen Wissenschaft im modernen Krieg und die Aufgaben der Militärgeographie. In: Mitteilungen des Chefs des Kriegskarten- und Vermessungswesens, Berlin, 1, 6, S. 2-9.

BoвEк H. (1942b): Begründung einer wissenschaftlichen Luftbildstelle der Deutschen Geographischen Gesellschaft bei der Gesellschaft für Erdkunde zu Berlin. In: Zeitschrift der Gesellschaft für Erdkunde zu Berlin, 3/4-1942, S. 372-374.

Boвeк H., Sснмітнüsen J. (1949): Die Landschaft im logischen System der Geographie. In: Erdkunde, 3, 2, S. 112-120.

Bоенм E. (1987): Aufbau und Einsatz der Forschungsstaffel z.b.V. Unveröffentlichtes Manuskript, Anlage 2 zu den der Stiftung Preußischer Kulturbesitz überlassenen 17 Kartenblättern aus der Fertigung der Forschungsstaffel z.b.V. 1944/45. Freiberg, Kartenabteilung der Staatsbibliothek Preußischer Kulturbesitz, $7 \mathrm{~S}$.

Boenм E. (1989): Aufbau und Einsatz der Forschungsstaffel z.b.V. In: BoEHм E., BRUCKLACHER W., Pillewizer W. (Hrsg.): Luftbildinterpretation und Geländevergleich (= Österreichische Akademie der Wissenschaften, Institut für Kartographie, Berichte und Informationen, 8). Wien, ÖAW, S. 9-15.

Boehm E., Brucklacher W., Pillewizer W. (1989): Luftbildinterpretation und Geländevergleich. Die Tätigkeit der Forschungsstaffel von 1943-1945. Wien, ÖAW (= Österreichische Akademie der Wissenschaften, Institut für Kartographie, Berichte und Informationen, 8).

Вӧнм Н. (1995): Luftbildforschung. Wissenschaftliche Überwinterung - Angewandte (kriegswichtige) Forschung - Rettung eines Paradigmas. In: Münsterische Geographische Arbeiten, 39, S. 129-139.

Bower T. (1987): Verschwörung Paperclip. NS-Wissenschaftler im Dienste der Siegermächte. München, List-Verlag.

Brandstätter L., Caulier-Eimbcke G., Göpner W., Otremba E., Pillewizer W., Schmithüsen J., SCHNEIDER S. (1947a): Report Concerning the Persons Who Worked with Forschungsstaffel, Sonderkommando Dora and Kommando Theo. Kransberg/Taunus, Enemy Personnel Exploitation Section, F.I.A.T., Interrogation Camp Dustbin, 5 February 1947.

Brandstätter L., Caulier-Eimbcke G., GöPner W., Otremba E., Pillewizer W., Schmithüsen J., SChNeIder S. (1947b): Organization, Chain of Command and Interrelations of Forschungsstaffel, Forschungsgruppe, Sonderkommando Dora and Kommando Theo, and Source of Revenue of Forschungsgruppe. Report I: Forschungsstaffel z.b.V.; Report II: Forschungsgruppe e.V.; Report III: Sonderkommando Dora; Report IV: Kommando Theo. Kransberg/Taunus, Enemy Personnel Exploitation Section, F.I.A.T., Interrogation Camp Dustbin, 5 February 1947.

British Intelligence Objectives Sub-Committee (1946a): Target No. 028/3.111: Dr. Otto Schulz-Kampfhenkel (C.O.G.A.): Interrogation Report No. 177, Ref. No. AIU/PIR/63. Kransberg/Taunus, Interrogation Camp Dustbin, 4 October 1946.

British Intelligence Objectives Sub-Committee (1946b): Target No. 028/3.111: Dr. Otto Schulz-Kampfhenkel Combination Mapping Method (C.O.G.A.): Interrogation Report No. 178, Ref. No. AIU/IS/25. Kransberg/Taunus, Interrogation Camp Dustbin, 4 October 1946.

Brogiato H. (2004): In memoriam Hans Böhm. Arbeitskreis Geschichte der Geographie, Rundschreiben 8, Oktober 2004. http://www.geographiegeschichte.de/wp-content/uploads /2011/ 03/Rundschreiben-08_Oktober-2004.pdf (letzter Zugriff: 10.01.2018). 
Brucklacher W. A. (1989): Bildbefliegungen und kartographische Arbeiten des Kommandos Bildoffizier der Forschungsstaffel. In: Boenm E., Brucklacher W., Pillewizer W. (Hrsg.): Luftbildinterpretation und Geländevergleich (= Österreichische Akademie der Wissenschaften, Institut für Kartographie, Berichte und Informationen, 8). Wien: ÖAW, S. 17-24.

Cornwell J. (2004): Forschen für den Führer. Deutsche Naturwissenschaftler und der Zweite Weltkrieg. Bergisch Gladbach, Gustav Lübbe Verlag.

FAHLBUSCH M. (1989): Die Geographie in Münster von 1920 bis 1945. In: Urbs et Regio, 51, S. $153-273$.

Finsterwalder R., Schneider E. (1958): Zur Karte des Chomolongma - Mount Everest 1:25 000. In: Zeitschrift für Vermessungswesen, 83, S. 123-136.

FlaChOWsKY S. (2011): „Die Forschungsgruppe Schulz-Kampfhenkel steht jetzt für Ostaufgaben zur Verfügung.“ Otto Schulz-Kampfhenkel als Beauftragter für Sonderaufgaben der erdkundlichen Forschung. In: Flachowsky S., Stoecker H. (Hrsg.): Vom Amazonas an die Ostfront. Der Expeditionsreisende und Geograph Otto Schulz-Kampfhenkel (1910-1989). Köln - Wien, Böhlau, S. 240-302.

Gruppe Dustbin (1947a): Report on the Program of the German Government Agencies of Supplying Scientific Institutes with Air Photos (German Version). Kransberg/Taunus, Interrogation Camp Dustbin, January 1, 1947.

Gruppe Dustbin (1947b): Report on German Air Photo Keys (German Version). Kransberg/Taunus, Interrogation Camp Dustbin, January 1, 1947.

HäUSLER H. (1995a): Die Wehrgeologie im Rahmen der Deutschen Wehrmacht und Kriegswirtschaft. Teil 1: Entwicklung und Organisation. Wien, Institut für Militärisches Geowesen, Bundesministerium für Landesverteidigung (= Informationen des Militärischen Geo-Dienstes, 47).

HäUSLER H. (1995b): Die Wehrgeologie im Rahmen der Deutschen Wehrmacht und Kriegswirtschaft. Teil 2: Verzeichnis der Wehrgeologen. Wien, Institut für Militärisches Geowesen, Bundesministerium für Landesverteidigung (= Informationen des Militärischen Geo-Dienstes, 48).

HäUSLER H. (2000): Deployment and Role of Military Geology Teams in the German Army 19411945. In: Rose E. P. F., Nathanail C. P. (Hrsg.): Geology and Warfare: Examples of the Influence of Terrain and Geologists on Military Operations. London, The Geological Society of London, S. 159-175.

HäUSLER H. (2007): Forschungsstaffel z.b.V. - Eine Sondereinheit zur militärgeografischen Beurteilung des Geländes im 2. Weltkrieg. Wien, Institut für Militärisches Geowesen, Bundesministerium für Landesverteidigung. (= MILGEO, Schriftenreihe des Militärischen Geowesens, 21).

HäUSLER H. (2018): Sonderkommando Dora - Specific Military Geoscientific Unit of the German Counter-Intelligence Service in North Africa 1942. In: Scientia Militaria, South African Journal of Military Studies, 46, 1, pp. 37-57.

HäUSLER H., Willig D. (2000): Development of Military Geology in the German Wehrmacht 19391945. In: Rose E. P. F., Nathanail C. P. (Hrsg.): Geology and Warfare: Examples of the Influence of Terrain and Geologists on Military Operations. London, The Geological Society of London, S. 141-158.

Hammerstein N. (1999): Die Deutsche Forschungsgemeinschaft in der Weimarer Republik und im Dritten Reich. Wissenspolitik in Republik und Diktatur. München, Beck.

KANTER H. (1967): Libyen - Libya. Eine geographisch-medizinische Länderkunde/A Geomedical Monograph. Berlin, Springer (Series of Monographs of the Heidelberger Akademie der Wissenschaften, mathematisch-naturwissenschaftliche Klasse). 
Kaufmann W. (2015): Das „Sonderkommando Dora“ der Abwehr im Einsatz in der Libyschen Wüste. Die militärgeographischen Erkundungen der Technischen Gruppe Ost im Juli 1942. In: Schmidt J. W. (Hrsg.): Geheimdienste in Deutschland: Affären, Operationen, Personen (= Geheimdienstgeschichte, 4, 2. Aufl.). Ludwigsfelde, Ludwigsfelder Verlagshaus, S. 226-262.

KLEE E. (2013): Das Personenlexikon zum Dritten Reich. Wer war was vor und nach 1945. Frankfurt am Main, Fischer.

KRÜGER P. (2011): Rezension der Arbeit von Häusler H. (2007), „Forschungsstaffel z.b.V. - Eine Sondereinheit zur militärgeografischen Beurteilung des Geländes im Zweiten Weltkrieg“. In: Geohistorica, 7, S. 37-40.

MANG R. (2007): Vorwort. In: HÄUSLER H. (2007): Forschungsstaffel z.b.V. - Eine Sondereinheit zur militärgeografischen Beurteilung des Geländes im 2. Weltkrieg (= MILGEO, Schriftenreihe des Militärischen Geowesens, 21). Wien, Institut für Militärisches Geowesen, Bundesministerium für Landesverteidigung, S. 3.

Meynen E. (1973): Multilingual Dictionary of Technical Terms in Cartography. Mehrsprachiges Wörterbuch kartographischer Begriffe. Wiesbaden, International Cartographic Association.

Meynen E. (1985): Internationales Geographisches Glossarium. Deutsche Ausgabe. Stuttgart, Franz Steiner Verlag.

MüLLER, T. (2009): Die Divisionskartenstellen des deutschen Heeres von 1939 bis 1945. In: Schriftenreihe Geoinformationsdienst der Bundeswehr, 5, S. 80-154.

MÜLleR T., Hubrich D. (2009): Überblick über das Karten- und Vermessungswesen des deutschen Heeres von 1919 bis 1945. In: Schriftenreihe Geoinformationsdienst der Bundeswehr, 5, S. $6-78$.

Otremba E. (1950): Der Unterlauf der Flüsse im Luftbild. In: Petermanns Geographische Mitteilungen, 94, 3, S. 177-186.

Pillewizer W. (1946a): Sonderkommando Dora. Unveröffentlichtes Manuskript, 20. Juli 1946, 6 S.

Pillewizer W. (1946b): Forschungsstaffel z.b.V. Unveröffentlichtes Manuskript, 20. Juli 1946, $39 \mathrm{~S}$.

Pillewizer W. (1968): Die Bedeutung der Karte für die Landschaftsforschung. In: Kartographische Nachrichten, 18, S. 170-173.

Pillewizer W. (1986): Zwischen Alpen, Arktis und Karakorum - Fünf Jahrzehnte kartographische Arbeit und glaziologische Forschung. Berlin, Reimer.

Pillewizer W. (1989): Die Herstellung von Karten zur Geländebeurteilung durch geowissenschaftliche Luftbildauswertung. In: Boemm E., Brucklacher W., Pillewizer W. (Hrsg.): Luftbildinterpretation und Geländevergleich (= Österreichische Akademie der Wissenschaften, Institut für Kartographie, Berichte und Informationen, 8). Wien, ÖAW, S. 25-46.

Pillewizer W. (1995): Als Kartograph im Krieg. Wien, Institut für Militärisches Geowesen, Bundesministerium für Landesverteidigung (= Informationen des Militärischen GeoDienstes, 49).

Pillewizer W., Jung R. F. (1954): Eräs kartoitustyö Pohjois-Suomessa [Kartenaufnahmen in Nordfinnland]. In: Maanmittaus [Vermessungswesen], 3/4-1952, S. 128-146.

ReichHeRzer F. (2012): „Alles ist Front!“ Wehrwissenschaften in Deutschland und die Bellifizierung der Gesellschaft vom Ersten Weltkrieg bis in den Kalten Krieg. Paderborn, Ferdinand Schöningh (= KRiG, Krieg in der Geschichte, 68).

Rolke M. (Hrsg.) (2003): Die Karten des „Sonderkommando Dora“. 23 vierfarbige Croquis von Südlibyen. München, belleville Verlag Michael Farin.

Rolke M., Flachowsky S. (2011): „Die geladene Maschinenpistole in der Rechten, in der Linken den Filmapparat." Schulz-Kampfhenkel im „Sonderkommando Dora“- Erkundungen in der Wüste Libyens vom Mai 1942 bis Januar 1943. In: Flachowsky S., Stoecker H. (Hrsg.): 
Vom Amazonas an die Ostfront. Der Expeditionsreisende und Geograph Otto SchulzKampfhenkel (1910-1989). Köln - Wien, Böhlau, S. 206-239.

RöSSLER M. (1989): Die Geographie an der Universität Freiburg 1933-1945. Ein Beitrag zur Wissenschaftsgeschichte des Faches im Dritten Reich. In: Urbs et Regio, 51, S. 77-151.

RösSLER M. (1990): „Wissenschaft und Lebensraum.“ Geographische Ostforschung im Nationalsozialismus. Ein Beitrag zur Disziplingeschichte der Geographie. Berlin, Reimer (= Hamburger Beiträge zur Wissenschaftsgeschichte, 8 ).

SANDER G. (1995): Die unmittelbare Nachkriegszeit: personelle, institutionelle und fachlich inhaltliche Aspekte 1945-1950. In: Münsterische Geographische Arbeiten, 39, S. 141-150.

SchmidT L. F. (1946): Interrogation Summary Schulz-Kampfhenkel Combination Mapping Method, Ref. No. AIU/IS/25, 22 p., Air Division Headquarters United States Forces in Austria, Air Interrogation Unit (Int. Center - Austria), APO 777, US ARMY (Camp Marcus W. Orr), Salzburg, 26 April 1946.

SснмітнüsEn J. (1946): Bemerkungen zu den von der Forschungsstaffel hergestellten Karten zur Geländebeurteilung. Unveröffentlichtes Manuskript, $49 \mathrm{~S}$.

SCHмiтнüsEn J. (1976): Allgemeine Geosynergetik. Berlin, de Gruyter (= Lehrbuch der Allgemeinen Geographie, 12).

SCHNEIDER S. (1957): Braunkohlebergbau über Tage im Luftbild dargestellt am Beispiel des Kölner Braunkohlenreviers. Landeskundliche Luftbildauswertung im mitteleuropäischen Raum. Remagen, Amt für Landeskunde (= Schriftenfolge des Amtes für Landeskunde, 2).

SCHNEIDER S. (1974): Luftbild und Luftbildinterpretation. Berlin, de Gruyter.

SCHNEIDER S. (1989): Die „Geographische Methode“ in der Luftbildinterpretation - nur eine historische Reminiszenz? In: Zeitschrift für Photogrammetrie und Fernerkundung, 57, 4, S. $139-148$.

SCHRÖDTER W. (2002): Luftgeographie, Bildmess-, Karten- und Vermessungswesen in den deutschen Luftstreitkräften 1888-2002. http://www.vexilli.net/HisMGLW/index.html\#http:// www.vexilli. net/HisMGLW/HisBio.html (letzter Zugriff: 10.1.2018).

SCHWIDEFSKY K. (1942): Einführung in die Luft- und Erdbildmessung. 3. erweiterte und verbesserte Auflage, Leipzig, Teubner.

SchWIDEFSKy K. (1963): Grundriss der Photogrammetrie. 6. neubearbeitete und erweiterte Auflage, Stuttgart, Teubner.

Sмith T. R., Black L. D. (1946): German Geography: War Work and Present Status. In: Geographical Review, 36, 3, S. 398-408.

Sonderkommando Dora, Technische Gruppe (1942a): Ergebnisse von Geländeerkundungen in Mittel- und Südlibyen. Bericht 1 (T.G. 1/42): Vorläufiger Ergebnisbericht über eine Erkundung in der ostwärtigen und mittleren Libyschen Sahara zwischen der Oase Hon und der nördlichen Serir Tibesti (Erkundung Ost vom 5.7.42 bis 24.7.42) mit 5 Karten (21 Blättern), 6 Landschaftsskizzen und 132 photographischen Aufnahmen. O. U., 15. August 1942.

Sonderkommando Dora, Technische Gruppe (1942b): Ergebnisse von Geländeerkundungen in Mittel- und Südlibyen. Bericht 2 (T.G. 2/42): Vorläufiger Ergebnisbericht über eine Erkundung in der mittleren Libyschen Sahara zwischen der Oase Hon und dem Wau el Kebir (Erkundung West vom 5.7.42 bis 30.7.42) mit 5 Karten (13 Blätter) und 39 photographische Aufnahmen. O. U., 15. August 1942.

Sonderkommando Dora, Technische Gruppe (1942c): Ergebnisse von Geländeerkundungen in Mittel- und Südlibyen. Bericht 3 (T.G. 3/42): Vorläufiger Bericht über die Nachschubwege nach Südlibyen (Westteil; mit 1 Karte und Entfernungstabelle) und allgemeine Übersichtskarten zu den Berichten der Erkundungen Ost und West (T.G. 1/42 und T.G. 2/42). O. U., 15. August 1942 . 
SvateK P. (2015): Geopolitische Kartographie in Österreich 1917-1939. In: Mitteilungen der Österreichischen Geographischen Gesellschaft, 157, S. 301-322.

Troll C. (1939a): Gedanken zur Systematik der Anthropogeographie. In: Zeitschrift der Gesellschaft für Erdkunde zu Berlin, 1939, 5/6, 210-215.

Troll C. (1939b): Luftbildplan und ökologische Bodenforschung. Ihr zweckmäßiger Einsatz für die wissenschaftliche Erforschung und praktische Erschließung wenig bekannter Länder. In: Zeitschrift der Gesellschaft für Erdkunde zu Berlin, 1939, 7/8, S. 241-298.

Troll C. (1941): Luftbild und ökologische Bodenforschung. In: Luftbild und Luftbildmessung, 20, S. $5-7$.

Troll C. (1947): Die geographische Wissenschaft in Deutschland in den Jahren 1933 bis 1945. Eine Kritik und Rechtfertigung. In: Erdkunde, 1, 1, S. 3-48.

Troll C. (1969): Die Pflege der Luftbildinterpretation in Deutschland. In: Bildmessung und Luftbildwesen, 4, S. 120-125.

Voppel K. (1969a): Die Dienststelle Münster/Rheda Mai 1941/Mai 1944. Unveröffentlichtes Manuskript, Duisburg, 9.12.1969, $5 \mathrm{~S}$.

Voppel K. (1969b): Raumkoppel, Schönberg (Mecklenburg). Abteilung des Kommandos der K-Verbände. Unveröffentlichtes Manuskript, Duisburg, 9.12.1969, 9 S.

Wardenga U., Henniges N., Brogiato H. P. und SchelhaAs B. (2011): Der Verband deutscher Berufsgeographen 1950-1979. Eine sozialgeschichtliche Studie zur Frühphase des DVAG. Leipzig, Leibniz-Institut für Länderkunde (= forum ifl, 16). 